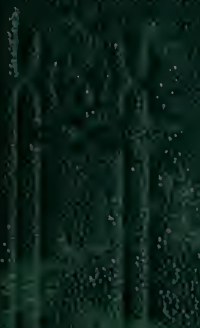

$(1-2)=8$

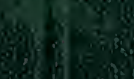

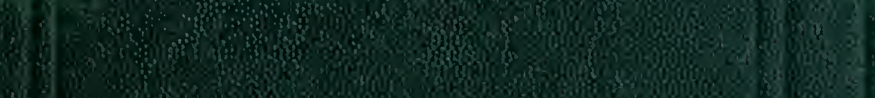
sine. sing

8.

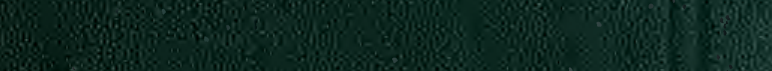

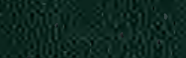
995 a con arios.

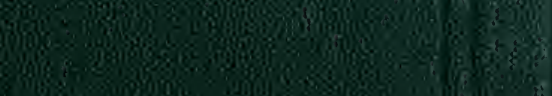

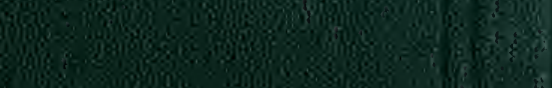
its 
Given in

Loving

Memory of

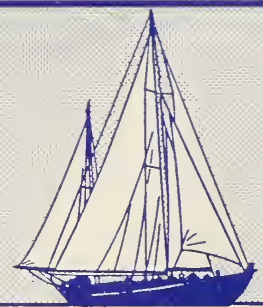

Daniel Merriman

Crew Member on the maiden voyage of the R/V Atlantis

Corporation Member,

$$
\text { 1944-79 }
$$

Trustee, 1944-64

Honorary Trustee $\theta$ corporation Member,

$$
\text { 1979-84 }
$$

Oceanographer, Writer, Editor, Fisherman, Educator, Mentor

Woods Hole Oceanographic Institution 



\title{
METIIODS OF STUDY
}

IN

$\mathrm{RB} \mathrm{Rr}$

\section{NAT UR A L HISTORY.}

\author{
By L. A GASSIZ.
}

\section{BOS TON:}

FIELDS, OSGOOD, \& CO.,

SUCCESSORS TO TICKNOR AND FIBLDS.

I 869 .

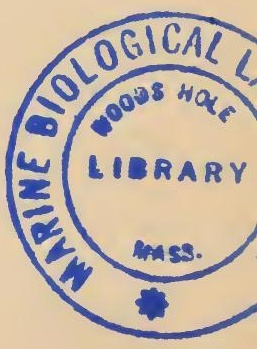


Entered according to Act of Congress, in the year 1863, by

TICKNOR AND FIELDS,

in the Clerk's Office of the District Court of the District of Massachusetts s

FIF TH EDITION.

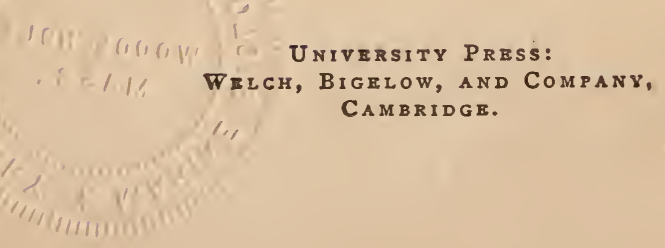




\section{P R E F A C E.}

THE series of papers collected in this volume may be considered as a complement or commentary to my "Essay on Classification," since I have endeavored to present here in a more popular form the views first expressed in that work. And although the direct intention of these pages has been, as their title indicates, to give some general hints to young students as to the methods by which scientific truth has been reached, including a general sketch of the history of science in past times, yet I have also wished to avail myself of this opportunity to enter my earnest protest against the transmutation theory, revived of late with so much ability, and so generally received. It is my belief that naturalists are chasing a phantom, in their search after some material gradation among created beings, by which the whole Animal Kingdom may have been derived by successive development from a 
single germ, or from a few germs It would seem, from the frequency with which this notion is revived, - ever returning upon us with hydraheaded tenacity of life, and presenting itself under a new form as soon as the preceding one has been exploded and set aside, - that it has a certain fascination for the human mind. This arises, perhaps, from the desire to explain the secret of our own existence; to have some simple and easy solution of the fact that we live.

I confess that there seems to me to be a repulsive poverty in this material explanation, that is contradicted by the intellectual grandeur of the universe; the resources of the Deity cannot be so meagre, that, in order to create a human being endowed with reason, he must change a monkey into a man. This is, however, merely a personal opinion, and has no weight as an argument; nor am I so uncandid as to assume that another may not hold an opinion diametrically opposed to mine in a spirit quite as reverential as my own. But I nevertheless insist, that this theory is opposed to the processes of Nature, as far as we have been able to apprehend them; that it is contradicted by the facts of Embryology and Paleontology, the former showing us norms of development as 
distinct and persistent for each group as are the fossil types of each period revealed to us by the latter; and that the experiments upon domesticated animals and cultivated plants, on which its adherents base their views, are entirely foreign to the matter in hand, since the varieties thus brought about by the fostering care of man are of an entirely different character from those ob- . served among wild species. And while their positive evidence is inapplicable, their negative evidence is equally unsatisfactory, since, however long and frequent the breaks in the geological series may be in which they would fain bury their transition types, there are many points in the succession where the connection is perfectly distinct and unbroken, and it is just at these points that new organic groups are introduced without any intermediate forms to link them with the preceding ones. In another series of papers, I shall endeavor to show the futility of the argument so far as it is founded upon the imperfection of the geological record.

I would add one word upon the way in which this volume has been prepared, since it has some features requiring explanation, if not apology. These chapters were first emkodied in a course 
of lectures delivered at the Lowell Institute in Boston, without any thought of their subsequent publication. Notes were, however, taken of them at the time, and I very willingly assented to the suggestion of some of my listeners, that they should be recorded in the form of articles for the Atlantic Monthly. They still retain something of the repetition which is needed in a public course of scientific lectures in order to keep the connection of the subjects clearly before the mind of a popular audience. An attempt to change this character would have amounted to writing the whole course anew, - a task for which I had neither time nor inclination. I have endeavored to avoid technicalities as far as possible in dealing with subjects many of which are quite unfamiliar to the general mind; and the closing chapter of the book, which has been incorporated in the volume, but did not appear in the Atlantic Monthly, is the only one especially addressed to the professional naturalist.

L. AGASSIZ.

Nahant, August 22, 1863. 


\section{CONTENTS.}

CHA P TER I.

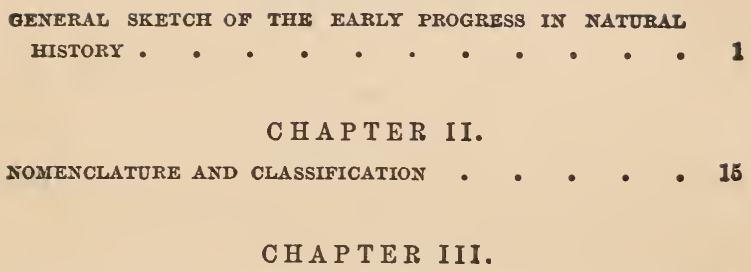


CHA P TER IX.

THE CHARACTERS OF GENERA

CHAPTER X.

SPECIES AND BREEDS

CHA P T E XI.

FORMATION OF CORAL REEFS

CHAPTER XII.

$\triangle G E$ OF CORAL REEFS AS SHOWING PERMANENCE OF SPECIES 175

CHAPTER XIII.

HOMOLOGIES

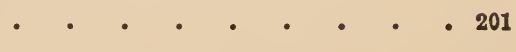

CHAPTER XIV.

ALTERNATE GENERATIONS

$\cdot \cdot \cdot \cdot \cdot 283$

CHAPTER XV.

THE OVARIAN EGG

CHAPTER XVI.

EMBRYOLOGY AND CLASSIFICATION . 


\section{METHODS OF STUDY IN NATURAL HISTORY.}

\section{CH A P T E R I}

GENERAL SKETCH OF THE EARLY PROGRESS IN NATURAL HISTORY.

Ir is my intention, in this series of papers, to give the history of the progress in Natural History from the beginning, - to show how men first approached Nature, - how the facts of Natural History have been accumulated, and how these facts have been converted into science. In so doing, I shall present the methods followed in Natural History on a wider scale and with broader generalizations than if I limited myself to the study as it exists to-day. The history of humanity, in its efforts to understand the Creation, resembles the development of any individual mind engaged in the same direction. It has its infancy, with the first recognition of surrounding objects; and, indeed, the early observers seem to us like children in their first attempts to understand the world in which they 
live. But these efforts, that appear childish to us now, were the first steps in that field of knowledge which is so extensive that all our progress seems only to show us how much is left to do.

Aristotle is the representative of the learning of antiquity in Natural Science. The great mind of Greece in his day, and a leader in all the intellectual culture of his time, he was especially a naturalist, and his work on Natural History is a record not only of his own investigations, but of all preceding study in this department. It is evident that even then much had been done, and, in allusion to certain peculiarities of the human frame, which he does not describe in full, he refers his readers to familiar works, saying, that illustrations in point may be found in anatomical text-books.*

Strange that in Aristotle's day, two thousand years ago, such books should have been in general use, and that in our time we are still in want of elementary text-books of Natural History, having special reference to the animals of our own country, and adapted to the use of schools. One fact in Aristotle's "History of Animals" is very striking, and makes it difficult for us to understand much of its contents. It never occurs to him that a time may come when the Greek language - the language of all

* See Aristotle's Zoölogy, Book I., Chapter XIV. 
culture and science in his time - would not be the language of all cultivated men. He took, therefore, little pains to characterize the animals he alludes to, otherwise than by their current names; and of his descriptions of their habits and peculiarities, much is lost upon us from their local character and expression. There is - also a total absence of systematic form, of any classification or framework to express the divisions of the animal kingdom into larger or lesser groups. His only divisions are genera and species : classes, orders, and families, as we understand them now, are quite foreign to the Greek conception of the animal kingdom. Fishes and birds, for instance, they considered as genera, and their different representatives as species. They grouped together quadrupeds also, in contradistinction to animals with legs and wings, and they distinguished those that bring forth living young from those that lay eggs. But though a system of Nature was not familiar even to their great philosopher, and Aristotle had not arrived at the idea of a classification on general principles, he yet stimulated a search into the closer affinities among animals by the differences he pointed out. He divided the animal kingdom into two groups, which he called Enaima and Anaima, or animals with blood and animals without blood. We must remember, 
however, that by the word blood he designated only the red fluid circulating in the higher animals; whereas a fluid akin to blood exists in all animals, variously colored in some, but colorless in a large number of others.

After Aristotle, a long period elapsed without any addition to the information he left us. Rome and the Middle Ages gave us nothing, and even Pliny added hardly a fact to those that Aristotle recorded. And though the great naturalists of the sixteenth century gave a new impulse to this study, their investigations were chiefly directed towards a minute acquaintance with the animals they had an opportunity of observing, mingled with commentaries upon the ancients. Systematic Zoölogy was but little advanced by their efforts.

We must come down to the last century, to Linnæus, before we find the history taken up where Aristotle had left it, and some of his suggestions carried out with new freshness and vigor. Aristotle had already distinguished between genera and species; Limnæus took hold of this idea, and gave special names to other groups, of different weight and value. Besides species and genera, he gives us orders and classes, - considering classes the most comprehensive, then orders, then genera, then species. He did not, however, represent these groups as distingıished 
by their nature, but only by their range; they were still to him, as genera and species had been to Aristotle, only larger or smaller groups, not founded upon and limited by different categories of structure. He divided the animal kingdom into six classes, which I give here, as we shall have occasion to compare them with other classifications : - Mammalia, Birds, Reptiles, Fishes, Insects, and Worms.

That this classification should have expressed all that was known, in the last century, of the most general relations among animals, only shows how difficult it is to generalize on such a subject; nor should we expect to find it an easy task, when we remember the vast number of species (about a quarter of a million) already noticed by naturalists. Linnæus succeeded, however, in finding a common character on which to unite most of his classes; but his definition of the class of Mammalia, that group to which we ourselves belong, remained very imperfect. Indeed, in the earlier editions of his classification, he does not apply the name of Mammalia to this class, but calls the higher animals Quadrupedia, characterizing them as the animals with four legs and covered with fur or hair, that bring forth living young and nurse them with milk. In thus admitting external features as class characters, he excluded many animals which by their 
mode of reproduction, as well as by their respiration and circulation, belong to this class as much as the Quadrupeds, - as, for instance, all the Cetaceans (Whales, Porpoises, and the like), which, though they have not legs, nor are their bodies covered with hair or fur, yet bring forth living young, nurse them" with milk, are warmblooded and air-breathing. As more was learned of these animals, there arose serious discussion and criticism among contemporary naturalists respecting the classification of Linnæus, all of which led to a clearer insight into the true relations among animals. Linnæus himself, in his last edition of the "Systema Naturæ," shows us what important progress he had made since he first announced his views; for he there substitutes for the name of Quadrupedia that of Mammalia, including among them the Whales, which he characterizes as air-breathing, warm-blooded, and bringing forth living young which they nurse with milk. Thus the very deficiencies of his classification stimulated naturalists to new criticism and investigation into the true limits of classes, and led to the recognition of one most important principle, - that such groups are founded, not on external appearance, but on internal structure, and that internal structure, therefore, is the thing to be studied. The group of Quadrupeds was not the only defective one 
in this classification of Linnæus; his class of Worms, also, was most heterogeneous, for he included among them Shell-Fishes, Slugs, StarFishes, Sea-Urchins, Corals, and other animals that bear no relation whatever to the class of Worms as now defined.

But whatever its defects, the classification of Limnæus was the first attempt at grouping animals together according to certain common structural characters. His followers and pupils engaged at once in a scrutiny of the differences and similarities among animals, which soon led to a great increase in the number of classes; instead of six, there were presently nine, twelve, and more. But till Cuvier's time there was no great principle of classification. Facts were accumulated and more or less systematized, but they were not yet arranged according to law; the principle was still wanting by which to generalize them and give meaning and vitality to the whole. It was Cuvier who found the key. He himself tells us liow he first began, in his investigations upon the internal organization of animals, to use his dissections with reference to finding the true relations between animals, and how ever after his knowledge of anatomy assisted him in his classifications, while his classifications threw new light again on his anatomical investigations, - each science thus helping to fertilize the other. 
He was not one of those superficial observers who are in haste to announce every new fact that they chance to find, and his first paper* specially devoted to classification gave to the world the ripe fruit of years of study. This was followed by his great work, "Le Règne Animal." He said that animals were united in their most comprehensive groups, not on special characters, but on different plans of structure, - moulds, he called them, in which all animals had been cast. He tells us this in such admirable language, that I must, to do justice to his thought, give it in his own words:-

"Si l'on considère le règne animal d'après les principes que nous venons de poser. en se débarrassant des préjugés établis sur les divisions anciennement admises, en n'ayant égard qu'à l'organisation et à la nature des animaux, et non pas à leur grandeur, à leur utilité, au plus ou moins de connaissance que nous en avons, ni à toutes les autres circonstances accessoires, on trouvera qu'il existe quatre formes principales, quatre plans généraux, si l'on peut s'exprimer ainsi, d'après lesquels tous les animaux semblent avoir été modelés, et dont les divisions ultérieures, de quelque titre que les naturalistes les aient décorées, ne sont que des modifications assez lêgèrec.

* "Sur un nouveau rapprochement à établir entre les Clan qui composent le Règne Animal." - Ann. Mus., Vol. XIX. 
fondées sur le développement ou l'addition de quelques parties, qui ne changent rien à l'essence du plan."*

The value of this principle was soon tested by its application to facts already known, and it was found that animals whose affinities had been questionable before were now at once referred to their true relations with other animals by ascertaining whether they were built on one or another of these plans. Of such plans or structural conceptions Cuvier found in the whole animal kingdom only four, which he called Vertebrates, Mollusks, Articulates, and Radiates.

With this new principle as the basis of investigation, it was no longer enough for the naturalist to know a certain amount of features characteristic of a certain number of animals, - he must penetrate deep enough into their organization to

* If we consider the animal kingdom according to the principles advanced above, - freeing ourselves at the same time from prejudices founded on previously established divisions, and looking at animals only with reference to their nature and organization, excluding their size, their utility, our greater or less familiarity with them, and all other accessory circumstances, we shall find that there exist four principal forms, four general plans, if we may so express it, in accordance with which all animals seem to have been modelled, and the ulterior divisions of which, by whatever title naturalists may have dignified them, are only comparatively light modifications, founded on the development or the addition of some parts not affecting the essen tial elements of the plan. 
find the secret of their internal structure. Till he can do this, he is like the traveller in a strange city, who looks on the exterior of edifices entirely new to him, but knows nothing of the plan of their internal architecture. To be able to read in the finished structure the plan on which the whole is built is now essential to every naturalist.

Each of these plans may be stated in the most general terms. In the Vertebrates there is a vertebral column terminating in a prominent head; this column has an arch above and an arch below, forming a double internal cavity. The parts are symmetrically arranged on either side of the longitudinal axis of the body. In the Mollusks, also, the parts are arranged according to a bilateral symmetry on either side of the body, but the body has but one cavity, and is a soft, concentrated mass, without a distinct individualization of parts. In the Articulates there is but one cavity, and the parts are here again arranged on either side of the longitudinal axis, but in these animals the whole body is divided from end to end into transverse rings or joints movable upon each other. In the Radiates we lose sight of the bilateral symmetry so prevalent in the other three, except as a very subordinate element of structure; the plan of this lowest type is an organic sphere, in which all parts bear definite relations to a vertical axis. 
It is not upon any special features, then, that these largest divisions of the animal kingdom are based, but simply upon the general structural idea. Striking as this statement was, it was coldly received at first by contemporary naturalists: they could hardly grasp Cuvier's wide generalizations, and perhaps there was also some jealousy of the grandeur of his views. Whatever the cause, his principle of classification was not fully appreciated; but it opened a new road for study, and gave us the key-note to the natural affinities among animals. Lamarck, his contemporary, not recognizing the truth of this principle, distributed the animal kingdom into two great divisions, which he calls Vertebrates and Invertebrates. Ehrenberg also, at a later period, announced another division under two heads, those with a continuous solid nervous centre, and those with merely scattered nerrous swellings.* But there was no real progress in either of these latter classifications, so far as the primary divisions are concerned; for they correspond to the old division of Aristotle, under the head of animals with or without blood, the Enaima and Anaima.

This coincidence between systems based on

* For more details upon the systems of Zoölogy, see Agassiz's Essay on Classification in his "Contributions to the Natural History of the United States," Vol. I.; also printed separately. 
different foundations may teach us that every structural combination includes certain inherent necessities which will bring animals together on whatever set of features we try to classify them; so that the division of Aristotle, founded on the circulating fluids, or that of Lamarck, founded on the absence or presence of a backbone, or that of Ehrenberg, founded on the differences of the nervous system, covers the same ground. Lamarck attempted also to make the faculties of animals a basis for division among them. But our knowledge of the psychology of animals is still too imperfect to justify any such use of it. His divisions into Apathetic, Sensitive, and Intelligent animals are entirely theoretical. He places, for instance, Fishes and Reptiles among the Intelligent animals, as distinguished from Crustacea and Insects, which he refers to the second division. But one would be puzzled to say how the former manifest more intelligence than the latter, or why the latter should be placed among the Sensitive animals. Again, some of the animals that he calls Apathetic have been proved by later investigators to show an affection and care for their young, seemingly quite inconsistent with the epithet he has applied to them. In fact, we know so little of the faculties of animals that any classification based upon our present information about them must be very imperfect. 
Many modifications of Cuvier's great divisions have been attempted; but though some improvements have been made in the details of his classification, all departures from its great fundamental principle are errors, and do but lead us away from the recognition of the true affinities among animals. Some naturalists, for instance, have divided off a part of the Radiates and Articulates, insisting upon some special features of structure, and mistaking these for the more important and general characteristics of their respective plans. Subsequent investigations have shown these would-be improvements to be retrograde movements, only proving more clearly that Cuvier detected in his four plans all the great structural ideas on which the vast variety of animals is founded. This result is of greater importance than may at first appear. Upon it depends the question, whether all such classifications represent merely individual impressions and opinions of men, or whether there is really something in Nature that presses upon us certain divisions among animals, certain affinities, certain limitations, founded upon essential principles of organization. Are our systems the inventions of naturalists, or only their reading of the Book of Nature? and can that book have more than one reading? If these classifications are not mere inventions, if they are 


\section{EARLY PROGRESS IN NATURAL HISTORY.}

not an attempt to classify for our own convenience the objects we study, then they are thoughts which, whether we detect them or not, are expressed in Nature, - then Nature is the work of thought, the production of intelligence, carried out according to plan, therefore premeditated, - and in our study of natural objects we are approaching the thoughts of the Creator, reading his conceptions, interpreting a system that is his and not ours.

All the divergence from the simplicity and grandeur of the division of the animal kingdom first recognized by Cuvier arises from an inability to distinguish between the essential features of a plan and its various modes of execution. We allow the details to shut out the plan itself, which exists quite independent of special forms. I hope we shall find a meaning in all these plans that will prove them to be the parts of one great conception and the work of one Mind. 


\section{CEAPTER II.}

NOMENCLATURE AND CLASSIFICATION.

Proceeding upon the view that there is a close analogy between the way in which every individual student penetrates into Nature and the progress of science as a whole in the history of humanity, I continue my sketch of the successive steps that have led to our present state of knowledge. I began with Aristotle, and showed that this great philosopher, though he prepared a digest of all the knowledge belonging to his time, yet did not feel the necessity of any system or of any scientific language differing from the common mode of expression of his day. He presents his information as a man with his eyes open narrates in a familiar style what he sees. As civilization spread and science had its representatives in other countries besides Greece, it became indispensable to have a common scientific language, a technical nomenclature, combining many objects under common names, and enabling every naturalist to express the results of his observations readily and simply in a man- 
ner intelligible to all other students of Natural History.

Linnæus devised such a system, and to him we owe a most simple and comprehensive scientific mode of designating animals and plants. It may at first seem no advantage to give up the common names of the vernacular and adopt the unfamiliar ones, but a word of explanation will make the object clear. Perceiving, for instance, the close relations between certain members of the larger groups, Linnæus gave to them names that should be common to all, and which are called generic names, - as we speak of Ducks, when we would designate in one word the Mallard, the Widgeon, the Canvas-Back, etc.; but to these generic names he added qualifying epithets, called specific names, to indicate the different kinds in each group. For example, the Lion, the Tiger, the Panther, the Domestic Cat constitute such a natural group, which Linnæus called Felis, Cat, indicating the whole genus; but the species he designates as Felis catus, the Domestic Cat, - Felis leo, the Lion,-Felis tigris, the 'iger. - Felis panthera, the Panther. So he called all the Dogs Canis; but for the different kinds we have Canis familiaris, the Domestic Dog, - Canis lupus, the Wolf, - Canis vulpes, the Fox, etc.

In some families of the regetable kingdom we 
can appreciate better the application of this nomenclature, because we have something corresponding to it in the vernacular. We have, for instance, one name for all the Oaks, but we call the different kinds Swamp Oak, Red Oak, White Oak, Chestnut Oak, etc. So Linnæus, in his botanical nomenclature, called all the Oaks by the generic name Quercus, (characterizing them by their fruit, the acorn, common to all,) and qualified them as Quercus bicolor, Quercus rubra, Quercus alba, Quercus castanea, etc., etc. His nomenclature, being so easy of application, became at once exceedingly popular, and made him the great scientific legislator of his century. He insisted on Latin names, because, if every naturalist should use his own language, it must lead to great confusion, and this Latin nomenclature of double significance was adopted by all. Another advantage of this binominal Latin nomenclature consists in preventing the confusion frequently arising from the use of the same name to designate different animals in different parts of the world, - as, for instance, the name of Robin, used in America to designate a bird of the Thrush family, which is entirely different from the Robin of the old World, one of the warblers, - or of different names for the same animal, as Perch or Chogset or Burgall for our Cunner. Nothing is more to be depre 
cated than an over-appreciation of technicalities, valuing the name more highly than the thing; but some knowledge of this scientific nomenclature is necessary to every student of Nature.

While Linnæus pointed out classes, orders, genera, and species, other naturalists had detected other divisions among animals, called families. Lamarck, who had been a distinguished botanist before he began his study of the animal kingdom, brought to his zoölogical researches his previous methods of investigation. Families in the regetable kingdom had long been distinguished by French botanists; and one cannot examine the groups they call by this name, without perceiving, that, though they bring them together and describe them according to other characters, they have been unconsciously led to unite them from the general similarity of their port and bearing. Take, for instance, the families of Pines, Oaks, Beeches, Maples, etc., and you feel at once, that, besides the common characters given in the technical descriptions of these different groups of trees, there is also a general resemblance among them that would naturally lead us to associate them together, even if we knew nothing of the special features of their structure. By an instinctive recognition of this family likeness between plants, botanists have been led to seek for 
structural characters on which to unite them, and the groups so founded generally correspond with the combinations suggested by their appearance.

By a like process Lamarck combined animals into families. His method was adopted by French naturalists generally, and found favor especially with Cuvier, who was particularly successful in limiting families among animals, and in naming them happily, generally selecting names expressive of the features on which the groups were founded, or borrowing them from familiar animals. Much, indeed, depends upon the pleasant sound and the significance of a name; for an idea reaches the mind more easily when well expressed, and Cuvier's names were both simple and significant. His descriptions are also remarkable for their graphic precision, - giving all that is essential, omitting all that is merely accessory. He has given us the keynote to his progress in his own expressive language :-

" Je dus donc, et cette obligation me prit un temps considérable, je dus faire marcher de front l'anatomie et la zoologie, les dissections et le classement; chercher dans mes premières remarques sur l'organisation des distributions meilleures; m'en servir pour arriver à des remarques nouvelles; employer encore ces re- 
marques à perfectiommer les distributions; faire sortir enfin de cette fécondation mutuelle des deux sciences, l'une par l'autre, un système zoologique propre à servir d'introducteur et de guide dans le champ de l'anatomie, et un corps de doctrine anatomique propre à servir de développement et d'explication au système zoologique." *

It is deeply to be lamented that so many naturalists have entirely overlooked this significant advice of Cuvier's, with respect to combining zoölogical and anatomical studies in order to arrive at a clearer perception of the true affinities among animals. To sum it up in one word, he tells us that the secret of his method is "comparison," - ever comparing and comparing throughout the enormous range of his knowledge of the organization of animals, and founding upon the differences as well as the similarities those broad generalizations under

* "I therefore felt myself obliged, and this obligation cost me no little time, to make my studies in anatomy and zoölogy, dissection and classification, keep pace with each other; to seek in my earlier investigations upon organization a better distribution of groups; to employ these again as a means of perfecting my classification; to arrive, in short, by this mutual fecundation of the two sciences at a zoölogical system which might serve as a pioneer and guide in the field of anatomy, and an anatomical method which would aid in the development and explanation of the zoölogical system." 
which he has included all animal structures. And this method, so prolific in his hands, has also a lesson for us all. In this country there is a growing interest in the study of Nature; but while there exist hundreds of elementary works illustrating the native animals of Europe, there are few such books here to satisfy the demand for information respecting the animals of our land and water. We are thus forced to turn more and more to our own investigations and less to authority; and the true method of obtaining independent knowledge is this very method of Cuvier's, - comparison.

Let us make the most common application of it to natural objects. Suppose we see together a Dog, a Cat, a Bear, a Horse, a Cow, and a Deer. The first feature that strikes us as common to any two of them is the horn in the Cow and Deer. But how shall we associate either of the others with these? We examine the teeth, and find those of the Dog, the Cat, and the Bear sharp and cutting, while those of the Cow, the Deer, and the Horse have flat surfaces, adapted to grinding and chewing, rather than cutting and tearing. We compare these features of their structure with the habits of these animals, and find that the first are carnivorous, that they seize and tear their prey, while the others are herbivorous or grazing animals, living only on 
vegetable substances, which they chew and grind. We compare further the Horse and Cow, and find that the Horse has front teeth both in the upper and lower jaw, while the Cow has them only in the lower; and going still further, and comparing the internal with the external features, we find this arrangement of the teeth in direct relation to the different structure of the stomach in the two animals, - the Cow having a stomach with four pouches, adapted to a mode of digestion by which the food is prepared for the second mastication, while the Horse has a simple stomach. Comparing the Cow and the Deer, we find that the digestive apparatus is the same in both; but though they both have horns, in the Cow the horn is hollow, and remains through life firmly attached to the bone, while in the Deer it is solid and is shed every year. With these facts before us, we cannot hesitate to place the Dog, the Cat, and the Bear in one division, as carnivorous animals, and the other three in another division as herbirorous animals, - and looking a little further, we perceive, that, in common with the Cow and the Deer, the Goat and the Sheep have cloven feet, and that they are all ruminants, while the Horse has a single hoof, does not ruminate, and must therefore be separated from them, even though, like them, he is herbivorous. 
This is but the simplest illustration, taken from the most familiar objects, of this comparative method; but the same process is equally applicable to the most intricate problems in animal structures, and will give us the clew to all true affinities between animals. The education of a naturalist now consists chiefly in learning how to compare. If he have any power of generalization, when he has collected his facts, this habit of mental comparison will lead him up to principles, and to the great laws of combination. It must not discourage us, that the process is a slow and laborious one, and the results of one lifetime after all very small. It might seem invidious, were I to show here how small is the sum total of the work accomplished even by the great exceptional men, whose names are known throughout the cirilized world. But I may at least be permitted to speak disparagingly of my own efforts, and to sum up in the fervest words the result of my life's work. I have deroted my whole life to the study of Nature, and yet a single sentence may express all that I have done. I have shown that there is a correspondence between the succession of Fishes in geological times and the different stages of their growth in the egg, - this is all. It chanced to be a result that was found to apply to other groups and has led to other conclusions of a like nature. 
But, such as it is, it has been reached by this system of comparison, which, though I speak of it now in its application to the study of Natural History, is equally important in every other branch of knowledge. By the same process the most mature results of scientific research in Philology, in Ethnology, and in Physical Science are reached. And let me say that the community should foster the purely intellectual efforts of scientific men as carefully as they do their elementary schools and their practical institutions, generally considered so much more useful and important to the public. For from what other source shall we derive the higher results that are gradually woven into the practical resources of our life, except from the researches of those very men who study science, not for its uses, but for its truth? It is this that gives it its noblest interest: it must be for truth's sake, and not even for the sake of its usefuluess to humanity, that the scientific man studies $\mathrm{Na}$ ture. The application of science to the useful arts requires other abilities, other qualities, other tools than his; and therefore I say that the man of science who follows his studies into their practical application is false to his calling. The practical man stands ever ready to take up the work where the scientific man leaves it, and to adapt it to the material wants and uses of daily life. 
The publication of Cuvier's proposition, that the animal kingdom is built on four plans, however imperfectly understood and appreciated at first, created, nevertheless, an extraordinary excitement throughout the scientific world. All naturalists proceeded to test it, and some-among them soon recognized in it a great scientific truth, - while others, who thought more of making themselves prominent than of advancing science, proposed poor amendments, that were sure to be rejected on further investiga tion. Some of these criticisms and additions, however, were truly improvements, and touched upon points overlooked by Cuvier. Blainville, especially, took up the element of form among animals, - whether divided on two sides, whether radiated, whether irregular, etc. He, however, made the mistake of giving very elaborate names to animals already known under simpler ones. Why, for instance, call all animals with parts radiating in every direction Actinomorpha or Actinozuaria, when they had received the significant name of Radiates? It seemed to be a new system, when in fact it was only a new name. Ehrenberg, likewise, made an important distinction, when he united the animals according to the difference in their nervous systems; but he also encumbered the nomenclature unnecessarily, when he added to the names Anaima. 
and Enaima of Aristotle those of Myeloneura and Ganglioneura.

But it is not my object to give all the classifications of different authors here, and I will therefore pass over many noted ones, as those of Burmeister, Milne-Edwards, Siebold and Stannius, Owen, Leuckart, Vogt, Van Beneden, and others, and proceed to give some account of one investigator who did as much for the progress of Zoölogy as Cuvier, though he is comparatively little known among us.

Karl Ernst von Baer proposed a classification based, like Cuvier's, upon plan; but he recognized what Cuvier failed to perceive,-namely, the importance of distinguishing between type (by which he means exactly what Cuvier means by plan) and complication of structure, - in other words, between plan and the execution of the plan. He recognized four types, which correspond exactly to Cuvier's four plans, though he calls them by different names. Let us compare them.

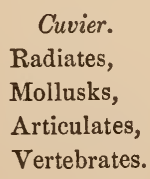

\section{Baer.}

Peripheric, Massive, Longitudinal, Doubly Symmetrical.

Though perhaps less felicitous, the names of Baer express the same ideas as those of Cuvier. By the Peripheric type he signififd those animals in 
which all the parts converge from the periphery or circumference of the animal to its centre. Cuvier only reverses this definition in his name of Radiates, signifying the animals in which all parts radiate from the centre to the circumference. By Massive, Baer indicated those animals in which the body is undivided, soft and concentrated, without a rery distinct individualization of parts, - exactly the animals included by $\mathrm{Cu}$ vier under his name of Mollusks, or soft-bodied animals. In his selection of the epithet Longitudinal, Baer was less fortunate; for all animals have a longitudinal diameter, and this word was not, therefore, sufficiently special. Yet his Longitudinal type answers exactly to Cuvier's Articulates, - animals in which all parts are arranged in a succession of articulated joints along a longitudinal axis. Cuvier has expressed this jointed structure in the name Articulates; whereas Baer, in his name of Longitudinal, referred only to the arrangement of joints in longitudinal succession, in a continuous string, as it were, one after another, indicating thus the prevalence of length as the predominant diameter of the body. For the Doubly Symmetrical type his name is the better of the two; since Cuvier's name of Vertebrates alludes only to the backbone, - while Baer, who is an embryologist, signifies in his their mode of growth also. He knew what Cuvier did not 
know, when he first proposed his classification, that in its first formation the germ of the Vertebrate divides in two folds; one turning up above the backbone, to form and enclose all the sensitive organs, - the spinal marrow, the organs of sense, all those organs by which life is expressed; the other turning down below the backbone, and enclosing all those organs by which life is maintained, - the organs of digestion, of respiration, of circulation, of reproduction, etc. So there is in this type not only an equal division of parts on either side, but also a division above and below, making thus a double symmetry in the plan, expressed by Baer in the name he gave it. Baer was perfectly original in his conception of these four types, for his paper was published in the very same year with that of Cuvier. But even in Germany, his native land, his ideas were not fully appreciated: strange that it should be so,-for, had his countrymen recognized his genius, they might have earlier claimed him as the compeer of the great French naturalist.

Baer also founded the science of Embryology, under the guidance of his teacher, Döllinger. His researches in this direction showed him that animals were not only built on four plans, but that they grew according to four modes of development. The Vertebrate arises from the egg differently from the Articulate, - the Articulate 
differently from the Mollusk, - the Mollusk differently from the Radiate. Cuvier only showed us the four plans as they exist in the adult; Baer went a step further, and showed us the four plans in the process of formation.

But his greatest scientific achievement is perhaps the discovery that all animals originate from eggs, and that all these eggs are at first identical in substance and structure. The wouderful and untiring research condensed into this simple statement, that all animals arise from eggs, and that all those eggs are identical in the beginning, may well excite our admiration. This egg consists of an outer envelope, the vitelline membrane, containing a fluid more or less dense, and variously colored, the yolk; within this is a second envelope, the so-called germinative vesicle, containing a somewhat different and more transparent fluid, and in the fluid of this second envelope float one or more so-called germinative specks. At this stage of their growth all eggs are microscopically small, yet each one has such tenacity of its individual principle of life that no egg was ever known to swerve from the pattern of the parent animal that gave it birth. 


\section{CHAPTER III.}

CATEGORIES OF CLASSIFICATION.

From the time that Linnæus showed us the necessity of a scientific system as a framework for the arrangement of scientific facts in Natural History, the number of divisions adopted by zoologists and botanists increased steadily. Not only were families, orders, and classes added to genera and species, but these were further multiplied by subdivisions of the different groups. But as the number of divisions increased, they lost in precise meaning, and it became more and more doubtful how far they were true to Nature. Moreover, these divisions were not taken in the same sense by all naturalists: what were called families by some were called orders by others, while the orders of some were the classes of others, till it began to be doubted whether these scientific systems had any foundation in Nature, or signified anything more than that it had pleased Linnæus, for instance, to call certain groups of animals by one name, while Cuvier had chosen to call them by another. 
These divisions are, first, the most comprehensive groups, the primary divisions, called branches by some, types by others, and divided by some naturalists into so-called sub-types, meaning only a more limited circumscription of the same kind of group; next we have classes, and these also have been divided into sub-classes; then orders and sub-orders; families and sub-families or tribes; then genera, species, and varieties. With reference to the question whether these groups really exist in Nature, or are merely the expression of individual theories and opinions, it is worth while to study the works of the early naturalists, in order to trace the natural process by which scientific classification has been reached; for in this, as in other departments of learning, practice has always preceded theory. We do the thing before we understand why we do it: speech precedes grammar, reason precedes logic ; and so a division of animals into groups, upon an instinctive perception of their differences, has preceded all our scientific creeds and doctrines. Let us, therefore, proceed to examine the meaning of these names as adopted by naturalists.

When Cuvier proposed his four primary divisions of the animal kingdom, he added his argument for their adoption,- - because, he said, they are constructed on four different plans. all the progress in our science since his time 
confirms this result; and I shall attempt to show that there are really four, and only four, such structional ideas at the foundation of the animal kingdom, and that all animals are included under one or another of them. But it does not follow, that, because we have arrived at a sound principle, we are therefore unerring in our practice. From ignorance we may misplace animals, and include them under the wrong division. This is a mistake, however, which a better insight into their organization rectifies ; and experience constantly proves, that, whenever the structure of an animal is perfectly understood, there is no hesitation as to the head under which it belongs. We may consequently test the merits of these four primary groups on the evidence furnished by investigation.

It has already been seen that these plans may be presented in the most abstract manner without any reference to special animals. Radiation expresses in one word the idea on which the lowest of these types is based. In Radiates we have no prominent bilateral symmetry, such as exists in all other animals, but an all-sided symmetry, in which there is no right and left, no anterior and posterior extremity, no above and below. It is true that in some of them there are indications of that bilateral symmetry which becomes a law in the higher animals; but 
wherever such a tendency is perceptible in the Radiates it is subordinate to the typical plan on which the whole group is founded. They are spheroidal bodies; yet, though many of them remind us of a sphere, they are by no means to be compared to a mathematical sphere, but rather to an organic sphere, so loaded with life, as it were, as to produce an infinite variety of radiate symmetry. The mathematical sphere has a centre to which every point of the surface bears identical relations; such spheres do not exist in the Animal Kingdom. A sphere of revolution, in consequence of its rotation upon its axis, presents equally flattened poles with meridians of equal value; this also is no organic character. A living sphere has unequal poles as well as unequal meridians, however much it may resemble a perfectly spheroidal body, and the whole organization is arranged, not necessarily around a centre, but always around a vertical axis, to which the parts bear equal relations.

In Mollusks there is a longitudinal axis and a bilateral symmetry; but the longitudinal axis in these soft concentrated bodies is not very prominent, except in the highest class; and though the two ends of this axis are distinct from each other, the difference is not so marked that we can say at once, for all of 
them, which is the anterior and which the posterior extremity. In this type, right and left have the preponderance over the other diameters of the body. The sides are the prominent parts, - they are loaded with the most important organs, or with those peculiarities of the structure that give it character. The Oyster is a good instance of this, with its double valve, so swollen on one side, so flat on the other. There is an unconscious recognition of this in the arrangement of all collections of Mollusks; for, though the collectors do not put up their specimens with any intention of illustrating this peculiarity, they instinctively give them the position best calculated to display their distinctive characteristics, and to accomplish this they necessarily place them in such a manner as to show the sides.

In Articulates there is also a longitudinal axis of the body and a bilateral symmetry in the arrangement of parts; the head and tail are marked, and the right and left sides are distinct. But the prominent tendency in this type is the development of the dorsal and ventral region; here above and below prevail over right and left. It is the back and the lower side that have the preponderance over any other part of the structure in Articulates. The body is divided from end to end by a succession of transverse 
constrictions, forming movable rings; but the striking features of the animal are always above or below, and especially developed on the back. Any collection of Insects or Crustacea is an evidence of this; being always instinctively arranged in such a manner as to show the predominant features, they uniformly exhibit the back of the animal. The profile view of an Articulate has no significance; whereas in a Mollusk, on the contrary, the profile view is the most illustrative of the structural character.

In the highest division, the Vertebrates, so characteristically called by Baer the Doubly Symmetrical type, a solid column runs through the body with an arch above and an arch below, thus forming a double internal cavity. In this type, the head is the prominent feature; it is, as it were, the loaded end of the longitudinal axis, so charged with vitality as to form an intelligent brain, and rising in man to such predominance as to command and control the whole organism. The structure is arranged above and below this axis, the upper cavity containing, as we have seen above, all the sensitive organs, and the lower cavity containing all those by which life is maintained.

While Cuvier and his followers traced these four distinet plans, as shown in the adult ani- 
mal, Baer opened to us a new field of investigation in the embryology of the four types, showing that for each there was a special mode of growth in the egg. Looking at them from this point of view, we shall see that these four types, with their four modes of growth, seem to fill out completely the plan or outline of the animal kingdom, and leave no reason to expect any further development or any other plan of animal life within these limits. The eggs of all animals are spheres, such as I have described them; but in the Radiate the whole periphery is transformed into the germ, so that it becomes, by the liquefying of the yolk, a hollow sphere. In the Mollusks, the germ lies above the yolk, absorbing its whole substance through the under side, thus forming a massive close body instead of a hollow one. In the Articulate, the germ is turned in a position exactly opposite to that of the Mollusk, and absorbs the yolk upon the back. In the Vertebrate, the germ divides in two folds, one turning upward, the other turning downward, above and below the central backbone. These four modes of development seem to exhaust the possibilities of the primitive sphere, which is the foundation of all animal life, and therefore I believe that Cuvier and Baer were right in saying that the whole animal kingdom is included under these four structural ideas. 
Leuckart proposed to subdivide the Radiates into two groups : the Colenterata, including Polyps and Acalephs or Jelly-Fishes, - and Echinoderms, including Star-Fishes, Sea-Urchins, and Holothurians. His reason for this distinction is the fact, that in the latter the organs or carities of the body have walls of their own, distinct from the body-wall; whereas in the former they are formed by internal folds of the outer wall of the body, as in the Polyps, or are hollowed out of the substance of the body, as in Jelly-Fishes. This implies no difference in the plan, but merely a difference in the execution of the plan. Both are equally radiate in their structure; and when Leuckart separated them as distinct primary types, he mistook a difference in the material expression of the plan for a difference in the plan itself.

So some naturalists have distinguished Worms from the other Articulates as a separate prime division. But the structural plan of this type is a cylinder divided by transverse constrictions or joints; and whether those joints are uniformly arranged from one end of the body to the other, as in the Worms, or whether the front joints are soldered together so as to form two regions of the body, as in Crustacea, or divided so as to form three regions of the body, as in winged insects, does not in the least affect the typical 
character of the structure, which remains the same in all, being, in fact, an articulated cylinder with variously combined rings and more or less complicated tubular appendages.

Branches or types, then, are natural groups of the animal kingdom, founded on plans of structure or structural ideas. What now are classes? Are they lesser divisions, differing only in extent, or are they founded on special characters? I believe the latter view to be the true one, and that class characters have a significance quite different from that of their mere range or extent. These divisions are founded on certain categories of structure; and were there but one animal of a class in the world, if it had those characters on which a class is founded, it would be as distinct from all other classes as if its kind were counted by thousands.

Baer approached the idea of the classes when he discriminated between plan of structure or type and the degree of perfection in the structure. But while he understands the distinction between a plan and its execution, his ideas respecting the different features of structure are not quite so precise. He does not, for instance, distinguish between the complication of a given structure and the mode of execution of a plan, both of which are combined in what he calls degrees of perfection. And yet, without this 
distinction, the difference between classes and orders cannot be understood; for classes and orders rest upon a just appreciation of these two categories, which are quite distinct from each other, and have by no means the same significance.

Again, quite distinct from both of these is the character of form, not to be confounded either with complication of structure, on which orders are based, or with the execution of the plan, on which classes rest. An example will show that form is no guide for the determination of classes or orders. Take, for instance, a Beche-de-Mer, a member of the highest class of Radiates, and compare it with a Worm. They are both long cylindrical bodies; but one has parallel divisions along the length of the body, the other has the body divided by transverse rings. Though in external form they resemble each other, the one is a worm-like Radiate, the other is a worm-like Articulate, each having the structure of its own type; so that they do not even belong to the same great division of the animal kingdom, much less to the same class. We have a similar instance in the Whales and Fishes, - the Whales having been for a long time considered as Fishes, on account of their form, while their structural complication shows them to be a low order of the class of Mammalia, to which we ourselves belong, 
that class being founded upon a particular mode of execution of the plan characteristic of the Vertebrates, while the order to which the Whales belong depends upon their complication of structure, as compared with other members of the same class.

We may therefore say that neither form nor complication of structure distinguishes classes, but simply the mode of execution of a plan. In Vertebrates, for instance, how do we distinguish the class of Mammalia from the other classes of the type? By the peculiar development of the brain, by their breathing through lungs, by their double circulation, by their bringing forth living young and nursing them with milk. In this class the beasts of prey form a distinct order, superior to the Whales or the herbivorous animals, on account of the higher complication of their structure; and for the same reason we place the Monkeys above them all. But among the beasts of prey we distinguish the Bears, as a family, from the family of Dogs, Wolves, and Cats, on account of their different form, which does not imply a difference either in the complication of their structure or in the mode of execution of their plan. 


\section{CHAPTER IV.}

\section{CLASSIFICATION AND CREATION.}

So close is the connection between classification and the plan of creation, the former being, so far as it is accurate, the literal interpreter of the latter, that the efforts of men to detect the natural affinities among animals, and to express them in clear, condensed forms, have always been recognized as the highest creations of scientific genius. Creations they were not, since the only valid classification is already recorded in organic forms, and a classification which is true to nature cannot be original; but works of genius some of them have unquestionably been, embodying the laborious, life-long investigations of men whose powerful imaginations vitalized anew the dead facts they collected. Such are the systems of classification of Linnæus, of Cuvier, of von Baer. And while in presenting classification as the subject of a series of papers in the "Atlantic Monthly," I am aware that I am drawing largely upon the patience of its readers, since the technical nature of the topic renders many details 
necessary which cannot be otherwise than dry to any but professional naturalists; yet believing, as I do, that classification, rightly understood, means simply the creative plan of God as expressed in organic forms, I feel the importance of attempting at least to present it in a popular guise, divested, as far as possible, of technicalities. I would therefore ask the indulgence of my readers for such scientific terms and details as cannot well be dispensed with, begging them to remember that a long and tedious road may bring us suddenly upon a glorious prospect, and that a clearer mental atmosphere and a new intellectual sensation may well reward us for a little weariness in the outset.

Besides, the time has come when scientific truth must cease to be the property of the few, when it must be woven into the common life of the world; for we have reached the point where the results of science touch the very problem of existence, and all men listen for the solving of that mystery. When it will come, and how, none can say; but this much at least is certain, that all our researches are leading up to that question, and mankind will never rest till it is answered. If, then, the results of science are of such general interest for the human race, if they are gradually interpreting the purposes of the Deity in creation, and the relation of man to all 
the past, then it is well that all should share in its teachings, and that it should not be kept, like the learning of the Egyptians, for an exclusive priesthood who may expound the oracle according to their own theories, but should make a part of all our intellectual culture and of our common educational systems. With this view, I will endeavor to simplify as far as may be my illustrations of the different groups of the Animal Kingdom, beginning with a more careful analysis of those structural features on which classes are founded.

I have said that the Radiates are the lowest type among animals, embodying, under an infinite variety of forms, that plan in which all parts bear definite relations to a vertical central axis. The three classes of Radiates are distinguished from each other by three distinct ways of executing that plan. I dwell upon this point ; for we shall never arrive at a clear understanding of the different significance and value of the various divisions of the Animal Kingdom, till we appreciate the distinction between the structural conception and the material means by which it is expressed. A comparison will, perhaps, better explain my meaning. There are certain architectonic types, including edifices of different materials, with an infinite variety of architectural details and external ornaments; but the 
flat rour and the colonnade are typical of all Grecian temples, whether built of marble or granite or wood, whether Doric or Ionic or Corinthian, whether simple and massive or light and ornamented; and, in like manner, the steep roof and pointed arch are the typical characters of all Gothic cathedrals, whatever be the material or the details. The architectural conception remains the same in all its essential elements, however the more superficial features vary. Such relations as these edifices bear to the architectural idea that includes them all, do classes bear to the primary divisions or branches of the Animal Kingdom.

The three classes of Radiates, beginning with the lowest, and naming them in their relative order, are Polyps or Sea-anemones and corals, Acalephs or Jelly-Fishes, and Echinoderms or Star-Fishes, Sea-Urchins and the like. In the Polyps the plan is executed in the simplest manner; the body consists of a sac, the sides of which are folded inward, at regular intervals, from top to bottom, so as to divide it by vertical radiating partitions, converging from the periphery toward the centre. These folds do not meet in the centre, but leare an open space, which is the main cavity of the body. This open space, however, occupies only the lower part of the body; for in the upper there is a second sac 
hanging to a certain distance within the first. This inner sac has an aperture in the bottom, through which whatever enters it passes into the main cavity of the body. A central opening in

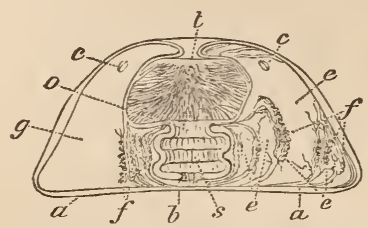

Vertical section of a contracted Sea-Anemone or Actinia : $o$, mouth ; $t$, tentacles ; $s$, inner sac or stomach ; $b$, main cavity ; $f f$, reproductive organs ; $g$, radiating partition; $e e e$, radiating chambers; $c c$, circular openings in the partitions; $a a$, lower floor. The tentacles are drawn in.

the top forms a kind of mouth, around which are radiating tentacles connecting with the open chambers formed by the partitions within. Cut-

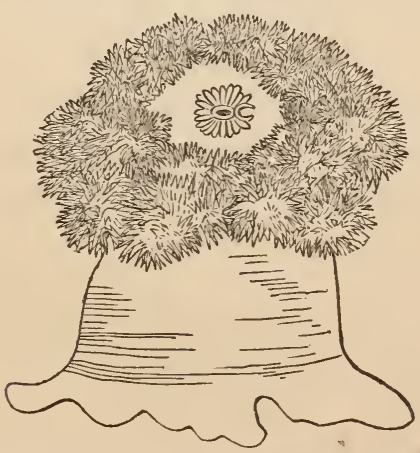

Sea-Anemone or Actinia, moderately expanded.

ting such an animal across in a transverse section, we shall see the radiation of the partitions 
from the centre to the circumference, showing

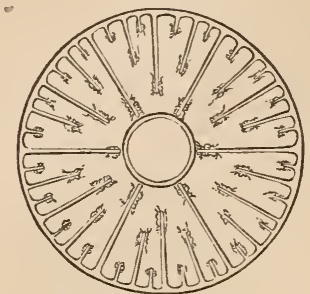

Transverse section of a Sea-Anemone or Actinia.

still more distinctly the typical structure of the division to which it belongs.

The second class is that of Jelly-Fishes or Acalephs; and here the same plan is carried out

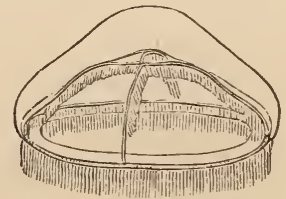

Staurophora seen in profile.

in the form of a hemispherical gelatinous disk, the digestive cavity being hollowed, or, as it

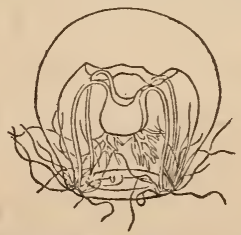

Hippocrene seen in profile.

were, scooped, out of the 'substance of the body, which is traversed by tubes that radiate from 
the centre to the periphery. Cutting it across transversely, or looking through its transparent mass, the same radiation of the internal structure is seen again; only that in this instance the radiating lines are not produced by rertical partitionwalls, with open spaces between, as in the Polyps, but by radiating tubes passing through the gelatinous mass of the body. At the periphery is a

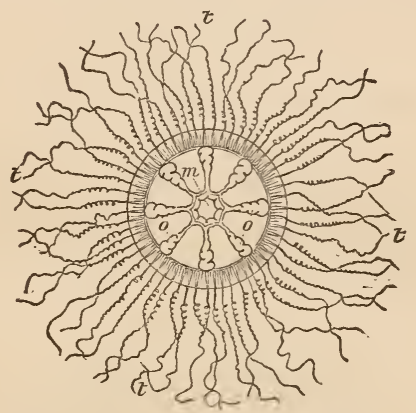

Melicertum seen from above, with the tentacles spreading: 00 , radiating tubes with ovaries; $m$, mouth ; $t t t t$, tentacles.

circular tube connecting them all, and the tentacles, which hang down when the animal is in its natural position, connect at their base with the radiating tubes, while numerous smaller tentacles may form a kind of fringe all round the margin.

The third and highest class includes the StarFishes, Sea-Urchins, and Holothurians or Bechesde-Mer. The radiation is equally distinct in each of these; but here again the mode of execution differs from that of the two other classes. 
The internal cavity and the radiating tubes, instead of being connected with the outer wall of

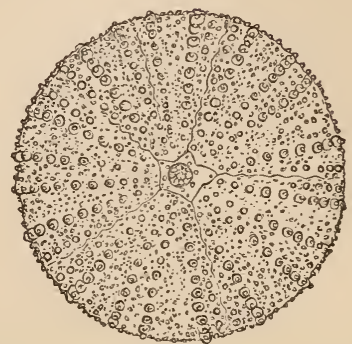

Common Sea-Urchin, Echinus, seen from above.

the body as in Polyps, or hollowed out of the substance of the body as in Jelly-Fishes, are here enclosed within independent walls of their own,

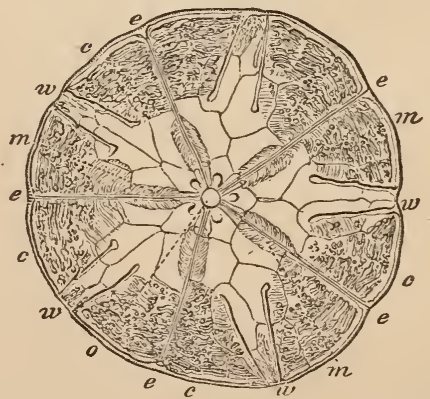

Echinarachnius, opened by a transverse or horizontal section, and showing the internal arrangement : $o$, mouth ; e e e e e, ambulacra, with their ramifications $c m c m c m ; w w w w$, interambulacra.

quite distinct from the wall of the body. But notwithstanding this difference, a transverse sec- 
tion shows in these animals, as distinctly as in all the rest, the radiating structure typical of the whole branch. In these three classes we have no difference of plan, nor even any modification of the same plan, - for either one of them expresses it as clearly as any other, - but simply three different ways of executing one and the same structural idea.

To those already familiar with these animals some technical details showing the absolute identity of structural plan in these three classes of Radiates may not be uninteresting.

Let us therefore return to the Polyps, and look at the Sea-Anemone in a new aspect. Suppose the inner sac to be turned out; it will then present the appearance of a bottle-shaped body, with a row of hollow projections around the base of the neck; the neck itself being the stomach turned outward, so that its inner surface becomes its outer surface. If we now compare this with the Jelly-Fish, placing both in the same attitude, with the mouth either downward or upward, it becomes apparent that the so-called arms surrounding the mouth of the Jelly-Fish correspond exactly to the neck of our bottleshaped animal, with the sole difference that it is split into lobes in the Jelly-Fish, instead of remaining tubular as in the Polyp. There are, however, many Jelly-Fishes in which it is strictly 
tubular as in the Polyps. To carry the comparison further, widen the partitions between the chambers of the Polyps, and the chambers are then reduced to narrow tubes, which completes the homology. In Echinoderms the difference consists, as we have seen, in the fact that the various cavities of the body, instead of being simply scooped out of its substance, have walls of their own; these walled cavities being enclosed as intestines by the outer wall of the body. I shall return to this subject again, when I explain the homologies of Radiates more in detail, but have thought it well to allude to it here in connection with this more general sketch of their structure.

I have mentioned only three classes of Radi. ates. Cuvier had five in his classification; for he had placed among them the Intestinal Worms and the Infusoria or Animalcules. The Intestinal Worms are much better known now than they were in his day. Their anatomy and embryology have been traced, and it has been shown that the essential features of these parasites are the same as those of all Articulates, their whole body being divided into successive movable joints or rings. Cuvier was misled by the circular arrangement of certain parts around the mouth, and by-the presence of a wreath of feelers around the head of some of these Worms, resembling the tentacles of many Radiates. This is, however, 
no indication of radiate structure, but a superficial feature in no way related to the internal organization; and therefore the Intestinal Worms must be removed from the branch of Radiates, and referred to that of Articulates.

- We must carefully distinguish between affinity and analogy among animals. The former is founded on identity of plan; the latter only upon external resemblance. This may be produced by similar features, which, when intimately connected with the whole internal organization, as in some groups, may be considered as typical characters, but when only grafted, as it were, in a superficial manner on animals of another type, have no relation to the essential elements of structure, and become at once subordinate and unimportant. Such is the difference between the tentacles in a Radiate and the wreath of feelers in a Worm;the external effect may be much the same; but in the former every tentacle opens into one of the chambers, as in a Polyp, or connects with one of the radiating tubes, as in Acalephs, or with the locomotive suckers, as in Star-Fishes, and is therefore closely linked with the whole internal organization; whereas the feelers in the latter are only external appendages, in no way connected with the essential structural elements. We have a striking illustration of this superficial resemblance in the wings of Birds and Insects. In 
Birds, wings are a typical feature, corresponding to the front limbs in all Vertebrates, which are constructed in the same way, whether they are arms as in Man, or fore-legs as in Quadrupeds, or pectoral fins as in Fishes, or wings as in Birds. The wing in an Insect, on the contrary, is a flattened, dried-up gill, having no structural relation whatever to the wing of a Bird. They are analogous ouly, because they resemble each other in form and in function, being in the same way subservient to flight; but as organs they are entirely different. The wings of Birds are homologous to the limbs of other Vertebrates, notwithstanding their great apparent difference; they are only analogous to the wings of Insects, notwithstanding their great external resemblance.

In adding Infusoria to the Radiates, Cuvier was false to his own principle of founding all classification on plan. He was influenced by their seeming simplicity of structure, and placed them in the lowest division of the Animal Kingdom on that account. But even this simplicity was only apparent in many of them. At certain seasons of the year myriads of these little Animalcules may be seen in every brook and road-side pool. They are like transparent little globules, without any special organization, apparently; and were it not that they are in constant rotation, exhibiting thus a motion of their own, 
one would hardly suspect that they were endowed with life. To the superficial observer they all look alike, and it is not strange, that, before they had been more carefully investigated, they should have been associated together as the lowest division of the Animal Kingdom, representing, as it were, a border-land between animal and regetable life. But since the modern improvements in the microscope, Ehrenberg, the great master in microscopic investigation, has shown that many of these little globules have an extraordinary complication of structure. Subsequent inrestigations have prored that they include a great variety of beings: some of them belonging to the type of Mollusks; others to the type of Articulates, being in fact little shrimps; while many others are the locomotive germs of plants, and so far from forming a class by themselves, as a distinct group in the Animal Kingdom, they seem to comprise not only representatives of all types, except Vertebrates, but to belong also in part to the Vegetable Kingdom.

Siebold, Leuckart, and other modern zoölogists, have considered them as a primary type, and called them Protozoa; but this is as great a mistake as the other. The rotatory motion in them all is produced by an apparatus that exists not only in all animals, but in plants also, and is a most important agent in sustaining the fresh- 
ness and vitality of their circulating fluids and of the surrounding medium in which they live. It consists of soft fringes, called vibratile cilia. Such fringes cover the whole surface of these little living beings, and by their unceasing play they maintain the rotating motion that carries them along in the water.

The Mollusks, the next great division of the Animal Kingdom, also include three classes. With them is introduced that character of bilateral symmetry, or division of parts on either side of a longitudinal axis, that prevails throughout the Animal Kingdom, with the exception of the Radiates. The lowest class of Mollusks has been named Acephala, to signify the absence of any distinct head; for though their whole organization is based upon the principle of bilateral symmetry, it is nevertheless very difficult to determine which is the right side and which the left in these animals, because there is so little prominence in the two ends of the body that the anterior and posterior extremities are hardly to be distinguished. Take the oyster as an example. It has, like most Acephala, a shell with two ralves united by a hinge on the back, one of these valves being thick and swollen, while the other is nearly flat. If we lift the shell, we find beneath a soft lining skin covering the whole animal, and called by naturalists the mantle, from the inner 
surface of which arises a double row of gills, forming two pendent folds on the sides of the body. At one end of the body these folds do not meet, but leave an open space, where is the aperture we call the mouth. This is the only indication of an anterior extremity; but it is enough to establish a difference between the front and hind ends of the body, and to serve as a guide in distinguishing the right and left sides. If now we lift the mantle and gills, we find the principal organs beneath: the stomach, with a

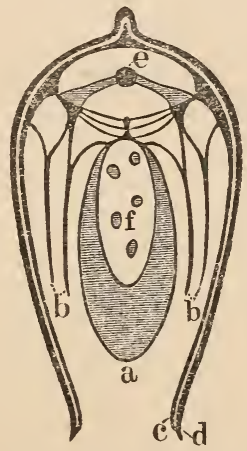

Common Fresh-water Mussel, Cnio, cut transversely : $a$, foot ; $b b$, gills ; $c$, mantle ; $d$, shell ; $e$, heart ; $f$, main cavity, with intestines.

winding alimentary canal; the heart and liver; the bloodvessels, branching from either side of the heart to join the gills; and a fleshy muscle passing from one valve of the shell to the other, enabling the animal by its dilation or contraction to open and close its shell at will. A cut across 
an animal of this class shows very distinctly the bilateral arrangement of the parts. In such a section we see the edge of the two shells on either side; within these the edge of the mantle; then the double rows of gills; and in the middle the alimentary canal, the heart, and the bloodressels branching right and left. Some of these animals have eye-specks on the edge of the mantle; but this is not a constant feature. This class of Acephala includes all the Oysters, Clams, Mussels, and the like. When named with reference to their double shells, they are called Bivalves;

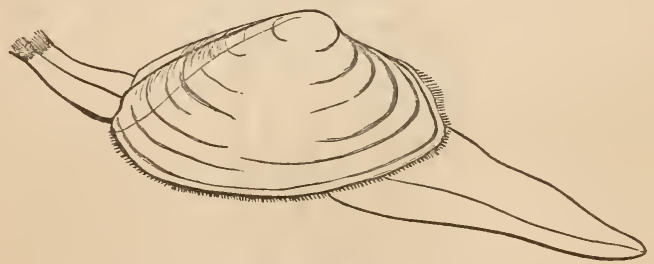

Common Hen-Clam, Mactra, in motion.

and with them are associated a host of less conspicuous animals, known as Ascidians, Brachiopods, and Bryozoa.

The second class in this type is that of Gasteropoda, so named from the fleshy muscular expansion on which they move, and which is therefore called a foot: a very inappropriate name; since it has no relation or resemblance to a foot, though it is used as a locomotive organ. This class includes all the Snails, Slugs, Cockles, 
Conchs, Periwinkles, Whelks, Limpets, and the like. Some of them have no solid covering; but the greater part are protected by a single shell, and on this account they are called Univalves, in contradistinction to the Acephala or Bivalves. These shells, though always single, differ from each other by an endless variety of form and color, - from the flat simple shell of the Limpet

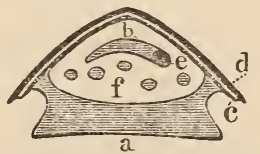

Limpet, Patella, cut transversely: $a$, foot ; $b$, gills ; $c$, mantle ; $d$, shell ; $e$, heart ; $f$, main cavity, with intestines.

to the elaborate spiral and brilliant hues of the Cones and Cowries. Different as is their external covering, however, if we examine the internal structure of a Gasteropod, we find the same general arrangement of parts that prevails in the Acephala, showing that both belong to the same great division of the Animal Kingdom. The mantle envelops the animal, and lines its single shell as it lined the double shell of the Oyster; the gills are placed on either side of it; the stomach, with the winding alimentary canal, is in the centre of the body; the heart and liver are placed in the same relation to it as in the Acephala; and though the so-called foot would seem to be a new feature, it is but a muscular 3 * 
expansion of the rentral side of the body, already well dereloped in the Mussels and Clams. There is an evident superiority in this class over the preceding one, in the greater prominence of the anterior extremity, where there are two or more feelers, with which eyes more or less developed are connected; and though there is nothing that can be properly called a head, yet there can be no hesitation as to the distinction between the front and hind ends of the body.

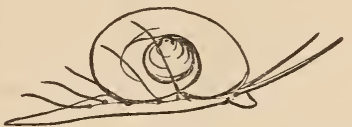

Margarita arctica, of the coast of New England.

The third and highest class of Mollusks has been called Cephalopoda, in reference again to a special feature of their structure. They have long arms or feelers around the head, serving as organs of locomotion, by which they propel themselves through the water with a velocity that is quite extraordinary, when compared with the sluggishness of the other Mollusks. In these animals the head is distinctly marked, - being separated, by a contraction or depression behind it, from the rest of the body. The feelers, so prominent on the anterior extremity of the Gasteropoda, are suppressed in Cephalopoda, and the eyes are consequently brought immediately 
on the side of the head, and are very large in proportion to the size of the animal. A skin corresponding to the mantle envelops the body, and the gills are on either side of it; - the stomach with its winding canal, the liver, and heart occupy the centre of the body, as in the other two classes. This class includes all the Cuttle-Fishes, Squids, and Nautili, and has a

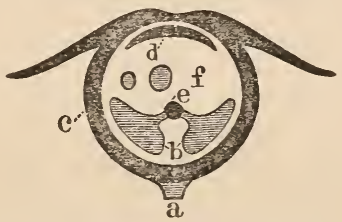

Common Squid, Loligo, cut transversely : $a$, foot or siphon ; $b$, gills ; $c$, mantle ; $d$, internal shell ; $e$, heart ; $f$, main cavity, with intestines.

vast number of fossil representatives. Many of these animals are destitute of any shell; and,

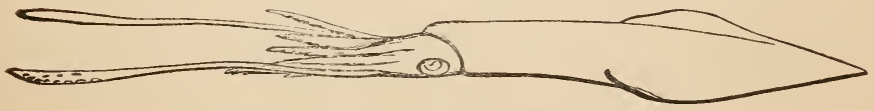

Common Squid, Loligo, in a swimming attitude.

with a single exception, when they have a shell, it is not coiled from right to left or from left to right, as in the spiral of the Gasteropoda, but from behind forwards, as in the Nautilus. These shells are usually divided into a number of chambers, - the animal, as it grows, building a wall behind it at regular intervals, and always occupying the external chamber, retaining, 
however, a connection with his past home by a siphon that runs through the whole succession of chambers. The readers of the "Atlantic Monthly" cannot fail to remember the exquisite poem suggested to the Autocrat of the Breakfast-Table by this singular feature in the structure of the so-called Chambered Shells.

Cuvier divided the Mollusks also into a larger number of classes than are now admitted. He placed the Barnacles with them, on account of their shells; and it is only since an investigation of the germs born from these animals has shown them to be Articulates that their true position is understood. They give birth to little Shrimps that afterwards become attached to the rocks and then assume the shelly covering that has misled naturalists about them. They ought therefore to be referred to the class of Crustacea, in which they are now generally included. Brachiopods formed another of his classes; but these differ from the other Biralves only in having a network of bloodvessels upon their mantle, in the place of free gills, and this is merely a complication of structure, not a difference in the general mode of execution, for the position and relation of these organs to the rest of the structure are exactly the same in both. Pteropods constituted another class in his divis ion of the type of Mollusks; but these animals, 
again, form only an order in the class of Gasteropoda, as Brachiopods form an order in the class of Acephala.

In the third division of the Animal Kingdom, the Articulates, we have again three classes: Worms, Crustacea, and Insects. The lowest of these three classes, the Worms, presents the typical structure of that branch in the most uniform manner, with little individualization of parts. The body is a long cylinder divided through its whole length by movable joints, while the head is indicated only by a difference in the front joints. There is here no concentration of vitality in special parts of the structure, as in the higher animals, but the nervous force is scattered through the whole body, - every ring having, on its lower side, either two nervous swellings, one on the right, the other on the left side, comnected by nervous threads with those that precede and those that follow them, or these swellings are united in the median line. It is to this equal distribution of nervous force through the whole system that these animals owe their extraordinary power of repairing any injured part, so that, if cut in two, the front part may even reconstruct a tail for itself, while the hind part produces a new head, and both continue to live as distinct animals. This facility of selfrepair, after a separation of the parts, which is 
even a normal mode of multiplication in some of them, does not indicate, as may at first appear, a greater intensity of vital energy, but, on the contrary, arises from an absence of any one nerrous centre such as exists in all the higher animals, and is the key to their whole organization. A serious injury to the brain of a Vertebrate destroys vitality at once, for it holds the very essence of its life; whereas in many of the lower animals any part of the body may be destroyed without injury to the rest. The digestive carity in the Worms runs the whole length of the body; and the respiratory organs, wherever they are specialized, appear as little vesicles or gill-like appendages either along the back or below the sides, connected with the locomotive appendages.

This class includes animals of various degrees of complication of structure, from those with highly dereloped organizations to the Worms that float in fresh water like long hairs and hardly seem to be animals, and to those still lower representatives of the class that live in the cavities of other animals. Yet even creatures so low in the scale of life as the Gordius, that long thread-like Worm found often in brooks and called Horsehair by the common people, are not devoid of some instincts, however dim, of feeling and affection. I remember a case in 
point, that excited my own wonder at the time, and may not be uninteresting to my readers.

I had received from Detroit, through the kindness of Messrs. Higby and Stearns, one of these singular animals. When I first saw it, it was coiled up in a close roll at the bottom of a bottle filled with fresh water, and looked more like a little tangle of black sewing-silk than anything else. Wishing to unwind it, that I might examine its entire length, I placed it in a large china basin filled with water, and proceeded very gently to disentangle its coils, when I perceived that the animal had twisted itself around a bundle of its eggs, holding them fast in a close embrace. In the process of unwinding, the eggs dropped away and floated to a little distance. Having finally stretched it out to its full length, perhaps half a yard, I sat watching to see if this singular being that looked like a long black thread in the water would give any signs of life. Almost immediately it moved towards the bundle of eggs, and, having reached it, began to sew itself through and through the little white mass, passing one end of its body through it, and then returning to make another stitch, as it were, till the eggs were at last completely entangled again in an intricate network of coils.

It seemed to me almost impossible that this care of offspring could be the result of any in- 
stinct of affection in a creature of so low an organization, and I again separated it from the eggs, and placed them at a greater distance, when the same action was repeated. On trying the experiment a third time, the bundle of eggs had become loosened, and a few of them dropped off singly into the water. The efforts which the animal then made to recover the missing ones, winding itself round and round them, but failing to bring them into the fold with the rest, because they were too small and evaded all efforts to secure them when once parted from the first little compact mass, convinced me that there was a definite purpose in its attempts, and that even a being so low in the scale of animal existence has some dim consciousness of a relation to its offspring.

I afterwards unwound the mass of eggs, which, when coiled up as I first saw it, made a roll of white substance about the size of a coffee-bean, and found that it consisted of a string of eggs, measuring more than twelve feet in length, the eggs being held together by some gelatinous substance that cemented them and prevented them from falling apart. Cutting this string across, and placing a small section under the microscope, I counted on one surface of such a cut from seventy to seventy-five eggs; and, estimating the entire number of eggs according to 
the number contained on such a surface, I found that there were not less than eight millions of eggs in the whole string. The fertility of these lower animals is truly amazing, and is no doubt a provision of Nature against the many chances of destruction to which these germs, so delicate and often microscopically small, must be exposed. The higher we rise in the Animal Kingdom, the more limited do we find the number of progeny, and the care bestowed upon them by the parents is in proportion to this diminution.

The subsequent adrentures of these germs form so odd a sequel to their early history, that I will add it here. The eggs are hatched in the water, the embryos first making their appearance as little transparent bodies, moving about by means of verbratile cilia. Their only appendages are minute horns attached to one end of the body. Strange to say, their next step in life is to creep into the legs of grasshoppers and burrow their way into the abdominal cavity of these animals, where they undergo their further development as Worms, sometimes growing to be two or three inches in length before they are freed. When they have grown so large that the grasshopper becomes distended by the size of its strange inhabitant, it bursts, the Worm is released, and returns to its aquatic life. When familiar with the vicissitudes in the life of these 
animals, one ceases to wonder that Nature should make large provision against the many chances of destruction that beset them, and one may readily believe, that, of the eight millions of eggs born from one individual, a comparatively small number survive.

The next class in the type of Articulates is that of Crustacea, including Lobsters, Crabs, and Shrimps. It may seem at first that nothing can be more unlike a Worm than a Lobster; but a comparison of the class-characters shows that the same general plan controls the organization in both. The body of the Lobster is divided into a succession of joints or rings, like that of the Worm; and the fact that the front rings in the Lobster are soldered together, so as to make a stiff front region of the body, enclosing the head and chest, while only the hind rings remain movable, thus forming a flexible tail, does not alter in the least the general structure, which consists in both of a body built of articulated rings. The nervous swellings, which were evenly distributed through the whole body in the Worm, are more concentrated here, in accordance with the prevalent combination of the rings in two distinct regions of the body, the larger ones corresponding to the more important organs ; but their relation to the rest of the organization, and their connection by nervous threads 
with each other, remain the same. The respiratory organs, which in most of the Worms were mere vesicles on the lower part of the sides of the body, are here more highly organized gills; but their general character and relation to other parts of the structure are unchanged, and there is a connection between the gills and the leg's in Crustacea, corresponding to that between the respiratory organs in Worms and their locomotive appendages. The alimentary canal consists of a single digestive cavity passing through the whole body, as in Worms, the anterior part of which is surrounded by a large liver. What is true of the Lobsters is true also, so far as classcharacters are concerned, of all the Crustacea.

Highest in this type are the Insects, and among these I include Spiders and Centipedes as well as Winged Insects. It is true that the Centipedes have a long uniform body like Worms, and the Spiders have the body divided into two regions like the Crustacea, while the body in true Insects has three distinct regions, head, chest, and hindbody; but, notwithstanding this apparent difference, both the former share in the peculiar class-character that places them with the Winged Insects in one class, distinct from all the other Articulates. We have seen that in the Worms the respiratory organs are mere vesicles, while in the Crustacea they are more highly organized gills; 
but in Centipedes, Spiders, and Winged Insects the breathing-apparatus is aerial, consisting of air-holes on the sides of the body, connected with a system of tubes and vessels extending into the body and admitting air to all parts of it. In the winged Insects this system is very elaborate, filling the body with air to such a degree as to render it exceedingly light and adapted to easy and rapid flight. The general arrangement of parts is the same in this class as in the two otlers, the typical character being alike in all.

We come now to the highest branch of the Animal Kingdom, that to which we ourselves belong, - the Vertebrates. This type is usually divided into four classes, Fishes, Reptiles, Birds, and Mammalia; and though many naturalists believe that it includes more, and I am myself of that opinion, I shall allude here only to the four generally admitted classes, as they are sufficient for my present purpose, and will serve to show the characters upon which classes are based. In a former paper I have explained in general terms the plan of structure of this type, - a bachbone, with a solid arch above and a solid arch below, forming two cavities that contain all the systems of organs, the whole being surrounded by the flesh and skin. Now whether a body so constructed lie prone in the water, like a Fish, - or be lifted on imperfect legs, like a 
Reptile, - or be balanced on two legs, while the front limks become wings, as in Birds, - or be raised upon four strong limbs terminating in paws or feet, as in Quadrupeds, - or stand upright with head erect, while the limbs consist of a pair of arms and a pair of legs, as in Man, - does not in the least affect that structural conception under which they are all included. Every Vertebrate has a backbone; every Vertebrate has a solid arch abore that backbone and a solid arch below it, forming two cavities, - no matter whether these arches be of hard bone, or of cartilage, or even of a softer substance; every Vertebrate has the brain, the spinal marrow or spinal cord, and the organs of the senses in the upper cavity, and the organs of digestion, respiration, circulation, and reproduction, in the lower one; every Vertebrate has four locomotive appendages built of the same bones and bearing the same relation to the rest of the organization, whether they be called pectoral and ventral fins, or legs, or wings and legs, or arms and legs. Notwithstanding the rudimentary condition of these limbs in some Vertebrates and their difference of external appearance in the different groups, they are all built of the same structural elements. And even where they seem wanting, as in Serpents, a minute study of the gradual reduction of the locomotive appendages in various groups 
of Reptiles will show that they too are true to this structural plan. These are the typical characters of the whole branch, and exist in all its representatives.

What now are the different modes of expressing this structural plan that lead us to associate certain Vertebrates together in distinct classes? Beginning with the lowest class, - the Fishes are cold-blooded, they breathe through gills, and they are egg-laying; in other words, though they have the same general structure as the other Vertebrates, they have a special mode of circulation, respiration, and reproduction. The Reptiles are also cold-blooded, though their system of circulation is somewhat morc complicated than that of the Fishes; they breathe through lungs, though part of them retain their gills through life; and they lay eggs, but larger and fewer ores than the Fishes, diminishing in number in proportion to their own higher or lower position in their class. They also bestow greater care upon their offspring than most of the Fishes. The Birds are warmblooded and air-breathing, having a double circulation; they are egg-laying, like the two other classes, but their eggs are comparatively few in number, and the young are hatched by the mother and fed by the parent hirds till they can provide for themselves.

The Mammalia are also warm-blooded and 
breathe through lungs; but they differ from all other Vertebrates in their mode of reproduction, bringing forth living young, which they nurse with milk. Even in the lowest members of this highest group of the Vertebrates, at the head of which stands Man himself, looking hearenward it is true, but nevertheless rooted deeply in the Animal Kingdom, we have the dawning of those family relations, those intimate ties between parents and children, on which the whole social organization of the humall race is based. Man is the crowning work of God on earth; but though so nobly endowed, we must not forget that we are the lofty children of a race whose lowest forms lie prostrate within the water, having no higher aspiration than the desire for food; and we cannot understand the possible degradation and moral wretchedness of Man, without knowing that his physical nature is rooted in all the material characteristics that belong to his type and link him even with the Fish. The moral and intellectual gifts that distinguish him from them are his to use or to abuse; he may, if he will, abjure his better nature and be Vertebrate more than Man. He may sink as low as the lowest of his type, or he may rise to a spiritual height that will make that which distinguishes him from the rest far more the controlling element of his being than that which unites him with them. 


\section{CHAPTER V .}

\section{DIFFERENT VIEWS RESPECTING ORDERS.}

Iт is in the search after the true boundaries and characteristics of orders that we may expect the greatest advance by the naturalists of the present day; and yet there is now much discrepancy among them, some mistaking orders for classes, others raising families to the dignity of orders. This want of agreement in their results is not strange, however; for the recognition of orders is indeed exceedingly difficult. If they are, as I have defined them, groups in Nature founded upon a greater or less complication of structure, they must, of course, form a regular gradation within the limits of their class, since comparative perfection implies comparative rank, and a correct estimate of these degrees of complication requires an intimate and extensive knowledge of structure throughout the class. There would seem to be an arbitrary element here, - that of our individual appreciation of structural character. If one man holds a certain kind of structural characters superior to another, 
ne will establish the rank of the order upon that feature, while some other naturalist, appreciating a different point of the structure more highly, will make that the test character of the group. Let us see whether we can eliminate this arbitrary element in our estimate of these groups, and find any mode of determining orders that shall be unquestionable, and give us results as positive as a chemical analysis according to quantitative elements. I believe that there are such absolute tests of structural relations. It is my conviction, that orders, like all the other groups of the Animal Kingdom, have a positive existence in Nature with definite limits; that no arbitrary element should enter into any part of our classifications; and that we have already the key by which to solve this question about orders.

To illustrate this statement, I must return to the class of Insects. We have seen that they are divided into three orders: the long cylindrical Centipedes, with the body divided throughout in uniform rings, like the worms; the Spiders, with the body divided into two regions; and the Winged Insects, with head, chest, and hind body distinct from each other, forming three separate regions. In the first group, the Centipedes, the nervous system is scattered through the whole body, as in the Worms; in the Spiders it is concentrated in two nervous swellings, as in Crusta- 
cea, the front one being the largest; and in the Insects there are three nervous centres, the largest in the head, a smaller one in the chest, and the smallest in the hind body. Now according to this greater or less individualization of parts, with the corresponding localization of the nervous centres, naturalists have established the relative rank of these three groups, placing Centipedes lowest, Spiders next, and Winged Insects highest. But naturalists may, and indeed they actually do, differ as to this estimation of the anatomical structure, for the Spiders are placed above Insects by some naturalists, and many even consider them a distinct class. Have we, then, any means of testing its truth to Nature? Let us look at the development of these animals, taking the highest order as an illustration, that we may have the whole succession of changes.

All know the story of the Butterfly with its three lives, as Caterpillar, Chrysalis, and Winged Insect. I speak of its three lives, but we must not forget that they make after all but one life, and that the Caterpillar is as truly the same being with the future Butterfly, as the child is the same being with the future man. The old significance of the word metamorphosis - the fabled transformation of one individual into another, in which so much of the imagination and poetical culture of the ancients found expression - still 
clings to us; and where the different phases of the same life assume such different external forms, we are apt to overlook the fact that it is one single continuous life. To a naturalist, metamorphosis is simply growth; and in that sense the different stages of development in animals that undergo their successive changes within the egg are as much metamorphoses as the successire phases of life in those animals that complete their development after they are hatched.

But to return to our Butterfly. In its most imperfect, earliest condition, it is Worm-like, the body consisting of thirteen uniform rings; but when it has completed this stage of existence, it passes into the Chrysalis state, during which the body has two regions, the front rings being soldered together to form the head and chest, while the hind joints remain distinct; and it is only when it bursts from its Chrysalis envelope, as a complete Winged Insect, that it has three distinct regions of the body. Do not the different periods of growth in this highest order explain the relation of all the orders to each other? The earliest condition of an animal cannot be its highest condition, - it does not pass from a more perfect to a less perfect state of existence. The history of its growth is, on the contrary, the listory of its progress in development; and therefore, when we find that the first stage of growth in the 
Winged Insect transiently represents a structura character that is permanent in the lowest order of its class, that its second stage of growth transiently represents a structural character that is permanent in the second order of its class, and that only in the last stage of its existence does the Winged Insect attain its complete and perfect condition, we may fairly infer that this division of the class of Insects into a gradation of orders, placing Centipedes lowest, Spiders next, and Winged Insects highest, is true to Nature.

This is not the only instance in which the embryological evidence confirms perfectly the anatomical evidence on which orders have been distinguished, and I believe that Embryology will give us the true standard by which to test the accuracy of our ordinal groups. In the class of Crustacea, for instance, the Crabs have been placed above the Lobsters by some naturalists, in consequence of certain anatomical features; but there may easily be a difference of individual opinion as to the relative value of these features. When we find, however, that the Crab, while undergoing its changes in the egg, passes through a stage in which it resembles the Lobster much more than it does its own adult condition, we cannot doubt that its earlier state is its lower one, and that the organization of the Lobster is not as high in the class of Crustacea as that of the 
Crab. While using illustrations of this kind, however, I must guard against misinterpretation. These embryological changes are never the pass. ing of one kind of animal into another kind of animal; the Crab is none the less a Crab during that period of its development in which it resembles a Lobster; it simply passes, in the natural course of its growth, through a phase of existence which is permanent in the Lobster, but transient in the Crab. Such facts should stimulate all our young students to embryological investigation, as a most important branch of study in the present state of our science.

But while there is this structural gradation among orders, establishing a relative rank between them, are classes and branches also linked together as a connected chain? That such a chain exists throughout the Animal Kingdom has long been a favorite idea, not only among naturalists, but also in the popular mind. Lamarck was one of the greatest teachers of this doctrine. He held, not only that branches and classes were connected in a direct gradation, but that within each class there was a regular series of orders, families, genera, and species, forming a continuous chain from the lowest animals to the highest, and that the whole had been a gradual development of higher out of lower forms. I have already alluded to his division of the 
Animal Kingdom into the Apathetic, Sensitive, and Intelligent animals. The Apathetic were those devoid of all sensitiveness except when aroused by the influence of some external agent. Under this head he placed five classes, including the Infusoria, Polyps, Star-Fishes, Sea-Urchins, Tunicata, and Worms, - thus bringing together indiscriminately Radiates, Mollusks, and Articulates. Under the head of Sensitive he had also a heterogeneous assemblage, including Winged Insects, Spiders, Crustacea, Annelids, and Barnacles, all of which are Articulates, and with these he placed in two classes the Mollusks, Conchifera, Gasteropoda, and Cephalopoda. Under the head of Intelligent he brought together a natural division, for he here united all the Vertebrates.

He succeeded in this way in making out a series which seemed plausible enough, but when we examine it, we find at once that it is perfectly arbitrary; for he has brought together animals built on entirely different structural plans, when he could find characters among them that seemed to justify his favorite idea of a gradation of qualities. Blainville attempted to establish the same idea in another way. He founded his series on gradations of form, placing together in one division all animals that he considered vague and indefinite in form, and in another all those that he 
considered symmetrical. Under a third head he brought together the Radiates; but his symmetrical division united Articulates, Mollusks, and Vertebrates in the most indiscriminate manner. He sustained his theory by assuming intermediate groups, - as, for instance, the Barnacles between the Mollusks and Articulates, whereas they are as truly Articulates as Insects or Crabs. Thus, by misplacing certain animals, he arrived at a series which, like that of Lamarck, made a strong impression on the scientific world, till a more careful investigation of facts exposed its fallacy.

Oken, the great German naturalist, also attempted to establish a connected chain throughout the Animal Kingdom, but on an entirely different principle; and I cannot allude to this most original investigator, so condemned by some, so praised by others, so powerful in his influence on science in Germany, without attempting to give some analysis of his peculiar philosophy. For twenty years his classification was accepted by his countrymen without question; and though I believe it to be wrong, yet, by the ingenuity with which he maintained it, he has shed a flood of light upon science, and has stimulated other naturalists to most important and interesting investigations.

This famous classification was founded upon 
the idea that the system of man, the most perfect created being, is the measure for the whole Animal Kingdom, and that in analyzing his organization we have the clew to all organized beings. The structure of man includes two systems of organs: those which maintain the body in its integrity, and which he shares in some sort with the lower animals, - the organs of digestion, circulation, respiration, and reproduction ; and that higher system of organs, the brain, spinal marrow, and nerves, with the organs of sense, on which all the manifestations of the intelligent faculties depend, and by which his relations to the external world are established and controlled : the whole being supported by a solid bony frame and surrounded by flesh, muscles, and skin. On account of this fleshy envelope of the hard parts in all the higher animals, Oken divided the Animal Kingdom into two groups, the Vertebrates and Invertebrates, or, as he called them, the "Eingeweide und Fleisch-Thiere," - which we may translate as the Intestinal Animals, or those that represent the intestinal systems of organs, and the Flesh Animals, or those that combine all the systems of organs under one envelope of flesh. Let us examine a little more closely this singular theory, by which each branch of the Invertebrates becomes, as it were, the exponent of a special system of organs, while the Vertebrates, 
with man at their head, include all these systems.

According to Oken, the Radiates, the lowest type of the Animal Kingdom, embody digestion. They all represent a stomach, whether it is the simple sac of the Polyps, or the cavity of the Acalephs, with its radiating tubes traversing the gelatinous mass of the body, or the cavity and tubes of the Echinoderms, enclosed within walls of their own.

The Mollusks represent circulation; and his division of this type into classes, according to what he considers the higher or lower organization of the heart, agrees with the ordinary division into Acephala, Gasteropoda, and Cephalopoda.

The Articulates are the respiratory animals in this classification: they represent respiration. The Worms, breathing, as he asserts, through the whole surface of the skin, without special breathing organs, are the lowest; the Crustacea, with gills, or aquatic breathing organs, come next; and he places the Insects highest, with their branching tracheæ, admitting air to all parts of the body.

The Vertebrates, or Flesh Animals, with their four classes, represent the Bones, the Muscles, the Nerves, and the Organs of Sense, the Fishes being par excellence the bony animals, the Rep- 
tiles representing especially the muscular system. the Birds the nervous system, while in the Mammalia the organs of the senses are most highly developed.

This theory, according to which there are as many great divisions or classes as there are structural systems or combinations of systems in the Animal Kingdom, seemed natural and significant, and there was something attractive in the idea that man represents, as it were, the synthetic combination of all these different systems. Oken also, in his exposition of his mode of classification, showed an insight into the structure and relations of animals that commended it to the interest of all students of Nature, and entitles him to their everlasting gratitude. Nevertheless, his theory fails, when it is compared with. facts. For instance, there are many Worms that have no respiration through the skin, while his appreciation of the whole class is founded on that feature; and in his type representing circulation, the Mollusks, there are those that have no heart at all.

It would carry me too far into scientific details, were I to explain all the points at which this celebrated classification fails. Suffice it to say, that there is no better proof of the discrepancy between the system and the facts than the constant changes in the different editions of Oken's 
own works and in the publications of his followers founded upon his views, showing that they were themselves conscious of the shifting and unstable character of their scientific ground. 


\section{CHAPTER VI.}

GRADATION AMONG ANIMALS.

WHAT, then, is the relation of these larger groups to each other, if they do not stand in a connected series from the lowest to the highest? How far are each of the branches and each of the classes superior or inferior one to another? All agree, that, while Vertebrates stand at the head of the Animal Kingdom, Radiates are lowest. There can be no doubt upon this point; for, while the Vertebrate plan, founded upon a double symmetry, includes the highest possibilities of animal organization, there is a certain monotony of structure in the Radiate plan, in which the body is divided into a number of identical parts, bearing definite relations to a central vertical axis. But while all admit that Vertebrates are highest and Radiates lowest, how do the Articulates and Mollusks stand to these and to each other? To me it seems, that, while both are decidedly superior to the Radiates and inferior to the Vertebrates, we cannot predicate absolute superiority or inferiority of organization of either 
group as compared with the other; they stand on one structural level, though with different tendencies, - the body in Mollusks having always a soft, massive, concentrated character, with great power of contraction and dilatation, while the body in Articulates is divided by transverse articulations, and has nothing of this compactness and concentration, but, on the contrary, is usually marked by a conspicuous external display of limbs and other appendages, and by a remarkable elongation of the body, - that feature characterized by Baer when he called them the Longitudinal type. There is in the Articulates an extraordinary tendency toward outward expression singularly in contrast to the soft, contractile body of the Mollusks. We need only remember the numerous Insects with small bodies and enormously large wings, or the Spiders with little bodies and long legs, or the number and length of the claws in the Lobsters and Crabs, as illustrations of this statement for the Articulates, while the soft, compact body of the Oyster or of the Snail is equally characteristic of the Mollusks; and though it may seem that this assertion cannot apply to the highest class of Mollusks, the Cephalopoda, including the CuttleFishes with their long arms or feelers, yet even these conspicuous appendages have considerable power of contraction and dilatation, and in 
the Nautili may be drawn completely within the shell. If this view be correct, these two types occupy an intermediate position between the highest and the lowest divisions of the Animal Kingdom, but stand on equal ground when compared with each other.

Another, though a less direct, evidence that there is no absolute structural superiority or inferiority between these two types as a whole may be found in the fact that the most profound naturalists who have attempted a serial arrangement of the whole Animal Kingdom have differed in their estimate of these two divisions, some placing the Mollusks highest, while others have given the ascendency to the Articulates.

But is there a transition from Radiates to Mollusks, or from Articulates to Vertebrates, or from any one of these divisions into any other? Let us first consider the classes as they stand within their divisions. We have seen that there are three classes of Radiates, - Polyps, Acalephs, and Echinoderms; three classes of Mollusks, Acephala, Gasteropoda, and Cephalopoda; three classes of Articulates, - Worms, Crustacea, and Insects; and, according to the usually accepted classification, four classes of Vertebrates, Fishes, Reptiles, Birds, and Mammalia. If there is indeed a transition between all these classes, it must become clear to us, when we have accurately interpreted their relative standing. 
Taking first, then, the lowest branch, how do the classes stand within the limits of the type of Radiates? I think I have said enough of these different classes to show that Polyps as a whole are inferior to the Acalephs as a whole, and that Acalephs as a whole are inferior to Echinoderms as a whole. But if they are linked together as a connected series, then the lowest Acaleph should stand next in structure above the highest Polyp; and the lowest Echinoderm next above the highest Acaleph. So far from this being the case, there are, on the contrary, many Acalephs which, in their specialization, are unquestionably lower in the scale of life than some Polyps, while there are some Echinoderms lower in the same sense than many Acalephs.

This remark applies equally to the classes within the other types; they stand, as an average, relatively to each other, lower and higher, but, considered in their diversified specification, there are some members of the higher classes that are inferior in organization to some members of the lower classes. The same is true of the great divisions as compared with each other. Instead of the highest Radiates being always lower in organization than the lowest Mollusks, there are many Star-Fishes and Sea-Urchins higher in organization than some Mollusks; and so when we pass from this branch to the Articulates, if we assume 
for the moment, as some naturalists believe, that the Mollusks are the inferior type, the CuttleFishes are certainly very superior animals to most of the Worms; and passing from Articulates to Vertebrates, not only are there Insects of a more complex organization than the lowest Fishes, but we bring together two kinds of animals so remote from each other in structure that the wildest imagination can scarcely fancy a transition between them.

A comparison may make my meaning clearer as to the relative standing of these groups. The Epic Poem is a higher order of composition than the Song, - yet we may have an Epic Poem which, from its inferior mode of execution, stands lower than a Song that is perfect of its kind. So the plan of certain branches is more comprehensive and includes higher possibilities than that of others, while at the same time there may be species in which the higher plan is executed in so simple a manner that it places their organization below some more highly developed being built on a lower plan. It is a poor comparison, because everything that God has made is perfect of its kind and in its place, though rel atively lower or higher; yet it is only by comparison of what is, after all, akin, - of mind with mind, - even though so far apart as the works of the divine and the human reason, that we 
may arrive at some idea, however dim, of the mental operations of the Creative Intellect.

. It is, then, in their whole bulk that any of these groups is above any other. We may represent the relative positions of the classes by a diagram in which each successive class in every type starts at a lower point than that at which the preceding class closes. Taking the Polyps as the lowest class of Radiates, for instance, its highest animals rise above the lowest members of the Acalephs, but then the higher members of the class of Acalephs reach a point far above any of the Polyps, - and so on.

Radiates. Mollusks. Articulates. Vertebrates.

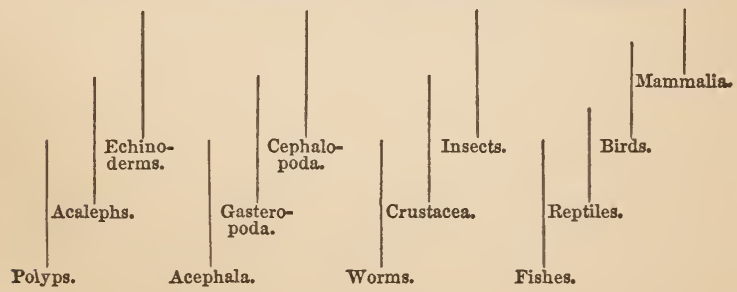

If this view be correct, it sets aside the possibility of any uninterrupted series based on akısolute superiority or inferiority of structure, on which so much ingenuity and intellectnal power have been wasted.

But it is not merely upon the structural relations established between these groups by ana- 
tomical features in the adult that we must decide this question. We must examine it also from the embryological point of view. Every animal in its growth undergoes a succession of changes: is there anything in these changes implying a transition of one type into another? Baer has given us the answer to this question. He has shown that there are four distinct modes of development, as well as four plans of structure; and though we have seen that higher animals of one class pass through phases of growth in which they transiently resemble lower animals of the same class, yet each one of these four modes of development is confined within the limits of the type, and a Vertebrate never resembles, at any stage of its growth, anything but a Vertebrate, or an Articulate anything but an Articulate, or a Mollusk anything but a Mollusk, or a Radiate anything but a Radiate.

Yet, although there is no embryological transition of one type into another, the gradations of growth within the limits of the same type and the same class, already alluded to, are very striking throughout the Animal Kingdom. There are periods in the development of the germ in the higher members of all the types, when they transiently resemble in their general outline the lower representatives of the same type, just as we have seen that the higher orders of one class 
pass through stages of development in which they trausiently resemble lower orders of the same class. This gradation of growth corresponds to the gradation of rank in adult animals, as established upon comparative complication of structure. For instance, according to their structural character, all naturalists have placed Fishes lowest in the scale of Vertebrates. Now all the ligher Vertebrates have a Fish-like character at first, and pass successively through phases in which they vaguely resemble other lower forms of the same type before they assume their own characteristic form; and this is equally true of the other great divisions, so that the history of the individual is, in some sort, the history of its type.

There is still another aspect of this question, - that of time. If neither the gradation of structural rank among adult animals nor the gradation of growth in their embryological development gives us any evidence of a transition between types, does not the sequence of animals in their successive introduction upon the globe afford any proof of such a connection? In this relation, I must briefly allude to the succession of geological formations that compose the crust of our globe. The limits of this article will not allow me to enter at any length into the geological details connected with this question; but I 
will, in the most cursory manner, give a sketch of the great geological periods, as generally accepted now by geologists.

The first of these periods has been called the Azoic or lifeless period, because it is the only one containing stratified deposits in which there are no remains of organic life, and it is therefore supposed that at that early stage of the world's history the necessary conditions for the maintenance of animals and plants were not yet established. After this, every great geological period that follows has been found to be characterized by a special set of animals and plants, differing from all that follow and all that precede it, till we arrive at our own period, when Man, with the animals and plants that accompany him on earth, was introduced.

There is, then, an order of succession in time among animals; and if there has been any transition between types and classes, any growth of higher out of lower forms, it is here that we should look for the evidence of it. According to this riew, we should expect to find in the first period in which organic remains are found at all only the lowest type, and of that type only the lowest class, and, indeed, if we push the theory. to its logical consequences, only the lowest forms of the lowest class. What are now the facts? This continent affords admirable opportunities for 
the investigation of this succession, because, in consequence of its mode of formation, we have, in the State of New York, a direct, unbroken sequence of all the earliest geological deposits.

The ridge of low hills, called the Laurentian Hills, along the line of division between Canada and the States was the first American land lifted abore the ocean. That land belongs to the Azoic period, and contains no trace of life. Along the base of that range of hills lie the deposits of the next great geological period, the Silurian; and the State of New York, geologically speaking, belongs almost entirely to this Silurian period, with its lowest Taconic division, and the Devonian period, the third in succession of these great epochs. I need hardly remind those of my readers who have travelled through New York, and have visited Niagara or Trenton, or, indeed, any of the localities where the broken edges of the strata expose the buried life within them, how numerous this early population of the earth must have been. No one who has held in his hand one of the crowded slabs of sandstone or limestone, or slate full of Crustacea, Shells, and Corals, from any of the old Silurian or Deronian beaches which follow each other from north to south across the State of New York, can suppose that the manifestation of life was less multitudinous then than now. 
Now, what does this fossil creation tell us? It says this: that, in the Silurian period, taken in its most comprehensive sense, the first in which organic life is found at all, there were the three classes of Radiates, the three classes of Mollusks, two of the classes of Articulates, and one class of Vertebrates. In other words, at the dawn of life on earth, the plan of the animal creation with its four fundamental ideas was laid out, - Radiates, Mollusks, Articulates, and Vertebrates were present at that first representation of life upon our globe. If, thell, all the primary types appeared simultaneously, one cannot have grown out of another, - they could not be at once contemporaries and descendants of each other.

The diagram on the opposite page represents the geological periods in their regular succession, and the approximate time at which all the types and all the classes of the Animal Kingdom were introduced; for there is still some doubt as to the exact period of the introduction of several of the classes, though all geologists are agreed respecting them, within certain limits, not very remote from each other, according to geological estimates of time.

If such discussions were not inappropriate here from their technical character, I think I could show, upon combined geological and zoölogical evidence, that the classes which are not present 
GRADATION AMONG ANIMALS.

95

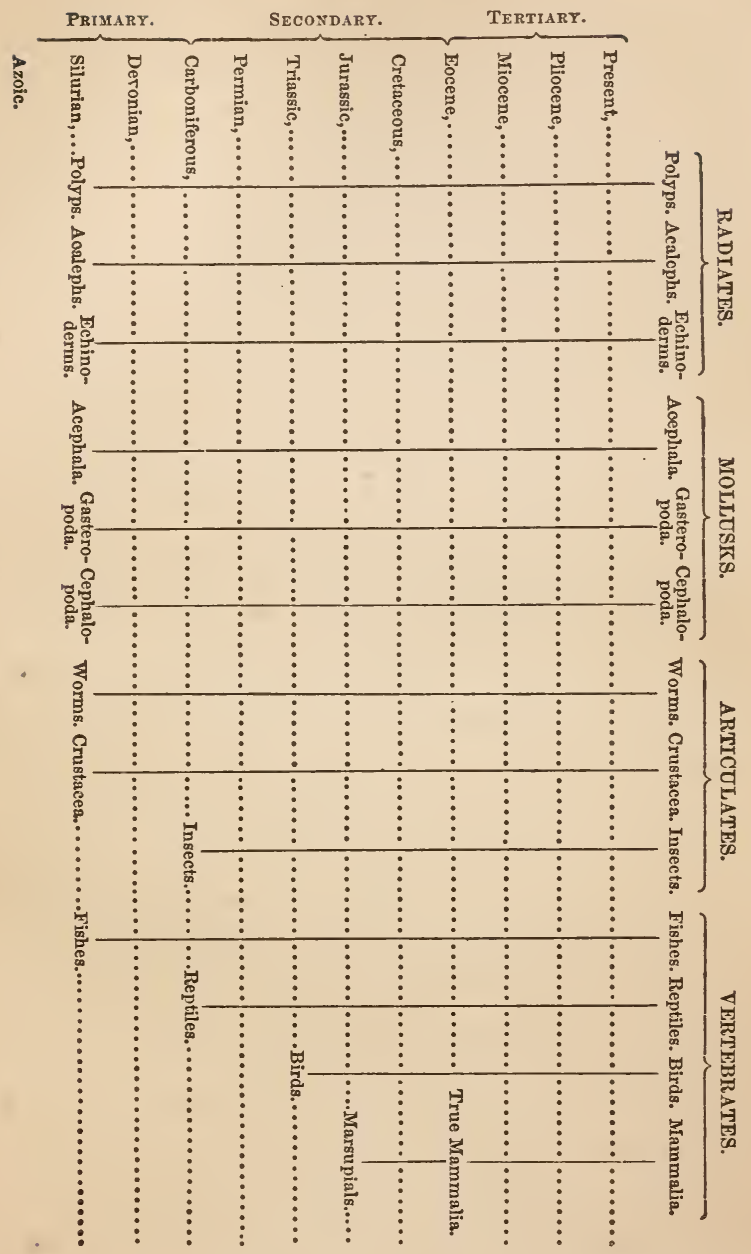


with the others at the beginning, such as Insects among Articulates, or Reptiles, Birds, and Mammalia among Vertebrates, are always introduced at the time when the conditions essential to their existence are established, - as, for instance, Reptiles, at the period when the earth was not fully redeemed from the waste of waters, and extensive marshes afforded means for the half-aquatic, half-terrestrial life even now characteristic of all our larger Reptiles, while Insects, so dependent on vegetable growth, make their appearance with the first forests; so that we need not infer, because these and other classes come in after the earlier ones, that they are therefore a growth out of them, since it is altogether probable that they would not be created till the conditions necessary for their maintenance on earth were established.

From a merely speculative point of view it seems to me natural to suppose that the physical and the organic world have progressed together, and that there is a direct relation between the successive creations and the condition of the earth at the time of those creations. We know that all the beings of the Silurian and Devonian periods were marine; the land, so far as it existed in their time, consisted of great beaches, and along those shores, wherever any part of the continent was lifted above the level of the waters, the Silurian and Devonian animals lived. Later in the 
marshes and the fern-forests of the Carboniferous period, Reptiles and Insects found their place; and only when the earth was more extensive, when marshes had become dry land, when islands had united to form continents, when mountainchains had been thrown up to make the inequalities of the surface, were the larger quadrupeds introduced, to whose mode of existence all these circumstances are important accessories.

But while all the types and most of the classes were introduced upon the earth simultaneously at the beginning, these types and classes have nevertheless been represented in every great geological period by different sets or species of animals. In this sense, then, there has been a gradation in time among animals, and every successive epoch of the world's physical history has had its characteristic population. We have found that there is a correspondence between the gradation of structural complication among adult animals as known to us to-day, which we may call the Series of Rank, and the gradation of embryological changes in the same animals, which we may call the Series of Growth; and there is also a correspondence between these two series and the order of succession in time, that establishes a certain gradation in the introduction of animals upon earth, and which we may call the Series of Timè. 
Take as an illustration the class of Echinoderms. The first representatives of this class were a sort of Star-Fishes on stems; then were introduced animals of the same order without stems; in later periods come in the true StarFishes and Sea-Urchins; and the highest order of the class, the Holothurians, are introduced only in the present geological epoch. Compare now with this the ordinal division of the class as it exists to-day. The present representative of those earliest Echinoderms on stems is an animal that upon structural eridence stands lowest in the class; next above it are the Comatulæ, corresponding to the early Echinoderms without stems; next in our classification are the StarFishes and Sea-Urchins; and the Holothurians stand highest, on account of certain structural features that place them at the head of their class. The Series of Time and the Series of Rank, then, accord perfectly, and investigations of the embryological development of these animals have shown that the higher Echinoderms pass through changes, during their growth, that indicate the same kind of gradation, for the young in some of them have a stem which is gradually dropped, and their successive phases of development recall the adult forms of the lower orders.

Take as another illustration the class of Polyps. First in time among the early Reef-Build- 
ers, who wrought their myriad lives into the solid crust of our globe then, as their successors do now, we find a peculiar kind of Polyp Coral. Theso old Corals have their representatires among the present Polyps, and from their structure they are placed lowest in their class, while the embryological development of the higher ones recalls in the younger condition of the germ the same character. I might multiply examples, and draw equally striking illustrations from the other classes; and though these correspondences callnot be fully established while our knowledge of the embryological growth of animals is so scanty, and there remain so many gaps in our information about their geological succession, yet wherever we have been able to trace the connected history of any group of animals in time, and to compare it with the history of their embryological development and their structural relations as they exist to-day, the correspondence is found to be so complete as to justify us in the belief that it will not fail in other instances.

I may add that a gradation of exactly the same character controls the geographical distribution of animals over the surface of the globe. Here again I must beg my readers to take much of the evidence, which, if expanded, would fill many volumes, for granted, since it would be entirely inappropriate here. But I may briefly state that 
animals are not scattered over the surface of our globe at random, but that they are associated together in what are called faune, and that these faunæ have their homes within certain districts called by naturalists zoölogical provinces. The limits of these provinces are absolutely fixed, in the ocean as well as on the land, by certain phys-ical conditions connected with climate, with altitude, with the pressure of the atmosphere, the weight of the water, etc.; and this is true even for animals of migratory habits, for all such migrations are periodical, and have boundaries as definite and impassable as those that limit the permanent homes of animals. There is a certair. series established by the relations between different kinds of animals, as thus distributed over the globe, agreeing with the gradation in their rank, their growth, and their succession in time; - the law which distributes animals in adjoining faunæ, and in accordance both with their relative superiority or inferiority, and with the physical conditions essential to their existence, being the same as that which controls their structural relations, their embryological development, and their succession in time.

What, then, does this correspondence between the Series of Rank, the Series of Growth, the Series of Time, and the Series of Geographical Distribution in the life of animals teach us? 
Sur ely not that the connection between animals is a material one; for the same kind of relation exists between lower and higher animals of one type or one class to-day, in their structural features, in their embryological growth, and in their geographical distribution, as we trace in their order of succession in time; and therefore, if this kind of evidence proves that the later animals are the descendants of the earlier in any genealogical sense, it should also prove that the animals living in one part of the earth at present grow out of animals living in another part, and that the higher animals of one class as it exists now are developed out of the lower ones. The first of these propositions needs no refutation; and with regard to the second, all our inrestigations go to show that every being born into the world to-day adheres to its individual law of life, and though it passes through transient phases of growth resembling other beings of its own kind, never pauses at a lower stage of development, or passes on to a higher condition than the one it is bound to fill.

If, then, this comnection is not a material one, what is it? - for that such a connection does exist throughout the Animal Kingdon, as intimate, as continuous, as complex, as any series which the development theorists have ever contended for, is not to be denied. What can it be but an intel- 
lectual one? These correspondences are correspondences of thought, - of a thought that is always the same, whether it is expressed in the history of the type through all time, or in the life of the individuals that represent the type at the present moment, or in the growth of the germ of every being born into that type to-day. In other words, the same thought that spans the whole succession of geological ages controls the structural relations of all living beings as well as their distribution over the surface of the earth, and is repeated within the narrow compass of the smallest eg'g in which any being begins its growth. 


\section{CHAPTER VII。}

ANALOGOUS TYPES.

I COME now to an obscure part of my subject, very difficult to present in a popular form, and yet so important in the scientific investigations of our day that I cannot omit it entirely. I allude to what are called by naturalists Collateral Series or Parallel and Analogous Types. These are by no means difficult to trace, because they are connected by seeming resemblances, which, though very likely to mislead and perplex the observer, yet naturally suggest the association of such groups. Let me introduce the subject with the statement of some facts.

There are in Australia numerous Mammalia, occupying the same relation and answering the same purposes as the Mammalia of other countries. Some of them are domesticated by the natives, and serve them with meat, milk, and wool, as our domesticated animals serve us. Representatives of almost all types, Wolves, Foxes, Sloths, Bears, Weasels, Martens, Squirrels, Rats, etc., are found there; and yet, though all these 
animals resemble ours so closely that the English settlers have called many of them by the same names, there are no genuine Wolres, Foxes, Sloths, Bears, Weasels, Martens, Squirrels, or Rats in Australia. The Australian Mammalia are peculiar to the region where they are found, and are all linked together by two remarkable structural features which distinguish them from all other Mammalia and unite them under one head as the so-called Marsupials. They bring forth their young in an imperfect condition, and transfer them to a pouch, where they remain attached to the teats of the mother till their development is as far advanced as that of other Mammalia at the time of their birth; and they are further characterized by an absence of that combination of transverse fibres forming the large -bridge which unites the two hemispheres of the brain in all the other members of their class. Here, then, is a series of animals parallel with ours, separated from them by anatomical features, but so united with them by form and external features that many among them have been at first associated together.

Cuvier has already alluded to this, when he speaks of subordination of characters, distinguishing between those controlling the whole organization and those that play only a secondary part in it. The skill of the naturalist consists 
in detecting the difference between the two, so that he may not take the more superficial features as the basis of his classification, instead of those important ones which, though often less easily recognized, are more deeply rooted in the organization. It is a difference of the same nature as that between affinity and analogy, to which I have alluded before, when speaking of the ingrafting of certain features of one type upon animals of another type, thus producing a superficial resemblance, not truly characteristic. In the Reptiles, for instance, there are two groups, those devoid of scales, with naked skin, laying numerous eggs, but hatching their young in an imperfect state, and the Scaly Reptiles, which lay comparatively few eggs, but whose young, when hatched, are completely developed, and undergo no subsequent metamorphosis. Yet, notwithstanding this difference in essential features of structure, and in the mode of reproduction and development, there is such an external resemblance between certain animals belonging to the two groups that they were associated together even by so eminent a naturalist as Linnæus. Compare, for example, the Serpents among the Scaly Reptiles with the Cæcilians among the Naked Reptiles. They have the same elongated form, and are both destitute of limbs; the head in both is on a level with the body, without any 
contraction behind it, such as marks the neck in the higher Reptiles, and moves only by the action of the backbone; they are singularly alike in their external features, but the young of the Serpent are hatched in a mature condition, while the young of the type to which the Crcilians belong undergo a succession of metamorphoses before their resemblance to the parent is clearly defined. Or compare the Lizard and the Salamander, in which the likeness is perhaps even more striking; for any inexperienced observer would mistake one for the other. Both are in some respects superior to the Serpents and Cæcilians, for in them the head moves freely on the neck, and they creep on short, imperfect legs. But the Lizard is clothed with scales, while the body of the Salamander is naked, and the young of the former is complete when hatched, while the Tadpole born from the Salamander has a life of its own to live, with certain changes to pass through before it assumes its mature condition; during the early part of its life it is even destitute of legs, and has gills like the Fishes.

Above the Lizards and Salamanders, highest in the class of Reptiles, stand two other collateral types, - the Turtles at the head of the Scaly Reptiles, the Toads and Frogs at the head of the Naked Reptiles. The external likeness between these two groups is perhaps less striking than 
between those mentioned above, on account of the large shield of the Turtle. But there are Turtles with a soft covering, and there are some Toads with a hard shield over the head and neck at least, and both groups are alike distinguished by the shortness and breadth of the body and by the greater development of the limbs as compared with the lower Reptiles. But here again there is the same essential difference in the mode of development of their young as distinguishes all the rest. The two series may thus be contrasted:-

Naked Reptiles.

Toads and Frogs,

Salamanders,

Cæcilians.
Scaly Reptiles.

Turtles,

Lizards,

Serpents.

Such corresponding groups or parallel types, united only by external resemblance, and distinguished from each other by essential elements of structure, exist among all animals, though they are less striking among Birds on account of the uniformity of that class. Yet even there we may trace such analogies, - as between the Palmate or Aquatic Birds, for instance, and the Birds of Prey, or between the Frigate Bird and the Kites. Among Fishes such analogies are very common, often suggesting a comparison even with land animals, though on account of the scales and spines of the former the likeness 
may not be easily traced. But the common names used by the fishermen often indicate these resemblances, - as, for instance, Sea-Vulture, Sea-Eagle, Cat-Fish, Flying-Fish, Sea-Porcupine, Sea-Cow, Sea-Horse, and the like.

In the branch of Mollusks, also, the same superficial analogies are found. In the lowest class of this division of the Animal Kingdom there is a group so similar to the Polyps, that, until recently, they have been associated with them, - the Bryozoa. They are very small animals, truly allied to the Clams by the plan of their structure, but resembling the Polyps on account of a radiating wreath of feelers around the upper part of their body: yet, when examined closely, this wreath is found to be incomplete; it does not form a circle, but leares an open space between the two ends, where they approach each other, so that it has a horseshoe outline, and partakes of the bilateral symmetry characteristic of its type and on which its own structure is based. These series have not yet been very carefully traced, and young naturalists should turn their attention to them, and be prepared to draw the nicest distinction between analogies and true affinities among animals. 


\section{CHÄPTER VIII.}

\section{FAMILY CHARACTERISTICS.}

LET us proceed to a careful examination of tlıe natural groups of animals called Families by naturalists, - a subject already briefly alluded to in a previous chapter. Families are natural assemblages of animals less extensive than Orders, but, like Orders, Classes, and Branches, founded upon certain categories of structure, as distinct for this kind of group as are those above specified for the other divisions in the classification of the Animal Kingdom, which we have thus far examined.

That we may understand the true meaning of these divisions, we must not be misled by the name given by naturalists to this kind of groups. Here, as in so many other instances, a word already familiar, and as it were identified with the special sense in which it had been used, was adopted by science, and received a new signification. When naturalists speak of Families among animals, they do not allude to the progeny of a known stock, as we designate, in com- 
mon parlance, the children or the descendants of known parents; they understand by this name natural groups including different kinds of animals, having no genetic relations so far as we know, but agreeing with one another closely enough to leave the impression of a more or less remote common parentage. The difficulty here consists in determining the natural limits of such groups, and in tracing the characteristic features by which they may be defined; for individual investigators differ greatly as to the degree of resemblance existing between the members of many Families, and there is no kind of group which presents greater diversity of circumscription in the classifications of animals proposed by different naturalists than these so-called Families.

It should be remembered, however, that, unless a sound criterion be applied to the limitation of Families, they, like all other groups introduced into zoölogical systems, must forever remain arbitrary divisions, as they have been hitherto. A retrospective glance at the progress of our science during the past century, in this connection, may perhaps help us to solve the difficulty. Linnæus, in his System of Nature, does not admit Families; he has only four kinds of groups, - Classes, Orders, Genera, and Species. It was, as I have stated in a previous chapter, among 
plants that naturalists first perceired those general traits of resemblance existing everywhere among the members of natural families, in consequence of which they added this kind of group to the framework of their system. In France, particularly, this method was pursued with success; and the improvements thus introduced by the French botanists were so great, and rendered their classification so superior to that of Linnæus, that the botanical systems in which Families were introduced were called natural systems, in contradistinction especially to the botanical classification of Linnæus, which was founded upon the organs of reproduction, and which received thenceforth the name of the sexual system of plants. The same method so successfully used by botanists was soon introduced into Zoölogy by the French naturalists of the beginning of this century, - Lamarck, Latreille, and Cuvier. But, to this day, the limitation of Families among animals has not reached the precision which it has among plants, and I see no other reason for the difference than the absence of a leading principle to guide us in Zoölogy.

Families, as they exist in Nature, are based upon peculiarities of form as dependent upon structure; but though a very large number of them have been named and recorded, very few are characterized with anything like scientific accuracy. 
It has been a very simple matter to establish such groups according to the superficial method that has been pursued, for the fact that they are determined by external outline renders the recognition of them easy and in many instances almost instinctive; but it is very difficult to characterize them, or, in other words, to trace the connection between form and structure. Indeed, many naturalists do not admit that Families are based upon form; and it was in trying to account for the facility with which they detect these groups, while they find it so difficult to characterize them, that I perceived them to be always associated with peculiarities of form. Naturalists have established Families simply by bringing together a number of animals resembling each other more or less closely, and, taking usually the name of the Genus to which the best known among them belongs, they have given it a patronymic termination to designate the Family, and allowed the matter to rest there, sometimes without even attempting any description corresponding to those by which Genus and Species are commonly defined.

For instance, from Canis, the Dog, Canida has been formed, to designate the whole Family of Dogs, Wolves, Foxes, etc. Nothing can be more superficial than such a mode of classification; and if these groups actually exist in Nature, they 
must be based, like all the other divisions, upon some combination of structural characters peculiar to them. Te have seen that Branches are founded upon the general plan of structure, Classes upon the execution of the plan, Orders upon the greater or less complication of a given mode of execution, and we shall find that form, as determined by structure, characterizes Families. I would call attention to this qualification of my definition ; since, of course, when speaking of form in this connection, I do not mean those superficial resemblances in external features already alluded to in my remarks upon Parallel or Collateral Types. I speak now of form as controlled by structural elements; and unless we analyze Families in this way, the mere distinguishing and naming them does not advance our science at all.

Compare, for instance, the Dogs, the Seals, and the Bears. These are all members of one order, - that of the Carnivorous Mammalia. Their dentition is peculiar and alike in all (cutting teeth, canine teeth, and grinders), adapted for tearing and chewing their food; and their intermal structure bears a definite relation to their dentition. But look at these animals with reference to form. The Dog is comparatively slender, with legs adapted for running and hunting his prey; the Bear is heavier, with shorter limbs; 
while the Seal has a continuous uniform outline adapted for swimming. They form separate Families, and are easily recognized as such by the difference in their external outline; but what is the anatomical difference producing the peculiarity of form in each, by which they have been thus distinguished? It lies in the structure of the limbs, and especially in that of the wrist and fingers. In the Seal the limbs are short, and the wrists are on one continuous line with them, so that it has no power of bending the wrist or the fingers, and the limbs, therefore, act like flappers or oars. The Bear has a well-developed paw with a flexible wrist, but it steps on the whole sole of the foot, from the wrist to the tip of the toe, giving it the heavy tread so characteristic of all the Bears. The Dogs, on the contrary, walk on tiptoe, and their step, though firm, is light, while the greater slenderness and flexibility of their legs add to their nimbleness and swiftness. By a more extensive investigation of the anatomical structure of the limbs in their connection with the whole body, it could easily be shown that the peculiarity of form in these animals is essentially determined by, or at least stands in the closest relation to, the peculiar structure of the wrist and fingers.

Take the Family of Owls, as distinguished from the Falcons, Kites, etc. Here the differ- 
ence of form consists in the position of the eyes. In the $0 w l$, the sides of the head are prominent, and the eye-socket is brought forward. In the Falcons and Kites, on the contrary, the sides of the head are flattened, and the eyes are set back. The difference in the appearance of the birds is evident to the most superficial observer; but to call the one Strigidæ and the other Falconidæ tells us nothing of the anatomical peculiarities on which this difference is founded.

These few examples, selected purposely among closely allied and universally known animals, may be sufficient to show, that, beyond the general complication of the structure which characterizes the Orders, there is a more limited element in the organization of animals, bearing chiefly upon their form, which, if it have any general application as a principle of classification, may well be considered as essentially characteristic of the Families. There are certainly closely allied natural groups of animals, belonging to the same Order, but including many Genera, which differ from each other chiefly in their form, while that form is determined by peculiarities of structure which do not influence the general structural complication upon which Orders are based, or relate to the minor details of structure on which Genera are founded. I am, therefore, convinced that form is the criterion by which Families may 
be determined. The great facility with which animals may be combined together in natural groups of this kind without any special investigation of their structure - a superficial method of classification in which zoölogists have lately indulged to a most unjustifiable degree-convinces me that it is the similarity of form which has unconsciously led such shallow investigators to correct results, since upon close examination it is found that a large number of the Families so determined, and to which no characters at all are assigned, nevertheless bear the severest criticism founded upon anatomical investigation.

The questions proposed to themselves by all students who would characterize Families should be these: What are, throughout the Animal Kingdom, the peculiar patterns of form by which Families are distinguished? and on what structural features are these patterns based ? Only the most patient investigations can give us the answer, and it will be very long before we can write out the formulæ of these patterns with mathematical precision, as I believe we shall be able to do in a more advanced stage of our science. But while the work is in progress, it ought to be remembered that a mere general similarity of outline is not yet in itself evidence of identity of form or pattern, and that, while seemingly very different forms may be derived from the same 
formula, the most similar forms may belong to entirely different systems, when their derivation is properly traced.

Our great mathematician, in a lecture delivered at the Lowell Institute last winter, showed that in his science, also, similarity of outline does not always indicate identity of character. Compare the different circles, - the perfect circle, in which every point of the periphery is at the same distance from the centre, with an ellipse in which the variation from the true circle is so slight as to be almost imperceptible to the eye; yet the latter, like all ellipses, has its two foci by which it differs from a circle, and to refer it to the family of circles instead of the family of ellipses would be overlooking its true character on account of its external appearance; and yet ellipses may be so elongated, that, far from resembling a circle, they make the impression of parallel lines linked at their extremities. Or we may have an elastic curve in which the appearence of a circle is produced by the meeting of the two ends; nevertheless it belong's to the family of elastic curves, in which may even be included a line actually straight, and is formed by a process entirely different from that which produces the circle or the ellipse.

But it is sometimes exceedingly difficult to find the relation between structure and form in Families. I remember a case which I had taken 
as a test of the accuracy of the riews I entertained upon this subject, and which perplexed and baffled me for years. It was that of our fresh-water Mussels, the Family of Unios. There is a great variety of outline among them, - some being oblong and very slender, others broad with seemingly square outlines, others having a nearly triangular form, while others again are almost circular; and I could not detect among them all any feature of form that was connected with any essential element of their structure. At last, however, I found this test-character, and since that time I have had no doubt left in my mind that form, determined by structure, is the true criterion of Families. In the Unios it consists of the rounded outline of the anterior end of the body reflected in a more or less open curve of the shell, bending more abruptly along the lower side with an inflection followed by a bulging. This bulging corresponds to the most prominent part of the gills, to which, in a large number of American Species of this Family, the eggs are exclusively transferred, giving to this part of the shell a prominence which it has not in any of the European Species. At the posterior end of the body this curve then bends upwards and backwards again, the outline meeting the side occupied by the hinge and ligament, which, when very short, may determine a triangular form of 
the whole shell, or, when equal to the lower side and connected with a great height of the body, gives it a quadrangular form, or, if the height is reduced, produces an elongated form, or, finally, a rounded form, if the passage from one side to the other is gradual. A comparison of the position of the internal organs of different Species of Unios with the outlines of their shells will leave no doubt that their form is determined by the structure of the animal.

A few other and more familiar examples may complete these remarks. Among Climbing Birds, for instance, which are held together as a more comprehensive group by the structure of their feet and by other anatomical features, there are two Families so widely different in their form that they may well serve as examples of this principle. The Woodpeckers (Picide) and the Parrots (Psittacide), once considered as two Genera only, have both been subdivided, in consequence of a more intimate knowledge of their generic characters, into a large number of Genera; but all the Genera of Woodpeckers and all the Genera of the Parrots are still held together by their form as Families, corresponding as such to the two old Genera of Picus and Psittacus. They are now known as the Families of Woodpeckers and Parrots; and though each group includes a number of Genera combined upon a 
variety of details in the finish of special parts of the structure, such as the number of toes, the peculiarities of the bill, etc., it is impossible to overlook the peculiar form characteristic of each. No one who is familiar with the outline of the Parrot will fail to recognize any member of that Family by a general form which is equally common to the diminutive Nonpareil, the gorgeous Ara, and the high-crested Cockatoo. Neither will any one, who has ever observed the small head, the straight bill, the flat back, and stiff tail of the Woodpecker, hesitate to identify the family form in any of the numerous Genera into which this group is now divided. The family characters are even more invariable than the generic ones; for there are Woodpeckers which, instead of the four toes, two turning forward and two backward, which form an essential generic character, have three toes only, while the family form is always maintained, whatever variations there may be in the characters of the more limited groups it includes.

The Turtles and Terrapins form another good illustration of family characters. They constitute together a natural Order, but are distinguished from each other as two Families very distinct in general form and outline. Among Fishes I may mention the Family of Pickerels, with their flat, long snout, and slender, almost 
cylindrical body, as contrasted with the plump, compressed body and tapering tail of the Trout Family. Or compare, among Insects, the HawkMoths with the Diurnal Butterfly, or with the socalled Miller, - or, among Crustacea, the common Crab with the Sea-Spider, or the Lobsters with the Shrimps, - or, among Worms, the Leeches with the Earth-Worms, - or, among Mollusks, the Squids with the Cuttle-Fishes, or the Snails with the Slugs, or the Periwinkles with the Limpets and Conchs, or the Clam with the so-called Venus, or the Oyster with the Motherof-Pearl shell, - everywhere, throughout the Animal Kingdom, difference of form points at difference of Families.

There is a chapter in the Natural History of Animals that has hardly been touched upon as yet, and that will be especially interesting with reference to Families. The voices of animals have a family character not to be mistaken. All the Canidæ bark and howl: the Fox, the Wolf, the Dog have the same kind of utterance, though on a somewhat different pitch. All the Bears growl, from the White Bear of the Arctic snows to the small Black Bear of the Andes. All the Cats miau, from our quiet fireside companion to the Lions and Tigers and Panthers of the forest and jungle. This last may seem a strange assertion; but to any one who has listened critically to their 
sounds and analyzed their voices, the roar of the Lion is but a gigantic miau, bearing about the same proportion to that of a Cat as its stately and majestic form does to the smaller, softer, more peaceful aspect of the Cat. Yet, notwithstanding the difference in their size, who can look at the Lion, whether in his more sleepy mood, as he lies curled up in the corner of his cage, or in his fiercer moments of hunger or of rage, without being reminded of a Cat? And this is not merely the resemblance of one carnivorous animal to another; for no one was ever reminded of a Dog or Wolf by a Lion.

Again, all the Horses and Donkeys neigh ; for the bray of the Donkey is only a harsher neigh, pitched on a different key, it is true, but a sound of the same character, - as the Donkey himself is but a clumsy and dwarfish Horse. All the Cows low, from the Buffalo roaming the prairie, the Musk-Ox of the Arctic ice-fields, or the Jack of Asia, to the Cattle feeding in our pastures.

Among the Birds, this similarity of voice in Families is sttll more marked. We need only recall the harsh and noisy Parrots, so similar in their peculiar utterance. Or take as an example the web-footed Family, - do not all the Geese and the innumerable host of Ducks quack? Does not every member of the Crow Family caw, whether it be the Jackdaw, the Jay, or the Magpie, the Rook 
in some green rookery of the Old World, or the Crow of our woods, with its long, melancholy caw that seems to make the silence and solitude deeper? Compare all the sweet warblers of the Songster Family, - the Nightingales, the Thrushes, the Mocking-Birds, the Robins; they differ in the greater or less perfection of their note, but the same kind of voice runs through the whole group.

These affinities of the vocal systems among animals form a subject well worthy of the deepest study, not only as another character by which to classify the Animal Kingdom correctly, but as bearing indirectly also on the question of the origin of animals. Can we suppose that characteristics like these have been communicated from one animal to another? When we find that all the members of one zoölogical Family, however widely scattered over the surface of the earth, inhabiting different continents and even different hemispheres, speak with one voice, must we not believe that they have originated in the places where they now occur with all their distinctive peculiarities? Who taught the American Thrush to sing like his European relative? He surely did not learn it from his cousin over the waters. Those who would have us believe that all animals have originated from common centres and single pairs, and have been thence distributed 
over the world, will find it difficult to explain the tenacity of such characters, and their recurrence and repetition under circumstances that seem to preclude the possibility of any communication, on any other supposition than that of their creation in the different regions where they are now found. We have much yet to learn from investigations of this kind, with reference not only to Families among animals, but to nationalities among men also. I trust that the nature of languages will teach us as much about the origin of the races, as the vocal system of the animals may one day teach us about the origin of the different groups of animals. At all events, similarity of vocal utterance among animals is not indicative of identity of Species; $I$ doubt, therefore, whether similarity of speech proves community of origin among men.

The similarity of motion in Families is another subject well worth the consideration of the naturalist: the soaring of the Birds of Prey, - the heavy flapping of the wings in the Gallinaceous Birds, - the floating of the Swallows, with their short cuts and angular turns, - the hopping of the Sparrows, - the deliberate walk of the Hens and the strut of the Cocks, - the waddle of the Ducks and Geese, - the slow, heavy creeping of the Land-Turtle, - the graceful flight of the Sea-Turtle under the water, - the leaping and 
swimming of the Frog, - the swift run of the Lizard, like a flash of green or red light in the sunshine, - the lateral undulation of the Serpent, - the dart of the Pickerel, - the leap of the Trout, - the rush of the Hawk-Moth through the air, - the fluttering flight of the Butterfly, - the quivering poise of the Humming-Bird, the arrow-like shooting of the Squid through the water, - the slow crawling of the Snail on the land, - the sideway movement of the Sand-Crab, - the backward walk of the Crawfish, - the almost imperceptible gliding of the Sea-Anemone over the rock, - the graceful, rapid motion of the Pleurobrachia, with its endless change of curve and spiral. In short, every Family of animals has its characteristic action and its peculiar voice; and yet so little is this endless variety of rhythm and cadence both of motion and sound in the organic world understood, that we lack words to express one half its richness and beauty. 


\section{CHAPTER IX.}

THE CHARACTERS OF GENERA.

THE well-known meaning of the words generic and specific may serve, in the absence of a more precise definition, to express the relative importance of those groups of animals called Genera and Species in our scientific systems. The Genus is the more comprehensive of the two kinds of groups, while the Species is the most precisely defined, or at least the most easily recognized, of all the divisions of the Animal Kingdom. But neither the term Genus nor Species has always been taken in the same sense. Genus especially has varied in its acceptation, from the time when Aristotle applied it indiscriminately to any kind of comprehensive group, from the Classes down to what we commonly call Genera, till the present day.

But we have already seen, that, instead of calling all the more comprehensive divisions by the name of Genera, modern science has applied special names to each of them, and we have now Families, Orders, Classes, and Branches above 
Genera proper. If the foregoing discussion upon the nature of these groups is based upon trustworthy principles, we must admit that they are all founded upon distinct categories of characters, - the primary divisions, or the Branches, upon plan of structure, the Classes upon the manner of its execution, the Orders upon the greater or less complication of a given mode of execution, the Families upon form; and it now remains to be ascertained whether Genera also exist in Nature, and by what kind of characteristics they may be distinguished.

Taking the practice of the ablest naturalists in discriminating Genera as a guide in our estimation of their true nature, we must, nevertheless, remember that even now, while their classifications of the more comprehensive groups usually agree, they differ greatly in their limitation of Genera, so that the Genera of some authors correspond to the Families of others, and vice versa. This undoubtedly arises from the absence of a definite standard for the estimation of these divisions. But the different categories of structure forming the distinctive criteria of the more comprehensive divisions once established, the question is narrowed down to an inquiry into the special category upon which Genera may be determined; and if this can be accurately defined, no difference of opinion need interfere hereafter with their uniform limitation. 
Considering all these divisions of the Animal Kingdom from this point of view, it is evident that the more comprehensive ones must be those which are based on the broadest characters, the Branches, as united upon plan of structure, standing of course at the head; next to these the Classes, since the general mode of executing the plan presents a wider category of characters than the complication of structure on which Orders rest; after Orders come Families, or the patterns of form in which these greater or less complications of structure are clothed; and, proceeding in the same way from more general to more special considerations, we can have no other category of structure as characteristic of Genera than the details of.structure by which members of the same Family may differ from each other, and this I consider as the only true basis on which to limit Genera, while it is at the same time in perfect accordance with the practice of the most eminent modern zoölogists. It is in this way that Cuvier has distinguished the large number of Genera he has characterized in his great Natural History of the Fishes, published in connection with Valenciennes. Latreille has done the same for the Crustacea and Insects; and Milne-Edwards, with the co-operation of Haime, has recently proceeded upon the same principle in characterizing a great number of Genera among 
the Corals. Many others have followed this example, but few have kept in view the necessity of a uniform mode of proceeding, or, if they have done so, their researches have corered too limited a ground to be taken into consideration in a discussion of principles.

It is, in fact, only when extending over a whole Class that the study of Genera acquires a truly scientific importance, as it then shows, in a connected manner, in what way, by what features, and to what extent a large number of animals are closely linked together in Nature. Considering the Animal Kingdom as a single complete work of one Creative Intellect, consistent throughout, such keen analysis and close criticism of all its parts have the same kind of interest, in a higher degree, as that which attaches to other studies undertaken in the spirit of careful comparative research. These different categories of characters are, as it were, different peculiarities of style in the author, different modes of treating the same material, new combinations of evidence bearing on the same general principles. The study of Genera is a department of Natural History which thus far has received too little attention even at the hands of our best zoölogists, and has been treated in the most arbitrary manner ; it should henceforth be made a philosophical investigation into the closer affinities which nat$6 *$ 
urally bind all the representatives of a natural Family in minor groups.

Genera, then, are divisions of a more restricted character than any of those we have examined thus far. Some of them include only one Species, while others comprise hundreds; since certain definite combinations of characters may be limited to a single Species, while other combinations may be repeated in many. We have striking examples of this among Birds: the Ostrich stands alone in its Genus, while the number of -Species among the Warblers is very great. Among Mammalia the Giraffe also stands alone, while Mice and Squirrels include many Species. Genera are founded, not, as we have seen, on general structural characters, but on the finish of special parts, as, for instance, on the dentition. The Cats have only four grinders in the upper jaw and three in the lower, while the Hyenas have one more above and below, and the Dogs and Wolves have two more above and two more below. In the last, some of the teeth have also flat surfaces for crushing the food, adapted especially to their habits, since they live on vegetable as well as animal substances. The formation of the claws is another generic feature. There is a curious example with reference to this in the Cheetah, which is again a Genus containing only one Species. It belongs to the Cat Family, but 
differs from ordinary Lions and Tigers in having its claws so constructed that it cannot draw them oack over the paws, though in every other respect they are like the claws of all the Cats. But while it has the Cat-like claw, its paws are like those of the Dog, and this singular combination of features is in direct relation to its habits, for it does not lie in wait and spring upon its prey like the Cat, but hunts it like the Dog.

While Genera themselves are, like Families, easily distinguished, the characters on which they are founded, like those of Families, are difficult to trace. There are often features belonging to these groups which attract the attention and suggest their association, though they are not those which may be truly considered generic characters. It is easy to distinguish the Foxes, for instance, by their bushy tail, and yet that is no true generic character; the collar of feathers round the neck of the Vultures leads us at once to separate them from the Eagles, but it is not the collar that truly marks the Genus, but rather the peculiar structure of the feathers which form it. No Bird has a more striking plumage than the Peacock, but it is not the appearance merely of its crest and spreading fan that conistitutes the Genus, but the peculiar structure of the feathers. Thousands of examples might be quoted to show how easily Genera may 
be singled out, named, and entered in our systems, without being duly characterized, and it is much to be lamented that there is no possibility of checking the loose work of this kind with which the annals of our science are daily flooded.

It would, of course, be quite inappropriate to present here any general revision of these groups ; but I may present a few instances to illustrate the principle of their classification, and to show on what characters they are properly based. Among Reptiles, we find, for instance, that the Genera of our fresh-water Turtles differ from each other in the cut of their bill, in the arrangement of their scales, in the form of their claws, etc. Among Fishes, the different Genera included under the Family of Perches are distinguished by the arrangement of their teeth, by the serratures of their gill-covers and of the arch to which the pectoral fins are attached, by the nature and combination of the rays of their fins, by the structure of their scales, etc. Among Insects, the various Genera of the Butterflies differ in the combination of the little rods which sustain their wings, in the form and structure of their antennæ, of their feet, of the minute scales which cover their wings, etc. Among Crustacea, the Genera of Shrimps vary in the form of the claws, in the structure of the parts of the mouth, in the articulations of their feelers, etc. Among 
Worms, the different Genera of the Leech Family are combined upon the form of the disks by which they attach themselves, upon the number and arrangement of their eyes, upon the structure of the hard parts with which the mouth is armed, etc. Among Cephalopods, the Family of Squids contains several Genera distinguished by the structure of the solid shield within the skin of the back, by the form and connection of their fins, by the structure of the suckers with which their arms are provided, by the form of their beak, etc. In every Class, we find throughout the Animal Kingdom that there is no sound basis for the discrimination of Genera except the details of their structure; but in order to define them accurately an extensive comparison of them is indispensable, and in characterizing them only such features should be enumerated as are truly generic ; whereas, in the present superficial method of describing genera, features are frequently introduced which belong not only to the whole Family, but even to the whole Class which includes them. 


\section{CHAPTER X.}

SPECIES AND BREEDS.

There remains but one more division of the Animal Kingdom for our consideration, the most limited of all in its circumscription, - that of Species. It is with the study of this kind of group that naturalists generally begin their investigations. I believe, however, that the study of Species as the basis of a scientific education is a great mistake. It leads us to overrate the value of Species, and to believe that they exist in Nature in some different sense from the other groups; as if there were something more real and tangible in Species than in Genera, Families, Orders, Classes, or Branches. The truth is, that to study a vast number of Species without tracing the principles that combine them under more comprehensive groups is only to burden the mind with disconnected facts, and more may be learned by a faithful and careful comparison of a few Species than by a more cursory examination of a greater number. When one considers the immense number of Species already known, naturalists 
might well despair of becoming acquainted with them all, were they not constructed on a few fundamental patterns, so that the study of one Species teaches us a great deal for all the rest. De Candolle, who was at the same time a great botanist and a great teacher, told me once that he could undertake to illustrate the fundamental principles of his science with the aid of a dozen plants judiciously selected, and that it was his unvarying practice to induce students to make a thorough study of a few minor groups of plants, in all their relations to one another, rather than to attempt to gain a superficial acquaintance with a large number of species. The powerful influence he has had upon the progress of Botany vouches for the correctness of his views. Indeed, every profound scholar knows that sound learning can be attained only by this method, and the study of Nature makes no exception to the rule.

I would therefore advise every student to select a few representatives from all the Classes, and to study these not only with reference to their specific characters, but as members also of a Genus, of a Family, of an Order, of a Class, and of a Branch. Ife will soon convince himself that Species have no more definite and real existence in Nature than all the other divisions of the Animal Kingdom, and that every animal is the representative of its Branch, Class, Order, Family, 
and Genus as much as of its Species. Specific characters are only those determining size, proportion, color, habits, and relations to surrounding circumstances and external objects. How superficial, then, must be any one's knowledge of an animal who studies it only with relation to its specific characters! He will know nothing of the finish of special parts of the body, - nothing of the relations between its form and its structure, - nothing of the relative complication of its organization as compared with other allied animals, - nothing of the general mode of execution of its structure, - nothing of the general plan of structure expressed in that mode of execution. Yet, with the exception of the ordinal characters, which, since they imply relative superiority and inferiority, require, of course, a number of specimens for comparison, his one animal would tell him all this as well as the specific characters.

All the more comprehensive groups, equally with Species, are based upon a positive, permanent, specific principle, maintained generation after generation with all its essential characteristics. Individuals are the transient representatives of all these organic principles, which certainly have an independent, immaterial existence, since they outlive the individuals that embody them, and are no less real after the generation that has represented them for a time has passed away, than they were before. 
From a comparison of a numberr of well-known Species belonging to a natural Genus, it is not difficult to ascertain what are essentially specific characters. There is hardly among Mammalia a more natural Genus than that which includes the Rabbits and Hares, or that to which the Rats and Mice are referred. Let us see how the different Species differ from one another. Though we give two names in the vernacular to the Genus Hare, both Hares and Rabbits agree in all the structural peculiarities constituting a Genus; but the different Species are distinguished by their absolute size when full-grown, - by the nature and color of their fur, - by the size and form of the ear, - by the relative length of their legs and tail, - by the more or less slender build of their whole body, - by their habits, some liring in open grounds, others among the bushes, others in swamps, others burrowing under the earth, - by the number of ,young they bring forth, - by their different seasons of breeding, and by still minor differences, such as the permanent color of the hair throughout the year in some, while in others it turns white in winter. The Rats and Mice differ in a similar way: there being large and small Species, — some gray, some brown, others rust-colored, - some with soft, others with coarse hair; they differ also in the length of the tail, and in having it more or less 
covered with hair, - in the cut of the ears, and their size, - in the length of their limbs, which are slender and long in some, short and thick in others, - in their various ways of living, - in the different substances on which they feed, - and also in their distribution over the surface of the earth, whether circumscribed within certain limited areas or scattered over a wider range.

What is now the nature of these differences by which we distinguish Species? They are totally distinct from any of the categories on which Gen. era, Families, Orders, Classes, or Branches are founded, and may readily be reduced to a few heads. They are differences in the proportion of the parts and in the absolute size of the whole animal, in the color and general ornamentation of the surface of the body, and in the relations of the individuals to one another and to the world around. A farther analysis of other Genera would show us that among Birds, Reptiles, Fishes, and, in fact, throughout the Animal Kingdom, Species of well-defined natural Genera differ in the same way. We are therefore justified in saying that the category of characters on which Species are based implies no structural differences, but presents the same structure combined under certain minor differences of size, proportion, and habits. All the specific characters stand in direct reference to the generic structure, 
the family form, the ordinal complication of structure, the mode of execution of the Class, and the plan of structure of the Branch, all of which are embodied in the frame of each individual in each Species, even though all these individuals are constantly reproducing others and dying away; so that the specific characters have no more permanency in the individuals than those which characterize the Genus, the Family, the Order, the Class, and the Branch. I believe, therefore, that naturalists have been entirely wrong in considering the more comprehensive groups to be theoretical, and in a measure arbitrary, - that is, an attempt of certain men to classify the Animal Kingdom according to their individual views, - while they have ascribed to Species, as contrasted with the other divisions, a more positive existence in Nature.

No further argument is needed to show that it is not only the Species that lives in the individual, but that every individual, though belonging to a distinct Species, is built upon a precise and definite plan which characterizes its Branch, that that plan is executed in each individual in a particular way which characterizes its Class, that every individual with its kindred occupies a definite position in a series of structural complications which characterizes its Order, - that in every individual all these structural features are 
combined under a definite pattern of form which characterizes its Family, - that every individual exhibits structural details in the finish of its parts which characterize its Genus, - and finally that every individual presents certain peculiarities in the proportion of its parts, in its color, in its size, in its relations to its fellow-beings and the surrounding objects, which constitute its specific cliaracters; and all this is repeated in the same kind of combination, generation after generation, while the individuals themselves die. If we accept these propositions, which seem to me selfevident, it is impossible to avoid the conclusion that Species do not exist in Nature in any other sense than the more comprehensive groups of the zoölogical system.

There is one question respecting Species that gives rise to very earnest discussions in our day, not only among naturalists, but among all thinking people. How far are they permanent, and how far mutable? With reference to the permanence of Species, there is much to be learned from the geological phenomena belonging to our own period, in as far as they bear witness to the invariability of types during hundreds of thousands of years at least. I hope to present a part of this evidence in a future article upon Coral Reefs, but in the mean time I cannot leave this subject without touching upon a point 
which has been urged with great persistency in recent discussions. I refer to the rariability of Species as shown in domestication.

The domesticated animals with their numerous breeds are constantly adduced as evidence of the changes which animals may undergo, and as furnishing hints respecting the way in which the diversity now observed among animals may have been produced. It is my conviction that such inferences are in no way sustained by the facts of the case, and that, however striking the differences may be between the breeds of our domesticated animals, as compared with the wild Species of the same Genus, they are of a peculiar character, entirely distinct from the features prevailing among the latter, and altogether incident to the circumstances under which they appear. By this I do not mean the natural action of physical conditions, but the more or less intelligent direction of the circumstances under which they live. The inference drawn from the varieties introduced among animals in a state of domestication, with reference to the origin of Species, is usually this: that what the farmer does on a small scale Nature may do on a large one. It is true that man has been able to produce certain changes in the animals under his care, and that these changes have resulted in a variety of breeds. But in doing this, he has, in my estimation, in 
no way altered the character of the Species, but only developed its pliability under the will of man, that is, under a power similar in its nature and mode of action to that power to which animals owe their very existence. The influence of man upon animals is, in other words, the action of mind upon them; and yet the ordinary mode of arguing upon this subject is, that, because the intelligence of man has been able to produce certain varieties in domesticated animals, therefore physical causes have produced all the diversity existing among wild ones. Surely, the sounder logic would be to infer, that, because our finite intelligence may cause the original pattern to vary by some slight shades of difference, therefore a superior intelligence must have established all the boundless diversity of which our boasted varieties are but the faintest echo. It is the most intelligent farmer who has the greatest success in improving his breeds; and if the animals he has so fostered are left to themselves without that intelligent care, they return to their normal condition. So with plants : the shrewd, observing, thoughtful gardener will obtain many varieties from his flowers; but those varieties will fade out, if left to themselves. There is, as it were, a certain degree of pliability and docility in the organization both of animals and plants, which may be dereloped by the fostering care of man, and with- 
in which he can exercise a certain influence; bat the variations thus produced are of a peculiar kind, and do not correspond to the differences of the wild Species. Let us take some examples to illustrate this assertion.

Every Species of wild Bull differs from the others in its size; but all the individuals correspond to the average standard of size characteristic of their respective Species, and show none of those extreme differences of size so remarkable among our domestic Cattle. Every Species of wild Bull has its peculiar color, and all the individuals of one Species share in it: not so with our domesticated Cattle, among which every individual may differ in color from every other. All the individuals of the same Species of wild Bull agree in the proportion of their parts, in the mode of growth of the hair, in its quality, whether fine or soft : not so with our domesticated Cattle, among which we find in the same Species overgrown and dwarfish individuals, those with long and short legs, with slender and stout build of the body, with horns or without, as well as the greatest variety in the mode of twisting the horns, in short, the widest extremes of development which the degree of pliability in that Species will allow.

A curious instance of the power of man, not only in developing the pliability of an animal's 
organization, but in adapting it to suit his own caprices, is that of the Golden Carp, so frequently seen in bowls and tanks as the ornament of drawing-rooms and gardens. Not only an infinite variety of spotted, striped, variegated colors has been produced in these Fishes, but, especially among the Chinese, so famous for their morbid love of whatever is distorted and warped from its natural shape and appearance, all sorts of changes have been brought about in this single Species. A book of Chinese paintings, showing the Golden Carp in its varieties, represents some as short and stout, others long and slender, - some with the ventral side swollen, others hunchbacked, - some with the mouth greatly enlarged, while in others the caudal fin, which, in the normal condition of the Species, is placed vertically at the end of the tail, and is forked like those of other Fishes, has become crested and arched, or is double or crooked, or has swerved in some other way from its original pattern. But, in all these variations, there is nothing which recalls the characteristic specific differences among the representatives of the Carp Family, which, in their wild state, are very monotonous in their appearance all the world over.

Were it appropriate to accumulate evidence here upon this subject, I could bring forward many more examples quite as striking as those 
above mentioned. The various breeds of our domesticated Horses present the same kind of irregularities, and do not differ from each other in the same way as the wild Species differ from one another. Or take the Genus Dog : the differences between its wild Species do not correspond in the least with the differences observed among the domesticated ones. Compare the differences between the various kinds of Jackals and Wolves with those that exist between the Bull-Dog and Greyhound, for instance, or between the St. Charles and the Terrier, or between the Esquimaux and the Newfoundland Dog. I need hardly add, that what is true of the Horses, the Cattle, the Dogs, is true also of the Donkey, the Goat, the Sheep, the Pig, the Cat, the Rabbit, the different kinds of barn-yard fowl, - in short, of all those animals that are in domesticity the chosen companions of man.

In fact, all the variability among domesticated Species is due to the fostering care, or, in its more extravagant freaks, to the fancies of man; and it has never been observed in the wild Species, where, on the contrary, everything shows the closest adherence to the distinct, well-defined, and invariable limits of the Species. It surely does not follow, that, because the Chinese can, under abnormal conditions, produce a variety of fantastic shapes in the Golden Carp, therefore 
water, or the physical conditions established in the water, can create a Fish, any more than it follows, that, because they can dwarf a tree, or alter its aspect, by stunting its growth in one direction, and forcing it in another, therefore the earth, or the physical conditions connected with their growth, can create a Pine, an Oak, a Birch, or a Maple.

I confess that, in all the arguments derived from the phenomena of domestication, to prove that animals owe their origin and diversity to the natural action of the conditions under which they live, the conclusion does not seem to me to follow logically from the premises. And the fact that the domesticated animals of all the races of men, equally with the white race, vary among themselves in the same way, and differ in the same way from the wild Species, makes it still more evident, that domesticated varieties do not explain the origin of Species, except, as I have said, by showing, that the intelligent will of man can produce effects which physical causes have never been known to produce, and that we must, therefore, look to some cause outside of Nature, corresponding in kind to the intelligence of man, though so different in degree, for all the phenomena connected with the existence of animals in their wild state.

So far from attributing these original differ- 
ences among animals to natural influences, it would seem, that, while a certain freedom of development is left, within the limits of which man can exercise his intelligence and his ingenuity, not even this superficial influence is allowed to physical conditions unaided by some guiding power, since, in their normal state, the wild Species remain, so far as we have been able to discover, entirely unchanged, - maintained, it is true, in their integrity by the circumstances established for their support, but never altered by them. Nature loolds inviolable the stamp that God has set upon his creatures; and if man is able to influence their organization in some slight degree, it is because the Creator has given to his relations with the animals he has intended for his companions the same plasticity which he has allowed to every other side of his life, in virtue of which he may in some sort mould and shape it to his own ends, and be held responsible also for its results.

The common sense of a civilized community has already pointed out the true distinction, in applying another word to the discrimination of the different kinds of domesticated animals. They are called Breeds, and Breeds among animals are the work of man: Species were created by God. 


\section{CHAPTER XI.}

FORIIATION OF CORAL REEFS.

Arong the astounding discoveries of modern science is that of the immense periods which have passed in the gradual formation of our earth. So vast were the cycles of time preceding eren the appearance of man on the surface of our globe, that our own period seems as yesterday when compared with the epochs that have gone before it. Had we only the evidence of the deposits of rock heaped above each other in regular strata by the slow accumulation of materials, they alone would convince us of the long and slow maturing of God's work on the earth; but when we add to these the successive populations of whose life this world has been the theatre, and whose remains are hidden in the rocks into which the mud or sand or soil of whatever kind on which they lived has hardened in the course of time, - or the enormous chains of mountains whose upheaval divided these periods of quiet accumulation by great convulsions, or the changes of a different nature in the con- 
figuration of our globe, as the sinking of lands beneath the ocean, or the gradual rising of continents and islands above it, - or the wearing of great river-beds, or the filling of extensive waterbasins, till marshes first and then dry land succeeded to inland seas, - or the slow growth of coral reefs, those wonderful sea-walls raised by the little ocean-architects whose own bodies furnish both the building-stones and the cement that binds them together, and who hare worked so busily during the long centuries, that there are extensive countries, mountain-chains, islands, and long lines of coast consisting solely of their remains, - or the countless forests that must hare grown up, flourished, died, and decayed, to fill the storehouses of coal that feed the fires of the human race to-day, - if we consider all these records of the past, the intellect fails to grasp a chronology for which our experience furnishes no data, and the time that lies behind us seems as much an eternity to our conception as the unknown future that stretches indefinitely before us.

The physical as well as the human history of the world has its mythical age, lying dim and vague in the morning mists of creation, like that of the heroes and demigods in the early traditions of man, defying all our ordmary dates and measures. But if the succession of periods 
that prepared the earth for the coming of man, and the animals and plants that accompany him on earth, baffles our finite attempts to estimate its duration, have we any means of determining even approximately the length of the period to which we ourselves belong? If so, it may furnish us with some data for the further solution of these wonderful mysteries of time, and it is besides of especial importance with reference to the question of permanence of Species.

Those who maintain the mutability of Species, and account for all the variety of life on earth by the gradual changes wrought by time and circumstances, do not accept historical evidence as affecting the question at all. The relics of those oldest nations, all whose history is preserved in monumental records, do not indicate the slightest variation of organic types from the earliest epoch to this day. The animals preserved within their tombs or carved upon the walls of their monuments by the ancient Egyptians were the same as those that have their home in the valley of the Nile to-day; the negro, whose peculiar features are unmistakable even in their rude artistic attempts to represent them, was the same woolly-haired, thicklipped, flat-nosed, dark-skinned being in the lays of the Rameses that he is now. The $\Lambda$ pis, the Ibis, the Crocodiles, the sacred Beetles, 
have brought down to us unchanged all the characters that superstition hallowed in those early days. The stony face of the Sphinx is not more true to its past, nor the massive architecture of the Pyramids more unchanged, than they are. But the adrocates of the mutability of Species say truly enough that the most ancient traditions are but as yesterday in the world's history, and that what six thousand years could not do sixty thousand years might effect. Leaving aside, then, all historical chronology, how far back can we trace our own geological period, and the Species belonging to it? By what means can we determine its duration? Within what limits, by what standard, may it be measured? Shall hundreds, or thousands, or hundreds of thousands, or millions of years be the unit from which we start?

I will begin this inquiry with a series of facts which I myself have had an opportunity of investigating with especial care respecting the formation and growth of the Coral Reefs of Florida. But first a few words on Coral Reefs in general. They are living limestone walls built up from certain depths in the ocean by the natural growth of a variety of animals, but limited by the level of high water, beyond which they cannot rise, since the little beings that compose them die as soon as they are removed from the vitalizing influence of the pure sea-water. These walls 
have a variety of outlines: they may be straight, circular, semicircular, or oblong, according to the form of the coast along which the little ReefBuilders establish themselves; and their height is, of course, determined by the depth of the bottom on which they rest. If they settle about an island on all sides of which the conditions for their growth are equally favorable, they will raise a wall all round it, thus encircling it with a ring of Coral growth. The Athols in the Pacific Ocean, those circular islands enclosing sometimes a fresh-water lake in mid-ocean, are Coral walls of this kind, that have formed a ring around a central island.

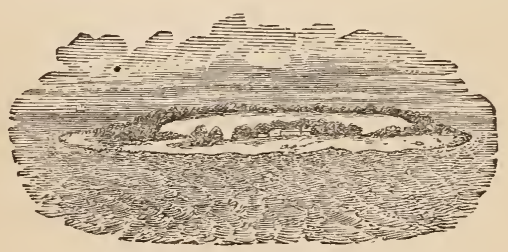

This is easily understood, if we remember that the bottom of the Pacific Ocean is by no means a stable foundation for such a structure. On the contrary, over a certain area, already surveyed with some accuracy by Professor Dana, during the United States Exploring Expedition, it is subsiding; and if an island upon which the Reef-Builders have established themselves 
be situated in that area of subsidence, it will, of course, sink with the floor on which it rests, carrying down also the Coral wall to a greater depth in the sea. In such instances, if the rate

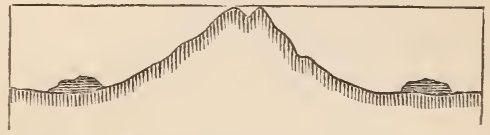

of subsidence be more rapid than the rate of growth in the Corals, the island and the wall itself will disappear beneath the ocean. But whenever, on the contrary, the rate of increase in the wall is greater than that of subsidence in the island, while the latter gradually sinks below the surface, the former rises in proportion, and by the time it has completed its growth the central island has ranished, and there remains only a ring of Coral Reef, with here and there a break perhaps, at some spot where the more prosperous growth of the Corals has been checked.

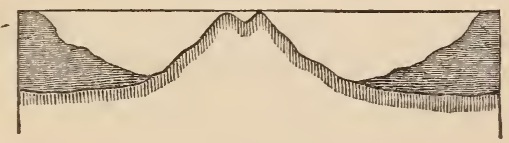

If, however, as sometimes happens, there is no such break, and the wall is perfectly uninterrupted, the sheet of sea-water so enclosed may be changed to fresh water by the rains that are poured into it. Such a water-basin will remain 
salt, it is true, in its lower part, and the fact that it is affected by the rise and fall of the tides shows that it is not entirely secluded from communication with the ocean outside; but the salt water, being hearier, sinks, while the lighter rain-water remains above, and it is to all appearance actually changed into a fresh-water lake.

I need not dwell here on the further history of such a Coral island, or follow it through the changes by which the summit of its circular wall becomes corered with a fertile soil, a tropical vegetation springs up upon it, and it is at last perhaps inhabited by man. There is something very attractive in the idea of these green rings enclosing sheltered harbors and quiet lakes in mid-ocean, and the subject has lost nome of its fascination since the mystery of their existence has been solved by the investigations of several contemporary naturalists, who have enabled us to trace the whole story of their structure. I would refer all who wish for a more detailed account of them to Charles Darwin's charming little volume on "Coral Reefs," where their mode of formation is fully described, and also to James D. Dana's "Geological Report of the United States Exploring Expedition."

Coral Reefs are found only in tropical regions: although Polyps, animals of the same class as those chiefly instrumental in their formation, are 
found in all parts of the globe, yet the ReefBuilding Polyps are limited to the Tropics. We are too apt to forget that the homes of animals are as definitely limited in the water as on the land. Indeed, the subject of the geographical distribution of animals according to laws regulated by altitude, by latitude and longitude, by pressure of atmosphere or pressure of water, by temperature, light, \&c., already alluded to in a previous article, is exceedingly interesting, and presents a most important field of investigation.

The climatic effect of different levels of altitude upon the growth of animals and plants is the same as that of different degrees of latitude; and the slope of a high mountain in the Tropics, from base to summit, presents in a condensed form, an epitome, as it were, of the same kind of gradation in vegetable growth that may be observed from the Tropics to the Arctics. At the base of such a mountain we have all the luxuriance of growth characteristic of the tropical forest, - the Palms, the Bananas, the Breadtrees, the Mimosas; higher up, these give way to a different kind of growth, corresponding to our Oaks, Chestnuts, Maples, etc. ; as these wane, on the loftier slopes comes in the Pine forest, fading gradually, as it ascends, into a dwarfish growth of the same kind; and this at last gives way to the low creeping Mosses and Lichens of 
the greater heights, till even these find a foothold no longer, and the summit of the mountain is clothed in perpetual snow and ice. What have we here but the same series of changes through which we pass, if, travelling northward from the Tropics, we leave Palms and Pomegranates and Bananas behind, where the LiveOaks and Cypresses, the Orange-trees and Myrtles of the warmer Temperate Zone come in, and these die out as we reach the Oaks, Chestnuts, Maples, Elms, Nut-trees, Beeches, and Birches of the colder Temperate Zone, these again waning as we enter the Pine forests of the Arctic borders, till, passing out of these, nothing but a dwarf regetation, a carpet of Moss and Lichen, fit food for the Reindeer and the Esquimaux, greets us, and beyond that lies the region of the snow and ice fields, impenetrable to all but the daring Arctic voyager?

I have thus far spoken of the changes in the vegetable growth alone as influenced by altitude and latitude, but the same is equally true of animals. Every zone of the earth's surface has its own animals, suited to the conditions uncer which they are meant to live; and, with the exception of those that accompany man in all his pilgrimages, and are subject to the same modifying influences by which he adapts his home and himself to all climates, animals are absolutely bound by 
the laws of their nature within the range assigned to them. Nor is this the case only on land, where river-banks, lake shores, and mountainranges might be supposed to form the impassable boundaries that keep animals within certain limits; but the ocean, as well as the land, has its faunæ and floræ bound within their respective zoölogical and botanical provinces; and a wall of granite is not more impassable to a marine animal than that ocean-line, fluid, and flowing, and ever-changing though it be, on which is written for him, "Hitherto shalt thou come, but no farther." One word as to the effect of pressure on animals will explain this.

We all live under the pressure of the atmosphere. Now, thirty-two feet under the sea doubles that pressure, since a column of water of that height is equal in weight to the pressure of one atmosphere. At the depth of thirty-two feet, then, any marine animal is under the pressure of two atmospheres, - that of the air, which surrounds our globe, and of a weight of water equal to it; at sixty-four feet he is under the pressure of three atmospheres, and so on, - the weight of one atmosphere being always added for every thirty-two feet of depth. There is a great difference in the sensitiveness of animals to this pressure. Some fishes live at a great depth, and find the weight of water genial to them; 
while others would be killed at once by the same pressure; and the latter naturally seek the shallow waters. Every fisherman knows that he must throw a long line for a Halibut, while with a common fishing-rod he will catch plenty of Perch from the rocks near the shore; and the differently colored bands of sea-weed revealed by low tides, from the green line of the Ulvas through the brown zone of the common Fucus, to the rosy and purple-hued sea-weeds of the deeper water, show that the floræ as well as the faunæ of the ocean have their precise boundaries.

This wider or narrower range of marine animals is in direct relation to their structure, which enables them to bear a greater or less pressure of water. All fishes, and, indeed, all animals having a wide range of distribution in ocean-depths, have a special apparatus of water-pores, so that the surrounding element penetrates their structure, thus equalizing the pressure of the weight, which is diminished from without in proportion to the quantity of water they can admit into their bodies. Marine animals differ in their ability to sustain this pressure, just as land animals differ in their power of enduring great variations of climate and of atmospheric pressure.

Of all air-breathing animals, none exhibits a more surprising power of adapting itself to great 
and rapid changes of external influences than the Condor. It may be seen feeding on the sea-shore under a burning tropical sun, and then, rising from its repast, it floats up among the highest summits of the Andes, and is lost to sight beyond them, miles above the line of perpetual snow, where the temperature must be lower than that of the Aretics. But even the Condor, sweeping at one flight from tropic heat to arctic cold, although it passes through greater changes of temperature, does not undergo such changes of pressure as a fish that rises from a depth of sixtyfour feet to the surface of the sea; for the former remains within the air that surrounds our globe, and therefore the increase or diminution of pressure to which it is subjected must be confined within the limits of one atmosphere; while the latter, at a depth of sixty-four feet, is under a weight equal to that of three such atmospheres, which is reduced to one when it reaches the sealevel. The change is proportionally greater for those fishes that come from a depth of several hundred feet. These laws of limitation in space explain many facts in the growth of Coral Reefs that would be otherwise inexplicable, and which I now will endeavor to make clear to my readers.

For a long time it was supposed that the ReefBuilders inhabited very deep waters, for they were sometimes brought up on sounding-lines from a 
depth of many hundreds, or even thousands, of feet, and it was taken for granted that they must have had their home where they were found; but the facts recently ascertained respecting the subsidence of ocean-bottoms have shown that the foundation of a Coral wall may have sunk far below the place where it was laid. And it is now proved, beyond a doubt, that no Reef-Building Coral can thrive at a depth of more than fifteen fathoms, though Corals of other kinds occur far lower, and that the dead Reef-Corals, sometimes brought to the surface from much greater depths, are only broken fragments of some Reef that has subsided with the bottom on which it was growing. But though fifteen fathoms is the maximum depth at which any Reef-Builder can prosper, there are many which will not sustain even that degree of pressure; and this fact has, as we shall see, an important influence on the structure of the Reef.

Imagine now a sloping shore on some tropical coast descending gradually below the surface of the sea. Upon that slope, at a depth of from ten to twelve or fifteen fathoms, and two or three or more miles from the main land, according to the shelving of the shore, we will suppose that one of those little Coral animals, to whom a home in such deep waters is genial, has established itself. How it happens that such a being, which we 
know is immovably attached to the ground, and forms the foundation of a solid wall, was ever able to swim freely about in the water till it found a suitable resting-place, I shall explain hereafter, when I say something of the mode of reproduction of these animals. Accept, for the moment, my unsustained assertion, and plant our little Coral on this sloping shore, some twelve or fifteen fathoms below the surface of the sea.

The internal structure of such a Coral corresponds to that of the Sea-Anemone. The body is divided by vertical partitions from top to bottom, leaving open chambers between; while in the centre hangs the digestive cavity, connected by an opening in the bottom with all these chambers. At the top is an aperture serving as a mouth, surrounded by a wreath of hollow tentam cles, each one of which connects at its base with one of the chambers, so that all parts of the animal communicate freely with each other. But though the structure of the Coral is identical in all its parts with that of the Sea-Anemone, it nevertheless presents one important difference. The body of the Sea-Anemone is soft, while that of the Coral is hard.

It is well known that all animals and plants have the power of appropriating to themselves and assimilating the materials they need, each selecting from the surrounding elements whatever 
contributes to its well-being. Now Corals possess, in an extraordinary degree, the power of assimilating to themselves the lime contained in the salt water around them; and as soon as our little Coral is established on a firm foundation, a lime deposit begins to form in all the walls of its body, so that its base, its partitions, and its outer wall, which in the Sea-Anemone remain always soft, become perfectly solid in the Polyp Coral, and form a frame as hard as bone.

It may naturally be asked where the lime comes from in the sea which the Corals absorb in such quantities. As far as the living Corals are concerned, the answer is easy, for an immense deal of lime is brought down to the ocean by rivers that wear away the lime deposits through which they pass. The Mississippi, whose course lies through extensive lime regions, brings down yearly lime enough to supply all the animals living in the Gulf of Mexico. But behind this lies a question not so easily settled, as to the origin of the extensive deposits of limestone found at the very beginning of life upon earth. This problem brings us to the threshold of astronomy, for the base of limestone is metallic in character, sus ceptible therefore of fusion, and may have formed a part of the materials of our earth, even in an incandescent state, when the worlds were forming. But though this investigation as to the origin of 
lime does not belong either to the naturalist or the geologist, its suggestion reminds us that the time has come when all the sciences and their results are so intimately connected that no one can be carried on independently of the others. Since the study of the rocks has revealed a crowded life whose records are hoarded within them, the work of the geologist and the naturalist has become one and the same, and at that border-land where the first crust of the earth was condensed out of the igneous mass of materials which formed its earliest coudition, their investigation mingles with that of the astronomer, and we cannot trace the limestone in a little Coral without going back to the creation of our solar system, when the worlds that compose it were thrown off from a central mass in a gaseous condition.

When the Coral has become in this way permeated with lime, all parts of the body are rigid, with the exception of the upper margin, the stomach, and the tentacles. The tentacles are soft and waving, projected or drawn in at will; they retain their flexible character through life, and decompose when the animal dies. For this reason the dried specimens of Corals preserved in museums do not give us the least idea of the living Corals, in which every one of the millions of beings composing such a community is crowned 
by a waving wreath of white or green or rosecolored tentacles.

As soon as the little Coral is fairly established and solidly attached to the ground, it begins to bud. This may take place in a variety of ways, dividing at the top or budding from the base or from the sides, till the primitive animal is surrounded by a number of individuals like itself, of which it forms the nucleus, and which now begin to bud in their turn, each one surrounding itself with a numerous progeny, all remaining, however, attached to the parent. Such a community increases till its individuals are numbered by millions; and I have myself counted no less than fourteen millions of individuals in a Coral mass of Porites measuring not more than twelve feet in diameter. The so-called Coral heads,

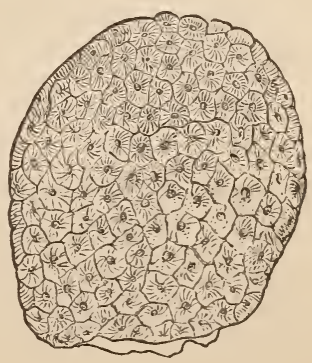

which make the foundation of a Coral wall, and seem by their massive character and regular form 
especially adapted to give a strong, solid base to the whole structure, are known in our classifications as the Astræans, so named on account of the star-shaped form of the little pits crowded upon their surface, each one of which marks the place of a single more or less isolated individual in such a community.

Thus firmly and strongly is the foundation of the reef laid by the Astræans; but we have seen that for their prosperous growth they require a certain depth and pressure of water, and when they have brought the wall so high that they have not more than six fathoms of water above them, this kind of Coral ceases to grow. They have, however, prepared a fitting surface for different kinds of Corals that could not live in the depths from which the Astræans have come, but find their genial home nearer the surface; such a home being made ready for them by their predecessors, they now establish themselves on the top of the Coral wall and continue its growth for a certain time. These are the Meandrinas, or the so-called Brain-Corals, and the Porites. The Meandrinas differ from the Astræans by their less compact and definite pits. In the Astræans the place occupied by the animal in the community is marked by a little star-shaped spot, in the centre of which all the partition-walls meet. But in the Meandrinas, although all the partitions con- 
verge toward the central opening, as in the Astræans, these central openings elongate, run into each other, and form waving furrows all over the surface, instead of the small round pits so

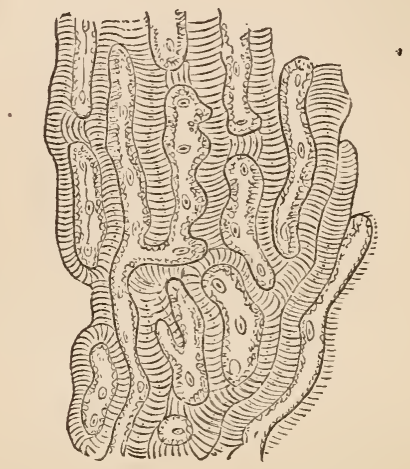

characteristic of the Astræans. The Porites resemble the Astræans, but the pits are smaller,

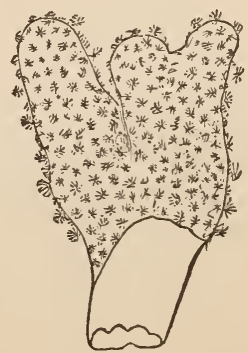

with fewer partitions and fewer tentacles, and their whole substance is more porous. 
But these also have their bounds within the

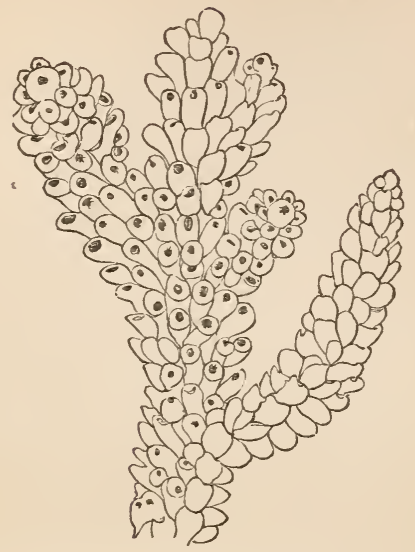

sea: they in their turn reach the limit beyond which they are forbidden by the laws of their na-

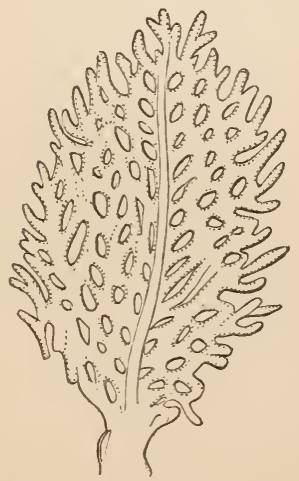

ture to pass, and there they also pause. But the 
Coral wall continues its steady progress; for here the lighter kinds set in, - the Madrepores (p. 167), the Millepores, and a great variety of Sea-Fans (p. 167, below) and Corallines, and the reef is crowned at last with a many-colored shrubbery of low feathery growth. These are all branching in form, and many of them are simple calciferous plants, though most of them are true animals, resembling, however, delicate Algæ more than any marine animals; but, on examination of the latter, one finds them to be covered with myriads of minute dots, each representing one of the little beings out of which the whole is built, while nothing of the kind is seen in Algæ.

I would add here one word on the true nature of the Millepores. long misunderstood by natu-

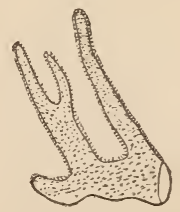

ralists, because this type throws light not only on some interesting facts respecting Coral Reefs, especially the ancient ones, but also because it tells us something of the early inhabitants of the globe, and shows us that a class of Radiates supposed to be missing in the primitive creation had its representatives then as now. 
In the diagram of the geological periods introduced in a previous article, I have represented all the three classes of Radiates, Polyps, Acalephs, and Echinoderms as present on the first floor of our globe which was inhabited at all. But it is only recently that positive proofs have been found of the existence of Acalephs or Jelly-Fishes, as they are called, at that early period. Their very name indicates their delicate structure; and were there no remains preserved in the rocks of these soft, transparent creatures, it would yet be no evidence that they did not exist. Fragile as they are, howerer, they have left here and there some faint record of themselves, and in the Museum at Carlsruhe, on a slab from Solenhofen, I have seen a very perfect outline of one which remains undescribed to this day. This, however, does not carry them farther back than the Jurassic period, and it is only lately that I have satisfied myself that they not only existed, but were among the most numerous animals in the first representation of organic life.

The earliest Corals correspond in certain features of their structure to the Millepores. They differ from them as all early animals differ from the succeeding ones, every geological period having its special set of representatives. But still they are always true to their class, and have a certain general correspondence with animals of 
like kind that follow them in later periods. In this sense the Millepores are in our epoch the representatives of those early Corals, called by naturalists Tabulata and Rugosa, - distinguished from the Polyp Corals by the horizontal floors, waving in some, straight in others, which divide the body transversely at successive heights through its whole length, and also by the absence of the vertical partitions, extending from top to bottom of each animal, so characteristic of the true Polyps.

Notwithstanding these differences, they were for a long time supposed to be Polyps, and I had shared in this opinion, till, during the winter of 1857, while pursuing my investigations on the Coral Reefs of Florida, one of these Millepores revealed itself to me in its true character of Acaleph. It must be remembered that they belong to the Hydroid group of Acalephs, of which our common jelly-fishes do not give a correct idea. it is by their soft parts alone - those parts which are seen only when these animals are alive and fully open - that their Acalephian character can be perceived, and this accounts for their being so long accepted as Polyps, when studied in the dry Coral stock. Nothing could exceed my astonishment when for the first time I saw such an animal fully expanded, and found it to be a true Acaleph. It is exceedingly difficult to 
obtain a view of them in this state, for, at any approach, they draw themselres in, and remain closed to all investigation. Only once, for a short hour, I had this opportunity; during that time one of these little creatures revealed to me its whole structure, as if to tell me, once for all, the story of its existence through all the successive epochs from the dawn of Creation till now, and then withdrew. With my most patient watching, I have never been able to see one of them open again. But to establish the fact that one of the Corals represented from the earliest period, and indeed far more numerous in the beginning than any other, was in truth no Polyp, but an Acaleph, the glimpse I had was all-sufficient. It came out as if to bear witness of its class, - as if to say, "We, too, were among the hosts of living beings with which God first peopled his earth."

With these branching Corals the reef reaches the level of high-water, beyond which, as I have said, there can be no further growth, for want of the action of the fresh sea-water. This dependence upon the vivifying influence of the sea accounts for one unfailing feature in the Coral walls. They are always abrupt and steep on the seaward side, but have a gentle slope towards the land. This is accounted for by the circumstance that the Corals on the outer side of the 
reef are in immediate contact with the pure ocean-water, while by their growth they partially exclude the inner ones from the same influence, - the rapid growth of the latter being also impeded by any impurity or foreign material washed away from the neighboring shore and mingling with the water that fills the channel between the main-land and the reef. Thus the Coral Reefs, whether built around an island, or along a straight line of coast, or concentric to a rounding shore, are always shelving toward the land, while they are comparatively abrupt and steep toward the sea. This should be remembered, for, as we shall see hereafter, it lias an important bearing on the question of time as illustrated by Coral Reefs.

I have spoken of the budding of Corals, by which each one becomes the centre of a cluster; but this is not the only way in which they multiply their kind. They give birth to eggs also, which are carried on the inner edge of their partition-walls, till they drop into the sea, where they float about, little, soft, transparent, pearshaped bodies, as unlike as possible to the rigid stony structure they are to assume hereafter. In this condition they are covered with vibratile cilia or fringes, that are always in rapid, uninterrupted motion, and by means of which they swim about in the water. These little germs of 
the Corals, swimming freely about during their earliest phases of life, continue the growth of the reef, those that prosper at shallower depths coming in at the various heights where their predecessors die out; otherwise it would be impossible to understand how this variety of building material, as it were, is introduced wherever it is needed. This point, formerly a puzzle to naturalists, has become quite clear since it has been found that myriads of these little germs are poured into the water surrounding a reef. There they swim about till they find a genial spot on which to establish themselves, when they become attached to the ground by one end, while a depression takes place at the opposite end, which gradually deepens to form the mouth and inner cavity, while the edges expand to form the tentacles, and the productive life of the little Coral begins: it buds from every side, and becomes the foundation of a new community.

I should add, that, beside the Polyps and the Acalephs, Mollusks also have their representatives among the Corals. There is a group of small Mollusks called Bryozoa, allied to the Clams by their structure, but excessively minute when compared to the other members of their class, which, like the other Corals, harden in consequence of an absorption of solid materials, and contribute to the formation of the reef. Besides 
these, there are certain plants, limestone Algx, - Corallines, as they are called, - which have their share also in the work.

I had intended to give some account of the Coral Reefs of Florida, and to show what bearing they have upon the question of time and the permanence of Species; but this cursory sketch of Coral Reefs in general has grown to such dimensions that I must reserve a more particular account of the Florida Reefs and Keys for a future article. 


\section{CHAPTER XII.}

AGE OF CORAL REEFS AS SHOWLNG PERMANENCE OF SPECIES.

A FEW miles from the southern extremity of Florida, separated from it by a channel, narrow at the eastern end, but widening gradually toward the west, and rendered every year more and more shallow by the accumulation of materials constantly collecting within it, there lies a line of islands called the Florida Keys. They are at different distances from the shore, stretching gradually seaward in the form of an open crescent, from Virginia Key and Key Biscayne, almost adjoining the main-land, to Key West, at a distance of twelve miles from the coast, which does not, however, close the series, for sixty miles farther west stands the group of the Tortugas, isolated in the Gulf of Mexico. Though they seem disconnected, these islands are parts of a submerged Coral Reef, parallel with the shore of the penimsula and continuous underneath the water, but visible above the surface at such points of the summit as have fully completed their growth. 
This demands some explanation, since I have already said that no Coral growth can continue after it has reached the line of high water. But

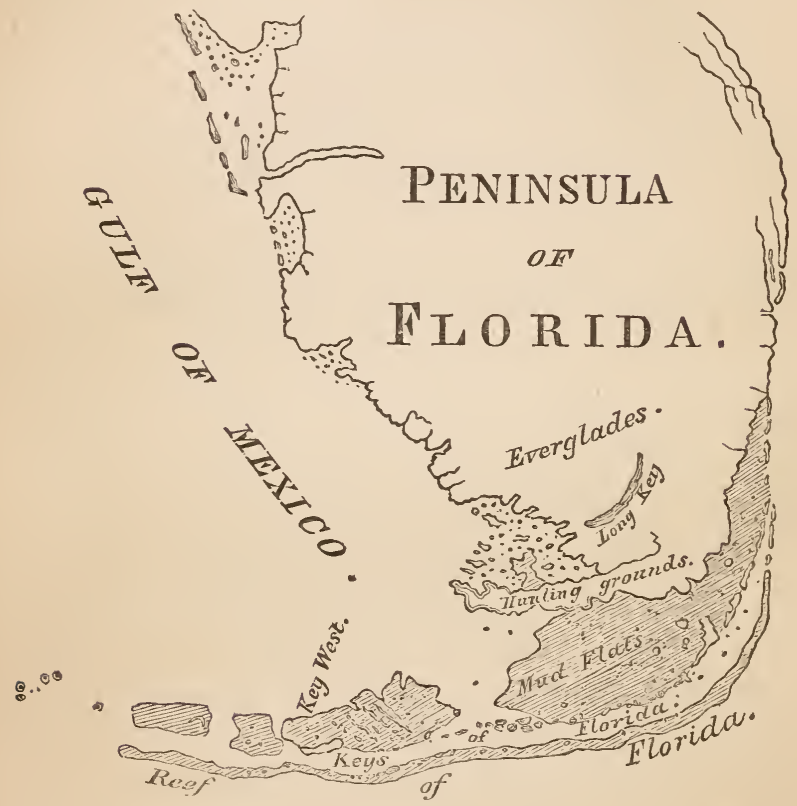

we have not finished the history of a Coral wall, when we have followed it to the surface of the ocean. It is true that its normal growth ceases there, but already a process of partial decay has begun that insures its further increase. Here, as elsewhere, destruction and construction go hand in hand, and the materials broken or 
worn away from one part of the Reef help to build it up elsewhere. The Corals forming the Reef are not the only beings that find their home there : many other animals - Shells, Worms, Crabs, Star-Fishes, Sea-Urchins - establish themselves upon it, work their way into its interstices, and seek a shelter in every little hole and cranny made by the irregularities of its surface. In the Zoölogical Museum at Cambridge there are some large fragments of Coral Reef which give one a good idea of the populous aspect that such a Reef would present, could we see it as it actually exists beneath the water. Some of these fragments consist of a succession of terraces, as it were, in which are many little miniature cares, where may still be seen the Shells or Sea-Urchins which made their snug and sheltered homes in these recesses of the Reef.

We must not consider the Reef as a solid, massive structure throughout. The compact kinds of Corals, giving strength and solidity to the wall, may be compared to the larger trees in a forest, giving it shade and density; but beneath these larger trees grow all kinds of trailing vines, ferns, and mosses, wild-flowers, and low shrubs, filling the spaces between them with a thick underbrush. The Coral Reef also has its underbrush of the lighter, branching, more brittle kinds, filling its interstices, and fringing the sum. 
mit and the sides with their delicate, graceful forms. Such an intricate underbrush of Coral growth affords an excellent retreat for many animals that like its protection better than exposure to the open sea, just as many land-animals prefer the close and shaded woods to the open plain. A forest is not more thickly peopled with Birds, Squirrels, Martens, and the like, than is the Coral Reef with a variety of animals which do not contribute in any way to its growth, but find shelter in its crevices, or in its near neighborhood.

But these larger animals are not the only ones that haunt the forest. There is a host of parasites besides, principally Insects and their larvæ, which bore their way into the very heart of the tree, making their home in the bark and pith, and not the less numerous because hidden from sight. These also have their counterparts. in the Reef, where numbers of boring Shells and marine Worms work their way into the solid substance of the wall, piercing it with holes in every direction, till large portions become insecure, and the next storm suffices to break off the fragments so loosened. Once detached, they are tossed about in the water, crumbled into Coral sand, crushed, often ground to powder by the friction of the rocks and the constant action of the sea.

After a time, an immense quantity of such 
materials is formed about a Coral Reef. Tides and storms constantly throw them up on its surface, and at last a soil collects on the top of the Reef, wherever it has reached the surface of the water, formed chiefly of its own débris, of Coral sand, Coral fragments, even large masses of Coral rock, mingled with the remains of the animals that have had their home about the Reef, with sea-weeds, with mud from the neighboring land, and with the thousand loose substances always floating about in the vicinity of a coast, and thrown upon the rocks or shore with every wave that breaks against them. Add to this the presence of a lime-cement in the water, resulting from the decomposition of some of these materials, and we have all that is needed to make a very compact deposit and fertile soil, on which a vegetation may spring up, whenever seeds floating from the shore, or dropped by birds in their flight, take root on the newly formed island.

There is one plant belonging to tropical or subtropical climates that is peculiarly adapted by its mode of growth to the soil of these islands, and contributes greatly to their increase. This is the Mangrove-tree. Its seeds germinate in the calyx of the flower, and, before they drop, grow to be little brown stems, some six or seven inches long, and about as thick as a finger, with little rootlets at one end. Such Mangrove-seedlings, looking 
more like cigars than anything else, float in large numbers about the Reef. I have sometimes seen them in the water about the Florida Reef in such quantities, that one would have said some vessel laden with Havana cigars had been wrecked there, and its precious cargo scattered in the ocean.

In consequence of their shape, and the development of the root, one end is a little heavier than the other, so that they float unevenly, with the loaded end a little lower than the lighter one. When they are brought by the tide against such a cap of soil as I have described, they become stranded upon it by their heavier end; the rootlets attach themselves slightly to the soil; the advancing and retreating waves move the little plant up and down, till it works a hole in the sand; and having thus established itself more firmly, steadied itself, as it were, it now stands upright; and, as it grows, throws out numerous roots, even from a height of several feet abore the ground, till it has surrounded the lower part of its stem with a close net-work of roots. Against this natural trellis, or screen, all sorts of materials collect. Sand, mud, and shells are caught in it. And as these Mangrore-trees grow in large numbers, and to the height of thirty feet, they contribute greatly to the solidity and compactness of the shores on which they are stranded. 
Such caps of soil on the summit of a Coral Reef are of course very insecure, till they are consolidated by a long period of accumulation, and they may eren be swept completely away by a riolent storm. It is not many years since the light-house, built on Sand Key for the greater security of navigation along the Reef, was swept away, with the whole island on which it stood. Thanks to the admirably conducted investigations of the Coast-Survey, this part of our seaboard, formerly so dangerous on account of the Coral Reefs, is now better understood, and every precaution has been taken to insure the safety of ressels sailing along the coast of Florida.

I camnot deny myself the pleasure of paying a tribute here to the high scientific character of the distinguished superintendent of this surrey, who has known so well how to combine the most important scientific aims with the most valuable practical results in his direction of it. If some have hitherto doubted the practical value of such researches, - and unhappily there are always those who estimate intellectual efforts only by their material results, - one would think that these doubts must be satisfied, now that the Coast-Survey is seen to be the right arm of our navy. Most of the leaders in our late naval expeditions have been men trained in its serrice, and familiar with all the harbors, with every 
bay and inlet of our Southern coasts, from having been engaged in the extensive researches undertaken by Dr. Bache, and carried out under his guidance. Many even of the pilots of our Southern fleets are men who have been employed upon this work, and owe their knowledge of the coast to their former occupation. It is a singular fact, that at this very time, when the whole country feels its obligation to the men who have devoted so many years of their lives to these investigations, a proposition should have been brought forward in Congress for the suspension of the Coast-Survey on economical grounds. Happily, the almost unanimous rejection of this proposition has shown the appreciation in which the work is held by our national legislature. Even without reference to their practical usefulness, it is a sad sign, when, in the hour of her distress, a nation sacrifices first her intellectual institutions. Then, more than ever, when she needs all the culture, all the wisdom, all the comprehensiveness of her best intellects, should she foster the institutions that have fostered them, and in which they have been trained to do good service to their country in her time of need.

Several of the Florida Keys, such as Key West and Indian Key, are already large, inhabited islands, several miles in extent. The interval between them and the main-land is gradually 
filling up, by a process similar to that by which the islands themselves were formed. The gentle landward slope of the Reef and the channel between it and the shore, are covered with a growth of the more branching lighter Corals, such as SeaFans, Corallines, etc., answering the same purpose as the intricate roots of the Mangrove-tree. All the débris of the Reef, as well as the sand and mud washed from the shore, collect in this net-work of Coral growth within the channel, and soon transform it into a continuous mass, with a certain degree of consistence and solidity. This forms the foundation of the mud-flats which are now rapidly filling the channel, and must eventually connect the Keys of Florida with the present shore of the peninsula.

Outside the Keys, but not separated from them by so great a distance as that which intervenes between them and the main-land, there stretches beneath the water another Reef, abrupt, like the first, on its seaward side, but sloping gently toward the inner Reef, and divided from it by a channel. This outer Reef and channel are, however, in a much less adranced state than the preceding ones. Only here and there a sand-flat large enough to afford a foundation for a beacon, or a light-house, shows that this Reef also is gradually coming to the surface, and that a - series of islands corresponding to the Keys must eventually be formed upon its summit. 
Some of my readers may ask why the Reef does not rise evenly to the level of the sea, and form a continuous line of land, instead of here and there an island. This is accounted for by the sensitiveness of the Corals to any unfavorable circumstances impeding their growth, as well as by the different rates of increase of their different kinds. Wherever any current from the shore flows over the Reef, bringing with it impurities from the land, there the growth of the Corals will be less rapid, and consequently that portion of the Reef will not reach the surface so soon as other parts, where no such unfavorable influences have interrupted the growth. But in the course of time the outer Reef will reach the surface for its whole length, and become united to the inner one by the filling up of the channel between them, while the inner one will long befure that time become solidly united to the present shore-bluffs of Florida by the consolidation of the mud-flats, which will one day transform the inner channel into dry land.

What is now the rate of growth of these Coral Reefs? We cannot, perhaps, estimate it with absolute accuracy, since they are now so nearly completed ; but Coral growth is constantly springing up wherever it can find a foothold, and it is not difficult to ascertain approximately the rate of growth of the different kinds. Even this, 
however, would give us far too high a standard; for the rise of the Coral Reef is not in proportion to the height of the living Corals, but to their solid parts which never decompose. Add to this that there are many brittle, delicate kinds that have a considerable height when alive, but contribute to the increase of the Reef only so much additional thickness as their branches would have if broken and crushed down upon its surface. A forest in its decay does not add to the soil of the earth a thickness corresponding to the height of its trees, but only such a thin layer as would be left by the decomposition of its whole vegetation. In the Coral Reef, also, we must allow not only for the deduction of the soft parts, but also for the comminution of all these little branches, which would be broken and crushed by the action of the storms and tides, and add, therefore, but little to the Reef in proportion to their size when alive.

The foundations of Fort Jefferson, which is built entirely of Coral rock, were laid on the Tortugas Islands in the year 1816. A very intelligent head-workman watched the growth of certain Corals that established themselves on these foundations, and recorded their rate of increase. He has shown me the rocks on which Corals had been growing for some dozen years, during which they had increased at the rate of 
about half an inch in ten years. I have collected facts from a variety of sources and localities that confirm this testimony. A brick placed under water, in the year 1850, by Captain Woodbury of Tortugas, with the view of determining the rate of growth of Corals, when taken up in 1858 had a crust of Mæandrina upon it a little more than half an inch in thickness. Mr. Allen also sent me from Key West a number of fragments of Mæandrina from the breakwater at Fort Taylor; they had been growing from twelve to fifteen years, and have an arerage thickness of about an inch. 'The specimens vary in this respect, - some of them being a little more than an inch in thickness, others not more than half an inch. Fragments of Oculina gathered at the same place-and of the same age are from one to three inches in height and width; but these belong to the lighter, more branching kinds of corals, which, as we have seen, cannot, from their brittle character, be supposed to add their whole lieight to the solid mass of the Coral wall. Millepore gives a similar result.

Estimating the growth of the Coral Reef according to these and other data of the same character, it should be about half a foot in a century; and a careful comparison which I have made of the condition of the Reef as recorded in an English survey made about a century ago 
with its present state would justify this conclusion. But, allowing a wide margin for inaccuracy of observation or for any circumstances that might accelerate the growth, and leaving out of consideration the decay of the soft parts and the comminution of the brittle ones, which would subtract so largely from the actual rate of growth, let us double this estimate and call the average increase a foot for every century. In so doing, we are no doubt greatly overrating the rapidity of the progress, and our calculation of the period that must have elapsed in the formation of the Reef will be far within the truth.

The outer Reef, still incomplete, as I have stated, and therefore of course somewhat lower than the inner one, measures about seventy feet in height. Allowing a foot of growth for every century, not less than seven thousand years must have elapsed since this Reef began to grow. Some miles nearer the main-land are the Keys, or the inner Reef; and though this must have been longer in the process of formation than the outer one, since its growth is completed, and nearly the whole extent of its surface is transformed into islands, with here and there a narrow break separating them, yet, in order to keep fully within the evidence of the facts, I will allow only seven thousand years for the formation of this Reef also, making fourteen thousand for the two. 
This brings us to the shore-bluffs, consisting simply of another Reef exactly like those already described, except that in course of time it has been united to the main-land by the complete filling up and consolidation of the channel which once divided it from the extremity of the peninsula, as a channel now separates the Keys from the shorebluffs, and the outer Reef, again, from the Keys. These three concentric Reefs, then, the outer Reef, the Keys, and the shore-bluffs, if we measure the growth of the two latter on the same low estimate by which I have calculated the rate of progress of the former, cannot have reached their present condition in less than twenty thousand years. Their growth must have been successive, since, as we have seen, all Corals need the fresh action of the open sea upon them, and if either of the outer Reefs had begun to grow before the completion of the inner one, it would have effectually checked the growth of the latter. The absence of an incipient Reef outside of the outer Reef shows these conclusions to be well - founded. The islands capping these three reefs do not exceed in height the level to which the fragments accumulated upon their summits may have been thrown by the heaviest storms. The highest hills of this part of Florida are not over ten or twelve feet above the level of the sea, and yet the luxuriant regetation with which they 
are corered gives them an imposing appearance, recalling the islands of the Pacific.

But this is not the end of the story. Travelling inland from the shore-bluffs, we cross a low, flat expanse of land, the Indian hunting-ground, which brings us to a row of elevations called the Hummocks. This hunting-ground, or Everglade as it is also called, is an old channel, changed first to mud-flats and then to dry land by the same kind of accumulation that is filling up the present channels, and the row of hummocks is but an old Coral Reef with the Keys or islands of past days upon its summit. Seven such Reefs and channels of former times have already been traced between the shore-bluffs and Lake Okee-cho-bee, adding some fifty thousand years to our prerious estimate. Indeed, upon the lowest calculation, based upon the facts thus far ascertained as to their growth, we cannot suppose that less than serenty thousand years have elapsed since the Coral Reefs already known to exist in Florida began to grow.

When we remember that this is but a small portion of the peninsula, and that, though we have no very accurate information as to the nature of its interior, yet the facts already ascertained in the northern part of the State, formed, like its southern extremity, of Coral growth, justify the inference that the whole peninsula is formed 
of successive concentric Reefs, we must believe that hundreds of thousands of years have elapsed since its formation began. Leaving aside, however, all that part of its history which is not susceptible of positive demonstration in the present state of our knowledge, I will limit my results to the evidence of facts already within our possession; and these give us as the lowest possible estimate a period of seventy thousand years for the formation of that part of the peninsula which extends south of Lake Okee-cho-bee to the present outer Reef.

So much for the duration of the Reefs themselves. What, now, do they tell us of the permanence of the Species by which they were formed? In these seventy thousand years has there been any change in the Corals living in the Gulf of Mexico? I answer most emphatically, No. Astræans, Porites, Mæandrinas, and Madrepores were represented by exactly the same Species serenty thousand years ago as they are now. Were we to classify the Florida Corals from the Reefs of the interior, the result would correspond exactly to a classification founded upon the living Corals of the outer Reef to-day. There would be among the Astræans the different Species of Astræa proper, forming the close round heads, - the Mussa, growing in smaller stocks, where the mouths coalesce and run into 
each other as in the Brain-Corals, but in which the depression formed by the mouths are deeper, and the Caryophyllians, in which the single individuals stand out more distinctly from the stock; among Porites, the P. Astræoides, with pits resembling those of the Astræans in form, though smaller in size, and growing also in solid heads, though these masses are covered with club-shaped protrusions, instead of presenting a smooth, even surface like the Astræans, - and the P. Clavaria, in which the stocks are divided in short, stumpy branches, with club-shaped ends, instead of growing in close, compact heads; among the Mæandrinas we should have the round heads we know as Brain-Corals, with their wavy lines over the surface, and the Manicina, differing again from the preceding by certain details of structure; among the Madrepodes we should have the Madrepora prolifera, with its small, short branches, broken up by very frequent ramifications, the M. cervicornis, with longer and stouter branches and less frequent ramifications, and the cup-like M. palmata, resembling an open sponge in form. Every Species, in short, that lives upon the present Reef is found in the more ancient ones. They all belong to our own geological period, and we cannot, upon the evidence before us, estimate its duration at less than serenty thousand years, during which 
time we have no evidence of any change in Species, but, on the contrary, the strongest proof of the absolute permanence of those Species whose past history we have been able to trace.

Before leaving the subject of the Coral Reefs, I would add a few words on the succession of the different kinds of Polyp Corals on a Reef as compared with their structural rank and also with their succession in time, because we have here another of those correspondences of thought, those intellectual links in Creation, which give such coherence and consistency to the whole, and make it intelligible to man.

The lowest in structure among the Polyps are not Corals, but the single, soft-bodied Actiniæ. They have no solid parts, and are independent in their mode of existence, never forming communities, like the higher members of the class. It might at first seem strange that independence, considered a sign of superiority in the higher animals, should here be looked upon as a mark of inferiority. But independence may mean either simple isolation, or independence of action; and the life of a single Polyp is no more independent in the sense of action than that of a community of Polyps. It is simply not connected with or related to the life of any others. The mode of development of these animals tells us something of the relative inferiority and su- 
periority of the single ones and of those that grow in communities. When the little Polyp Coral, the Astræan or Madrepore, for instance, is born from the egg, it is as free as the Actinia, which remains free all its life. It is only at a later period, as its development goes on, that it becomes solidly attached to the ground, and begins its compound life by putting forth new beings like itself as buds from its side. Since we cannot suppose that the normal development of any being can have a retrograde action, we are justified in believing that the loss of freedom is in fact a stage of progress in these lower animals, and their more intimate dependence on each other a sign of maturity.

There are, however, structural features by which the relative superiority of these animals may be determined. In proportion as the number of their parts is limited and permanent, their structure is more complicated; and the indefinite multiplication of identical parts is connected with inferiority of structure. Now in these lowest Polyps, the Actiniæ, the tentacles increase with age indefinitely, never ceasing to grow while life lasts, new chambers being constantly added to correspond with them, till it becomes impossible to count their numbers. Next to these come the true Fungidæ. They are also single, and, though they are stony Corals, they have no share 
in the formation of Reefs. In these, alsc, tho tentacles multiply throughout life, though they are usually not so numerous as in the Actinix. But a new feature is added to the complication of their structure, as compared with Actiniæ, in the transverse beams which connect their vertical partitions, though they do not stretch across the chambers so as to form perfect floors, as in some of the higher Polyps. These transverse beams or floors must not be confounded with the horizontal floors alluded to in a former article as characteristic of the ancient Acalephian Corals, the Rugosa and Tabulata. For in the latter these floors stretch completely across the body, uninterrupted by vertical partitions, which, if they exist at all, pass only from floor to floor, instead of extending unbroken through the whole height of the body, as in all Polyps. Where, on the contrary, transverse floors exist in true Polyps, they never cut the vertical partitions in their length, but simply connect their walls, stretching wholly or partially from wall to wall.

In the Astræans, the multiplication of tentacles is more definite and limited, rising sometimes to ninety and more, though often limited to forty-eight in number, and the transverse floors between the vertical partitions are more complete than in the Fungidæ. The Porites have twelve tentacles only, never more and never less, 
and in them the whole solid frame presents a complicated system of connected beams. The Madrepores have also twelve tentacles, but they have a more definite character than those of the Porites, on account of their regular alternation in six smaller and six larger ones; in these also the transverse floors are perfect, but exceedingly delicate. Another remarkable feature among the Madrepores consists in the prominence of one of the Polyps on the summit of the branches, showing a kind of subordination of the whole community to these larger individuals, and thus sustaining the view expressed above, that the combination of many individuals into a connected community is among the Polyps a character of superiority when contrasted with the isolation of the Actiniæ. In the Sea-Fans, the Halcyonoids, as they are called in our classification, the number of tentacles is always eight, four of which are already present at the time of their birth, arranged in pairs, while the other four are added later. Their tentacles are lobed all around the margin, and are much more complicated in structure than those of the preceding Polyps.

According to the relative complication of their structure, these animals are classified in the following order : - 
Structural \{́feries.

HaLcroxoids: eight tentacles in pairs, lobed around the margin, always combined in large communities, some of which are free and movable like single animals.

MADREPores: twelve tentacles, alternating in six larger and six smaller ones; frequently a larger top animal standing prominent in the whole community, or on the summit of its branches.

Porites: twelve tentacles, not alternating in size; system of connected beams.

Astræans: tentacles not definitely limited in number, though usually not exceeding one hundred, and generally much below this number; transverse floors. Mæandrinas, generally referred to Astræans, are higher than the true Astræans, on account of their compound Polyps.

FUNGID E: indefinite multiplication of tentacles; imperfect transverse beams.

ACtrisie: indefinite multiplication of tentacles; soft bodies and no transverse beams.

If now we compare this structural gradation among Polyps with their geological succession, we shall find that they correspond exactly. The following table gives the gcological order in which they have been introd::ced upon the surface of thw earth.

GEOLOGICAL SUCCESSION.

$\begin{aligned} & \text { Present, } \\ & \text { Pliocene, } \\ & \begin{array}{l}\text { Miocene, } \\ \text { Eocene, } \\ \text { Cretaceous, }\end{array} \\ & \left.\begin{array}{l}\text { Jurassic, } \\ \text { Triassic, } \\ \begin{array}{l}\text { Permian, } \\ \text { Carboniferous, } \\ \text { Devonian, } \\ \text { Silurian, }\end{array}\end{array}\right\} \text { Madrepores. } \\ & \text { Porites } \\ & \text { And }\end{aligned}$
Fungidæ.


With regard to the geological position of the Actiniæ we can say nothing, because, if their soft, gelatinous bodies have left any impressions in the rocks, none such have ever been found; but their absence is no proof that they did not exist, since it is exceedingly improbable that animals destitute of any hard parts could be preserved.

The position of the Corals on a Reef accords with these series of structural gradation and geological succession. It is true that we do not

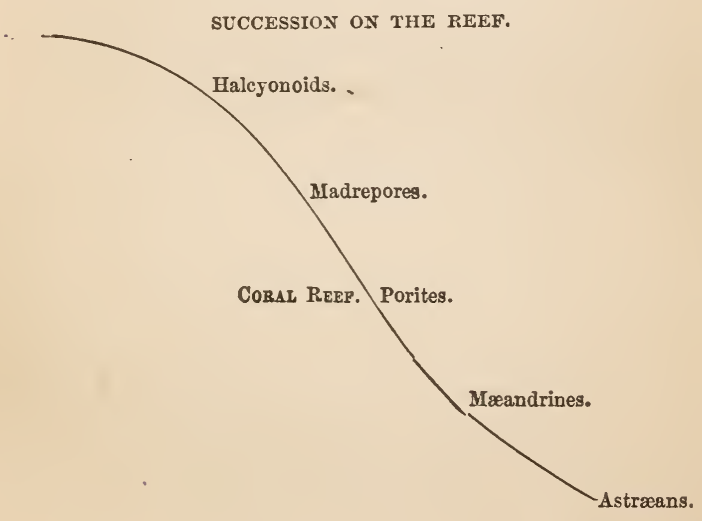

find the Actiniæ in the Reef any more than in the crust of the earth, for the absence of hard parts in their bodies makes them quite unfit to serve as Reef-Builders. Neither do we find Fungidæ, for they, like all low forms, are single, and not confined to one level, having a wider range in depth 
and extent than other stony Polyps. But the true Reef-Building Polyps follow each other on the Reef in the same order as prevails in their structural gradation and their geological succession ; and whether we classify them according to their position on the Reef, or their introduction upon the earth in the course of time, or their relative rank, the result is the same.

It would require an amount of details that would be tedious to many of my readers, were I to add liere the evidence now on record proving that the embryological development of these animals, so far as it is known, and their geographical distribution over the whole surface of our globe, show the same correspondence with the other three series. But this recurrence of the same thought in the history of animals of the same Type, showing that, from whatever side we consider them, their creation and existence seem to be guided by one Mind, is so important in the study of Nature, that I shall constantly refer to it in the course of these papers, even though I may sometimes be accused of unnecessary repetition, or of extending my conclusions beyond the facts.

What is the significance of these coincidences? They were not sought for by the different investigators, who have worked quite independently while ascertaining all these facts, without even knowing that there was any relation between 
them. The succession of fossil Corals has been found in the rocks by the geologist, - the embryologist has followed the changes in the growth of the living Corals, - the zoölogist has traced the geographical distribution and the structural relations of the full-grown animals; but it is only after the results of their separate investigations are collected and compared that the coincidence is perceived, and all find that they have been working unconsciously to one end. These thoughts in Nature, which we are too prone to call simply facts, when in reality they are the ideal conception antecedent to the very existence of all created beings, are expressed in the objects of our study. It is not the zoölogist who invents the structural relations establishing a gradation between all Polyps: - it is not the geologist who places them in the succession in which he finds them in the rocks, - it is not the embryologist who devises the changes through which the living Polyps pass as he watches their growth; these investigators only read what they see, and, when they compare their results, it is found that they all tell the same story. He who reads most correctly from the original is the best naturalist. What unites all their investigations, and makes them perfectly coherent with each other, is the coincidence of thought expressed in the facts themselves. In other words, it is the working 
of the same Intellect through all time, everywhere.

When we observe the practical results of this sequence in the position of Corals on the reef, we cannot fail to see that it is not a mere accidental difference of structure and relation, but that it bears direct reference to the part these little beings were to play in Creation. It places the solid part of the structure at the base of the Reef, - it fills in the interstices with a lighter growth, - it crowns the summit with the more delicate kinds, that yield to the action of the tides and are easily crushed into the fine sand that forms the soil, - it makes a masonry solid, compact, time-defying, such a masonry as was needed by the great Architect, who meant that these smallest creatures of His hand should help to build His islands and His continents. 


\section{CHAPTER XIII.}

\section{HOMOLOGIES.}

IT may seem to some of my readers that ] have wandered from my subject and forgotten the title of these articles, which purport to be a series of papers on "Methods of Study in Natural History." But some idea of the progress of Natural History, of its growth as a science, of the gradual evolving of general principles out of a chaotic mass of facts, is a better aid to the student than direct instruction upon special modes of investigation; and it is with the intention of presenting the study of Natural History from this point of view that I have chosen my title.

I have endeavored thus far to show how scientific facts have been systematized so as to form a classification that daily grows more true to $\mathrm{Na}$ ture, in proportion as its errors are corrected by a more intimate acquaintance with the facts; but I will now attempt a more difficult task, and try to give some idea of the mental process by which facts are transformed into scientific truth. I fear that the subject may seem very dry to my read- 
ers, and I would again ask their indulgence for details absolutely essential to my purpose, but which would indeed be very wearisome, did they not lead us up to an intelligent and most significant interpretation of their meaning.

I should be glad to contribute my share towards removing the idea that science is the mere amassing of facts. It is true that scientific results grow out of facts, but not till they hare been fertilized by thought. The facts must be collected, but their mere accumulation will never advance the sum of human knowledge by one step; it is the comparison of facts and their transformation into ideas that lead to a deeper insight into the significance of Nature. Stringing words together in incoherent succession does not make an intelligible sentence; facts are the words of God, and we may heap them together endlessly, but they will teach us little or nothing till we place them in their true relations, and recognize the thought that binds them together as a consistent whole.

I have spoken of the plans that lie at the foundation of all the variety of the Animal Kingdom as so many structural ideas which must have had an intellectual existence in the Creative Conception independently of any special material expression of them. Difficult though it be to present these plans as pure abstract formulæ, distinct from the animals that represent 
them, I would nevertheless attempt to do it, in order to show how the countless forms of animal life have been generalized into the few grand, but simple intellectual conceptions on which all the past populations of the earth as well as the present creation are founded. In such attempts to divest the thought of its material expression, especially when that expression is multiplied in such thousand-fold rariety of form and color, our familiarity with living animals is almost an obstacle to our success. For I shall hardly be able to allude to the formula of the Radiates, for instance, - the abstract idea that includes all the structural possibilities of that division of the Animal Kingdom, - without recalling to my reader's a Polyp or a Jelly-Fish, a Sea-Urchin or a Star-Fish. Neither can I present the structural elements of the Mollusk plan, without reminding them of an Oyster or a Clam, a Snail or a CuttleFish, - or of the Articulate plan, without calling up at once the form of a Worm, a Lobster, or an Insect, - or of the Vertebrate plan, without giving it the special character of Fish, Reptile, Bird, or Mammal. Yet I insist that all living beings are but the different modes of expressing these formulæ, and that all animals have, within the limits of their own branch of the Animal Kingdom, the same structural elements, though each branch is entirely distinct. If this be true, 
and if these organic formulæ have the precision of mathematical formulæ, with which I have compared them, they should be susceptible of the same tests.

The mathematician proves the identity of propusitions that have the same mathematical vaiue and significance by their convertibility. If they hare the same mathematical quantities, it musi be possible to transform them, one into another. without changing anything that is essential ir either. The problem before us is of the samo character. If, for instance, all Radiates, be they Sea-Anemones, Jelly-Fishes, Star-Fishes, or SeaUrchins, are only various modes of expressing the same organic formula, each having the sum of all its structural elements, it should be possible to demonstrate that they are reciprocally convertible. This is actually the case, and I hope to be able to convince my readers that it is no fanciful theory, but may be demonstrated as clearly as

v the problems of the geometer. The naturalist has his mathematics, as well as the geometer and the astronomer ; and if the mathematics of the Animal Kingdom have a greater flexibility than those of the positive sciences, and are therefore not so easily resolved into their invariable elements, it is because they have the freedom and pliability of life, and evade our efforts to bring all their external variety within the limits of the same structu- 
ral Jaw which nevertheless controls and includes them all.

I wish that I could take as the illustration of this statement animals with whose structure the least scientific of my readers might be presumed to be familiar; but such a comparison of the Vertebrates, showing the identity and relation of structural elements throughout the Branch, or even in any one of its Classes, would be too extensive and complicated, and I must resort to the Radiates, - that branch of the Animal Kingdom which, though less generally known, has the simplest structural elements.

I will take, then, for the further illustration of my subject, the Radiates, and especially the class of Echinoderms, Star-Fishes, Sea-Urchins, and the like, both in the fossil and the living types, and though some special description of these animals is absolutely essential, I will beg my readers to remember that the general idea, and not its special manifestations, is the thing I am aiming at, and that, if we analyze the special parts characteristic of these different groups, it is only that we may resolve them back again into the structural plan that includes them all.

I have already in a previous article named the different Orders of this Class in their relative rank, and have compared the standing of the living ones, according to the greater or less compli- 
cation of their structure, with the succession of the fossil ones. Of the five Orders, Beches-de-Mer, Sea-Urchins, Star-Fishes, Ophiurans, and Crinoids, - or, to name them all according to their scientific nomenclature, Holothurians, Echinoids, Asterioids, Ophiurans, and Crinoids, - the lastnamed are lowest in structure and earliest in time. Cuvier was the first naturalist who detected the true nature of the Crinoids, and placed them where they belong in the classification of the Animal Kingdom. They had been observed before, and long and laborious investigations had been undertaken upon them, but they were especially baffling to the student, because they were known only in the fossil condition from incomplete specimens; and though they still have their representatives among the type of Echinoderms as it exists at present, yet, partly owing to the rarity of the living specimens and partly to the imperfect condition of the fossil ones, the relation between them was not recognized. The errors about them certainly did not arise from any want of interest in the subject among naturalists, for no less than three hundred and eighty authors have published their investigations upon the Crinoids, and the books that have been printed about these animals, many of which were written long before their animal nature was suspected, would furnish a library in themselves. 
The ancients knew little about them. The only one to be found in the European seas resembles the free Star-Fishes closely, and is now called Comatula; but eren Aristotle was ignorant of its true structural relations, and alludes only to its motion and general appearance. Some account of the gradual steps by which naturalists have deciphered the true nature of these lowest Echinoderms and their history in past times may not be without interest, and is very instructive as showing how such problems may be solved.

In the sixteenth century some stones were found bearing the impression of a star on their surface. They received the name of Trochites, and gave rise to much discussion. Naturalists puzzled their brains about them, called them starshaped crystals, aquatic plants, corals; and to these last Linnæus himself, the great authority of the time on all such questions, referred them. Beside these stony stars, which were found in great quantities when attention was once called to them, impressions of a peculiar kind had been observed in the rocks, resembling flowers on long stems, and called "stone lilies" naturally enough, for their long, graceful stems, terminating either in a branching crown or a closer cup, recall the lily tribe among flower's. The long stems of these seeming lilies are divided transversely at regular intervals; the stem is easily broken at any of 
these natural divisions, and on each such fragment is stamped a star-like impression resembling those found upon the loose stones or Trochites.

About a century ago, Guettard the naturalist described a curious specimen from Porto Rico, so similar to these fossil lilies of the rocks that he believed they must have some relation to each other. He did not detect its animal nature, but from its long stem and branching crown he called it a marine palm. Thus far neither the true nature of the living specimen, nor of the Trochites, nor of the fossil lilies was understood, but it was nevertheless an important step to have found that there was a relation between them. A century passed away, and Guettard's specimen, preserved at the Jardin des Plantes, waited with Sphinx-like patience for the man who should solve its riddle.

Cuvier, who held the key to so many of the secrets of Nature, detected at last its true structure; he pronounced it to be a Star-Fish with a stem, and at once the three series of facts respecting the Trochites, the fossil lilies, and Guettard's marine palm assumed their true relation to each other. The Trochites were recognized as simply the broken portions of the stem of some of these old fossil Crinoids, and the Crinoids themselves were seen to be the ancient representatives of 
the present Comatulæ and Star-Fishes with stems. So is it often with the study of Nature; many scattered links are collected before the man comes who sees the counection between them and speaks the word that reconstructs the broken chain.

I will begin my comparison of all Echinoderms with an analysis of the Star-Fishes and SeaUrchins, because I think I can best show the identity of parts between them, notwithstanding the difference in their external form; the SeaUrchins having always a spherical body, while the Star-Fishes are always star-shaped, though in some the star is only hinted at, sketched out, as it were, in a simply pentagonal outline, while in others the indentations between the rays are very deep, and the rays themselves so intricate in their ramifications as to be broken up into a complete net-work of branches. But under all this variety of outline, our problem remains always the same: to build with the same number of pieces a star and a sphere, having the liberty, however, of cutting the pieces differently and changing their relative proportions. Let us take first the Sea-Urchin and examine in detail all parts of its external structure. I shall say nothing of the internal structure of any of these animals, because it does not affect the comparison of their different forms and the external arrangement 
of parts, which is the subject of the present article.

On the lower side is the mouth, and we may call that side and all the parts radiating from it the oral region. On the upper side is a small area to which the parts converge, and which, from its position just opposite the so-called mouth or oral opening, we may call the ab-oral region. I prefer these more general terms, because, if we speak of the mouth, we are at once reminded of the mouth in the higher animals, and in this sense the word, as applied to the aperture through which the Sea-Urchins receive their food, is a misnomer. Very naturally the habit has become prevalent of naming the different parts of animals from their function, and not from their structure; and in all animals the aperture through which food enters the body is called the mouth, though there is not the least structural relation between the organs so designated, except within the limits of each different branch or division. To speak of these opposite regions in the Sea-Urchin as the upper and lower sides would equally mislead us, since, as we have seen, there is, properly speaking, no above and below, no right and left sides, no front and hind extremities in these animals, all parts being evenly distributed around a vertical axis. I will therefore, although it has been my wish to avoid technicalities as 
much as possible in these papers, make use of the unfamiliar terms oral and ab-oral regions, to indicate the mouth with the parts diverging from it and the opposite area towards which all these parts converge.*

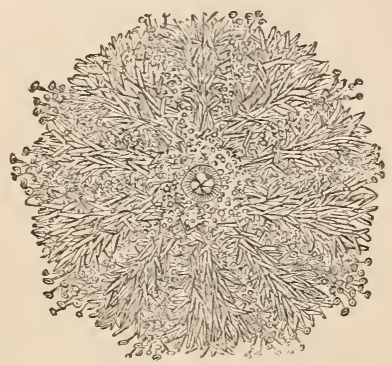

Sea-Lrchin seen from the oral side, showing the zones with the spines and the suckers ; for the ab-oral side, on the summit of which the zones unite, see the wood-cut on the next page, which shows a portion of that region.

The whole surface of the animal is divided by zones, - ten in number, five broader ones alternating with five narrow ones. The five broad zones are composed of large plates on which are the most prominent spines, attached to tubercles that remain on the surface even when the spines drop off after death, and mark the places where the spines have been. The five small zones are perforated with regular rows of holes, and through these perforations pass the suckers or

* When reference is made to the whole structure, including the internal organs as well as the solid parts of the surface, the terms actinal and ab-actinal are preferable to oral and ab-oral. 
water-tubes which are their locomotive appendages. For this reason these narrower zones are

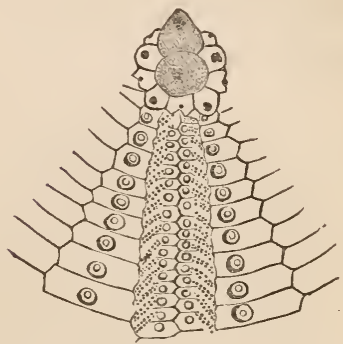

Portion of Sea-Trchin representing one narrow zone with a part of the broad zones on either side and the ab-oral area on the summit.

called the ambulacra, while the broader zones intervening between them and supporting the spines are called the interambulacra. Motion, however, is not the only function of these suckers; they are subservient also to respiration and circulation, taking in water, which is conveyed through them into various parts of the body.

The oral aperture is occupied by five sets of pieces, which may be called jaws, remembering always that here again this word signifies the function, and not the structure usually associated with the presence of jaws in the higher animals; and each of these jaws terminates with a tooth, set in its centre. Even the mode of eating in these animals is controlled by their radiate structure; for these jaws, evenly distributed about the 
circular oral aperture, open to receive the prey, and then are brought together to crush it, the points meeting in the centre, thus working concentrically instead of moving up and down or from right to left, as in other animals. From the oral opening the ten zones diverge, spreading over the whole surface, like the ribs on a melon, and converging in the opposite direction till they meet in a small space which we have called the ab-oral region opposite the starting-point.

Here the broad zones terminate in five large plates differing somewhat from those that form the zones in other parts of the body, and called ovarian plates, because the eggs pass out through certain openings in them; while the five narrow zones terminate in five small plates on each of which is an eye, making thus five eyes alternating with five ovarian plates. The centre of this area containing the ovarian plates and the visual plates is filled up with small movable plates closing the space between them. I should add, that one of the five ovarian plates is larger than the other four, and has a peculiar structure, long a puzzle to naturalists. It is perforated with minute holes, forming an exceedingly delicate sieve, and this is actually the purpose it serves. It is, as it were, a filter, and opens into a canal which conducts water through the interior of the body; slosed by this sieve on the outside, all the water 
that passes into it is purified from all foreign substances that might be injurious to the animal, and is thus fitted to pass into the water-system, from which arise the main branches leading to the minute suckers projecting through the holes in the narrow zones of plates.

Now, in order to transform theoretically our Sea-Urchin into a Star-Fish, what have we to do? Let the reader imagine for a moment that the small ab-oral area closing the space between the ovarian plates and the eye-plates is elastic, and may be stretched out indefinitely; then split the five broad zones along the centre, and draw them down to the same level with the mouth, carrying the ovarian plates between them. We have

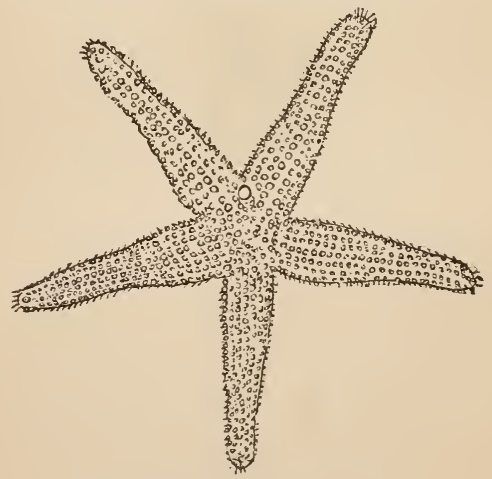

Star-Fish from the ab-oral side.

then a star; just as, dividing, for instance, the peel of an orange into five segments, left, of 
course, united at the base, then stripping it off and spreading it out flat, we should have a firerayed star. But in thus dividing the broad zones of the Sea-Urchin into halves, we leave the narrow zones in their original relation to them, except that every narrow zone, instead of being placed between two broad zones, has now one half of each of the zones with which it alternated in the Sea-Urchin on either side of it, and lies between them. The adjoining woodcut represents a single ray of a Star-Fish,

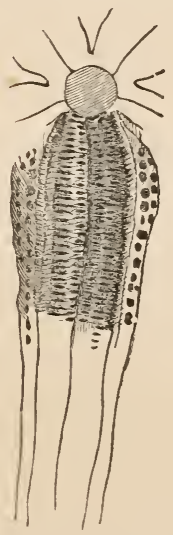

One arm of Star-Fish from the oral side.

drawn from what we call its lower or oral side. Along the centre of every such ray, diverging from the central opening or the mouth, we have a furrow, corresponding exactly to the narrower 
zones of the Sea-Urchin. It is composed of corrparatively small perforated plates, through which pass the suckers or locomotive appendages; and on either side of the furrows are other plates, corresponding to the plates of the broad zones in the Sea-Urchin. Where shall we now look for the five eyes? Of course, at the tip of every ray; exactly where they were when the rays were drawn up to form the summit of a sphere, for then the eyes, which are now at the extremities of the rays, were clustered together near the point of meeting of the five zones on the ab-oral side of the Sea-Urchin. Where shall we look for the ovarian plates? At each angle of the five rays, because, when the broad zones of which they formed the summit were divided, they followed the split, and now occupy the place which, though seemingly so different on the surface of the Star-Fish, is nevertheless, relatively to the rest of the body, the same as they occupied in the Sea-Urchin. Assuming, as we premised, that the central area of the ab-oral region, forming the space between the plates at the summit of the zones in the Sea-Urchin, is elastic, it has stretched with the spreading out of the zones, following the indentation between the rays, and now forms the whole upper surface of the body. All the internal organs of the animal lie between the oral and the ab-oral regions, just as they did in the Sea- 
Urchin, only that in the Star-Fish these regions are coequal in extent, while in the Sea-Urchin the ab-oral region is very contracted, and the oral region, with the parts belonging to it, occupies the greater part of its surface.

Such being the identity of parts between a Star-Fish and a Sea-Urchin, let us see now how the Star-Fish may be transformed into the Pedunculated Crinoid, the earliest representative of its Class, or into a Comatula, one of the free animals that represent the Crinoids in our day.

We have seen that in the Sea-Urchins the aboral region is very contracted, the oral region and the parts radiating from it and forming the sides being the predominant features in the structure; and we shall find, as we proceed in our comparison, that the different proportions of these three parts, the oral and ab-oral regions and the sides, determine the different outlines of the various Orders in this Class. In the Sea-Urchin the oral region and the sides are predominant, while the ab-oral region is very small. In the Star-Fish, the oral and ab-oral regions are brought into equal relations, neither pre,ponderating over the other, and the sides are compressec, so that, seen in profile, the outline of the StarFish is that of a slightly convex disk, instead of a sphere, as in the Sea-Urchin. But when wo come to the Crinoids, we find that the great pre- 
ponderance of the ab-oral region determines all that peculiarity of form which distinguishes them from the other Echinoderms, while the oral region is comparatively insignificant. The ab-oral region in the Crinoid rises to form a sort of cup-like or calyx-like projection. The plates forming it, which in the Star-Fish or the Sea-Urchin are movable, are soldered together so as to be per-

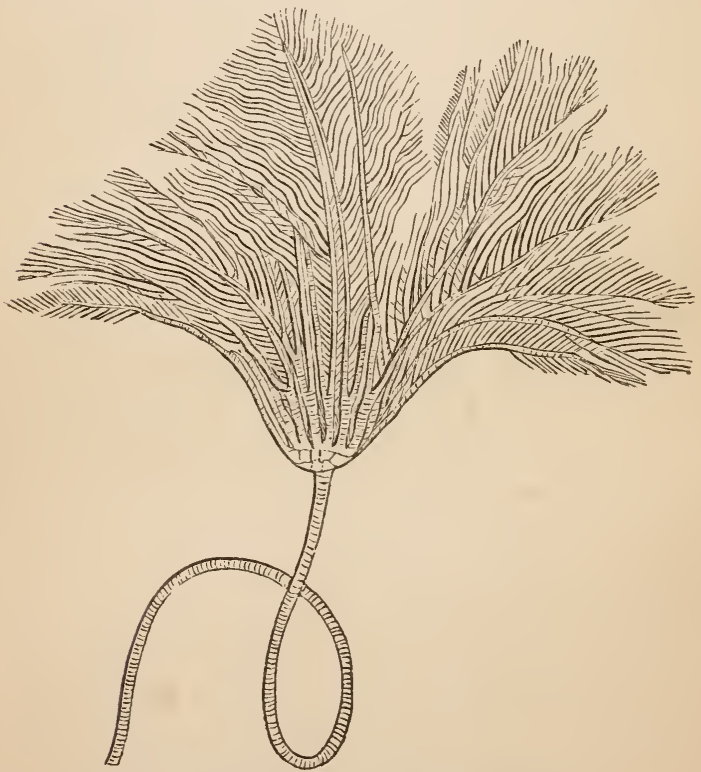

Crinoid with branching crown; oral side turned upward.

fectly immovable in the Crinoid. Let this seeming calyx be now prolonged into a stem, and we 
see at once how striking is the resemblance to a flower; turn it downwards, an attitude which is natural to these Crinoids, and the likeness to a drooping lily is still more remarkable. The oral region, with the radiating ambulacra, is now limited to the small flat area opposite the juncture of the stem with the calyx; and whether it stretches out to form long arms, or is more compact, so as to close the calyx like a cup, it seems in either case to form a flower-like çrown, budlike in Encrinus and other genera, and more like an open flower in Platycrinus and the like. In these types of Echinoderms the interambulacral plates are absent; there are no rows of plates of a different kind alternating with the ambulacral ones, as in the Sea-Urchins and Star-Fishes, but the ab-oral region closes immediately upon the ambulacra.

It seems a contradiction to say, that, though these Crinoids were the only representatives of their Class in the early geological ages, while it includes five Orders at the present time, Echinoderms were as numerous and various then as now. But, paradoxical as it may seem, this is nevertheless true, not only for this Class, but for many others in the Animal Kingdom. The same numerical proportions, the same richness and vividness of conception, were manifested in the early creation as now ; and though many of the 
groups were wanting that are most prominent in modern geological periods, those that existed were expressed in such endless variety that the Animal Kingdom seems to have been as full then as it is to-day. The Class of the Echinoderms is one of the most remarkable instances of this peculiar distribution. In the Silurian period, the Crinoids stood alone; there were neither Ophiurans, Asterioids, Echinoids, nor Holothurians; and yet in one single locality, Lockport, in the State of New York, over an area of not more than a few square miles, where the Silurian deposits have been carefully examined, there have been found more different Species of Echinoderms than are living now along our whole Atlantic coast from Maine to Florida, where we find representatives of all the five orders of the class.

There is nothing more striking in these early populations than the richness of the types. It would seem as if, before the world was prepared for the manifold existences that now find their home upon our earth, when organic life was limited by the absence of many of the physical conditions now prevalent, the whole wealth of the Creative Thought lavished itself upon the forms first introduced upon the globe. After thirty years' study of the fossil Crinoids, I am every day astonished by some new evidence of 
the ingenuity, the invention, the skill, if I may so speak, shown in varying this single pattern of animal life. When one has become, by long study of Nature, in some sense intimate with the animal creation, it is impossible not to recognize in it the immediate action of thought, and eren to specialize the intellectual faculties it reveals. It speaks of an infinite power of combination and analysis, of reminiscence and prophecy, of that which has been, in eterual harmony with that which is to be; and while we stand in reverence before the grandeur of the Creative Conception as a whole, there breaks from it such lightness of fancy, such richness of invention, such variety and vividness of color, nay, even the ripple of mirthfulness, - for Nature has its humorous side also, - that we lose our grasp of its completeness in wonder at its details, and our sense of its unity is clouded by its marvellous fertility. There may seem to be an irreverence in thus characterizing the Creative Thought by epithets which we derive from the exercise of our own mental faculties; but it is nevertheless true, that, the nearer we come to Nature, the more does it seem to us that all our intellectual endowments are merely the echo of the Almighty Mind, and that the eternal archetypes of all manifestations of thought in man are found in the Creation of which he is the crowning work. 
In no group of the Animal Kingdom is the fertility of invention more striking than in the Crinoids. They seem like the productions of one who handles his work with an infinite ease and delight, taking pleasure in presenting the same thought under a thousand different aspects. Some new cut of the plates, some slight cliange in their relative position, is constantly varying their outlines, from a close cup to an open crown, from the long pear-shaped oval of the calyx in some to its circular or square or pentagonal form in others. An angle that is simple in one projects by a fold of the surface and becomes a fluted column in another; a plate that was smooth but now has here a symmetrical figure upon it drawn in beaded lines; the stem which is perfectly unbroken in one, except by the transverse divisions common to them all, in the next puts out feathery plumes at every such transverse break. In some the plates of the stem are all rigid and firmly soldered together; in others they are articulated upon each other in such a manner as to give it the greatest flexibility, and allow the seeming flower to wave and bend upon its stalk. It would require an endless number of illustrations to give even a faint idea of the variety of these fossil Crinoids. There is no change that the fancy can suggest within the limits of the same structure that does not find expression 
among them. Since I have become intimate with their wonderful complications, I have sometimes amused myself with anticipating some new variation of the theme, by the introduction of some undescribed structural complication, and then seeking for it among the specimens at my command, I have rarely failed to find it in one or other of these ever-changing forms.

The modern Crinoid without stem, or the Comatula, though agreeing with the ancient in all the essential elements of structure, differs from it in some specific features. It drops its stem when full grown, though the ab-oral region still remains the predominant part of the body, and retains its cup-like or calyx-like form. The Comatulæ are not abundant, and though represented by a number of Species, yet the type as it exists at present is meagre, in comparison to its richness in former times. Indeed, this group of Echinoderms, which, in the earliest periods, was the exponent of all its kind, has dwindled gradually, in proportion as other representatives of the Class have come in; and there exists only one species now, the Pentacrinus of the West Indies, which retains its stem in its adult condition. It is a singular fact, to which I have before alluded, and which would seem to have especial reference to the maintenance of the same numeric proportions in all times, that, while a Class is 
represented by few types, those types are wonderfully rich and varied; but in proportion as other expressions of the same structure are introduced, the first dwindle, and, if they do not entirely disappear, become at least much less prominent than before.

There remain only two other Orders to be considered, the Ophiurans and the Holothurians. The Ophiurans approach the Crinoids more nearly than any other group of Echinoderms, and in our classifications are placed next above them. In them the ab-oral region, which has

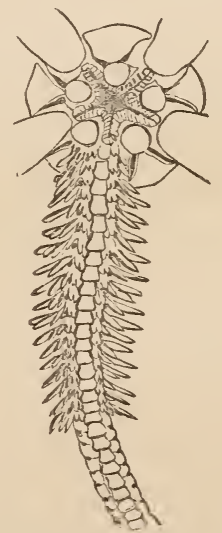

Ophiuran; showing one ray from the oral side.

such a remarkable predominance in the Crinoid, has become depressed: it no longer extends into a stem, nor does it even rise into the calyx-like 
or cup-like projection so characteristic of the Crinoids, - though, when the animal is living, the ab-oral side of the disk is still quite convex. The disk in the Ophiurans is small in comparison to the length of the arms, and perfectly circular. It does not merge gradually into the arms, as in the Star-Fish, but the arms start abruptly from its periphery. In these, as in the Crinoids, the interambulacral plates are absent, and the interambulacral spaces are filled by an encroachment of the ab-oral region upon them. There is an infinite variety and beauty both of form and color in these Sea-Stars. The arms frequently measure many times the diameter of the whole disk, and are so different in size and ornamentation in the different Species, that, at first sight, one might take them for animals entirely distinct from each other. In some the arms are comparatively short, and quite simple; in others they are very long, and may be either stretched to their full length, or partly contracted, to form a variety of graceful curves. In some they are fringed all along the edges; in others they are so ramified that every arm seems like a little bush, as it were, and, intertwining with each other, they make a thick net-work all around the animal. In the geological succession, these Ophiurans follow the Crinoids, being introduced at about the Carboniferous period, and perhaps earlier. They have had 
their representatives in all succeeding times, and are still very numerous in the present epoch.

To show the correspondence of the Holothurians with the typical formula of the whole class of Echinoderms, I will return to the Sea-Urchins, since they are more nearly allied with that Order than with any of the otler groups. We have seen that the Sea-Urchins approach most nearly to the sphere, and that in them the oral region and the sides predominate so greatly over the ab-oral region, that the latter is reduced to a small area on the summit of the spliere. In order to transform the Sea-Urchin into a Holothurian, we have only to stretch it out from end to end till it becomes a cylinder, with the oral region or mouth at one extremity, and the ab-oral region, which, in the Holothurian, is reduced to its minimum,

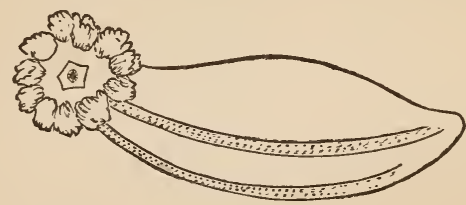

Holothurian.

at the other. The zones of the Sea-Urchin now extend as parallel rows on the Holothurian, running from one end to the other of the long cylindrical body. On account of their form, some of them have been taken for Worms, and so clas- 
sified by naturalists; but as soon as their true structure was understood, agreeing in every respect with that of the other Echinoderms, and having no affinity whatever with the articulated structure of the Worms, they found their true place in our classifications.

The natural attitude of these animals is different from that of the other Echinoderms. They lie on one side, and move with the oral opening forward; and this has been one cause of the mistakes as to their true affinity. But when we would compare animals, we should place them, not in the attitude which is natural to them in their native element, but in what I would call their normal position, - that is, such a position as brings the corresponding parts into the same relation in all. For instance, the natural attitude of the Crinoid is with the ab-oral region downward, attached to a stem, and the oral region or mouth upward. The Ophiuran turns its oral region, along which all the suckers or ambulacra are arranged, toward the surface along which it moves. The Star-Fish does the same. The SeaUrchin also has its oral opening downward. But the Holothurian moves on one side, mouth foremost, as represented in the preceding wood-cut, dragging itself onward, like all the rest, by means of its rows of suckers. If, now, we compare these animals in the various attitudes natural to 
them, we may fail to recognize the identity of parts, or, at least, it will not strike us at once. But if we place them all-Holothurian, SeaUrchin, Star-Fish, Ophiuran, and Crinoid - with the oral or mouth side downward, for instance, we shall see immediately that the small area at the opposite end of the Holothurian corresponds to the area on the top of the Sea-Urchin; that the upper side of the Star-Fish is the same region enlarged; that, in the Ophiuran, that region makes one side of the small circular disk; while in the Crinoid it is enlarged and extended to make the calyx-like projection and stem. In the same way, if we place them in the same attitude, we shall see that the long, straight rows of suckers along the length of the Holothurian, and the arching zones of suckers on the spherical body of the Sea-Urchin, and the furrows with the suckers protruding from them along the arms of the StarFish and Ophiuran, and the radiating series of pores from the oral opening in the Crinoid, are one and the same thing in all, only altered somewhat in their relative proportion and extent. Around the oral opening of the Holothurian there are appendages capable of the most extraordinary changes, which seem at first to be peculiar to these animals, and to have no affinity with any corresponding feature in the same Class. But a closer investigation has shown them to be only 
modifications of the locomotive suckers of the Star-Fishes and Sea-Urchins, but ramifying to such an extent as to assume the form of branching feelers. The little tufts projecting from the oral side in the Sea-Urchins, described as gills, are another form of the same kind of appendage.

The Holothurians have not the hard, brittle surface of the other Echinoderms; on the contrary, their envelope is tough and leathery, capable of great contraction and dilatation. No idea can be formed of the beauty of these animals either from dried specimens or from those preserved in alcohol. Of course, in either case, they lose their color, become shrunken, and the movable appendages about the mouth shrivel up. One who had seen Holothurians only as preserved in museums would be amazed at the spectacle of the living animal, especially if his first introduction should be to one of the deep, rich crimson-colored species, such as are found in quantities in the Bay of Fundy. I hare seen such an animal, when first thrown into a tank of sea-water, remain for a while closely contracted, looking like a soft crimson ball. Slowly, almost imperceptibly, as it becomes accustomed to its new position, it begins to elongate; the fringes creep softly out, spreading gradually all their ramifications, till one end of the animal seems crowned with feathery, crimson sea-weeds of the most 
delicate tracery. It is much to be regretted that these lower marine animals are not better known. The plumage of the tropical birds, the down on the most brilliant butterfly's wing, are not more beautiful in coloring than the hues of many Radiates, and there is no grace of motion surpassing the movements of some of them in their native element. The habit of keeping marine animals in tanks is happily growing constantly more popular, and before long the beauty of these inhabitants of the ocean will be as familiar to us as that of Birds and Insects. Many of the most beautiful among them are, however, difficult to obtain, and not easily kept alive in confinement, so that they are not often seen in aquariums.

Having thus endeavored to sketch each different kind of Echinoderm, let us try to forget them all in their individuality, and think only of the structural formula that applies equally to each. In all, the body has three distinct regions, the oral, the ab-oral, and the sides; but by giving a predominance to one or the other of these regions, a variety of outlines characteristic of the different groups is produced. In all, the parts radiate from the oral opening, and join in the ab-oral region. In all, this radiation is accompanied by rows of suckers following the line of the diverging rays. It is always the same structure, but, endowed with the freedom of life, it is never monot- 
onous, notwithstanding its absolute permanence. In short, drop off the stem of the Crinoid, and depress its calyx to form a flat disk, and we have an Ophiuran; expand that disk, and let it merge gradually in the arms, and we have a Star-Fish; draw up the rays of the Star-Fish, and unite them at the tips so as to form a spherical outline, and we have a Sea-Urchin; stretch out the SeaUrchin to form a cylinder, and we have a Holothurian.

And now let me ask, - Is it my ingenuity that has imposed upon these structures the conclusions I have drawn from them ? - have I so combined them in my thought that they have become to me a plastic form, out of which I draw a Crinoid, an Ophiuran, a Star-Fish, a Sea-Urchin, or a Holothurian at will? or is this structural idea inherent in them all, so that every observer who has a true insight into their organization must find it written there? Had our scientific results anything to do with our inventive faculties, every naturalist's conclusions would be colored by his individual opinions; but when we find all zoölogists converging more and more towards each other, arriving, as their knowledge increases, at exactly the same views, then we must believe that these structures are the Creative Ideas in living reality. In other words, so far as there is truth in them, our systems are what they are, 
not because Aristotle, Linnæus, Cuvier, or all the men who ever studied Nature, have so thought and so expressed their thought, but because God so thought and so expressed his thought in material forms when he laid the plan of Creation, and when man himself existed only in the intellectual conception of his Maker. 


\section{CHAPTER XIV。}

ALTERNATE GENERATIONS.

IF I succeeded in explaining my subject clearly in the last chapter, my readers will have seen that the fire Orders of the Echinoderms are but five expressions of the came idea ; and I will now endeavor to show that the same identity of structural conception prevails also throughout the two other Classes of Radiates, and further, that not only are the Orders within each Class built upon the same plan, but that the three Classes themselves, Echinoderms, Acalephs, and Polyps, are also based upon one organic formula.

We will first compare the three Orders of Acalephs, among which the Hydroids stand lowest, the Discophoræ next, and the Ctenophoræ highest. The fact that these animals have no popular names shows how little they are known. It is true that we hear some of them spoken of as Jelly-Fishes; but this name is usually applied to the larger Discophore, when it is thrown upon the beach and lies a shapeless mass of gelatinous substance on the sand, or is seen floating on the 
surface of the water. The name gives no idea of the animal as it exists in full life and activity. When we speak of a Bird or an Insect, the mere name calls up at once a characteristic image of the thing; but the name of Jelly-Fish, or SunFish, or Sea-Blubber, as the larger Acalephs are also called, suggests to most persons a vague idea of a fish with a gelatinous body, - or, if they have lived near the sea-shore, they associate it only with the unsightly masses of jelly-like substance sometimes strewn in thousands along the beach after a storm. To very few does the term recall either the large Discophore, with its purple disk and.its long streamers floating perhaps twenty or thirty feet behind it as it swims, - or the Ctenophore, with its more delicate, transparent structure, and almost invisible fringes in parallel rows upon the body, which decompose the rays of light as the creature moves through the water, so that hues of ruby-red and emeraldgreen, blue, purple, yellow, all the colors of the rainbow, ripple constantly over its surface when it is in motion, - or the Hydroid, with its little shrub-like communities living in tide-pools, establishing themselves on rocks, shells, or sea-weeds, and giving birth not only to animals attached to submarine bodies, like themselves, but also to free Medusæ or Jelly-Fishes that in their turn give birth again to eggs which return to the 
parent form, and thus, by alternate generations, maintain two distinct patterns of animal life within one cycle of growth.

Perhaps, of all the three Classes of Radiates, Acalephs are the least known. The general interest in Corals has called attention to the Polyps, and the accessible haunts of the SeaUrchins and Star-Fishes have made the Echinoderms almost as familiar to the ordinary observer as the common sea-shells, while the Acalephs are usually to be found at a greater distance from the shore, and are not easily kept in confinement. It is true that the Hydroids live along the shore, and may be reared in tanks without difficulty; but they are small, and would be often taken for sea-weeds by those ignorant of their true structure. Thus this group of animals, with all their beauty of form, color, and movement, and peculiarly interesting from their singular modes of growth, remains comparatively unknown except to the professional naturalist.

It may, therefore, be not uninteresting or use less to my readers, if $I$ give some account of the appearance and habits of these animảls, keeping in view, at the same time, my ultimate object, namely, to show that they are all founded on the same structural elements and have the same ideal significance. I will begin with some account of the Hydroids, including the story of the 
alternate generations, by which they give birth to Medusæ, while the Medusæ, in their turn, reproduce the Hydroids, from which they spring. But first, a few words upon the growth of Radiates in general.

There is no more interesting series of transformations than that of the development of $\mathrm{Ra}$ diates. They are all born as little transparent globular bodies, covered with vibratile cilia, swimming about in this condition for a longer or shorter time; then, tapering somewhat at one end and broadening at the other, they may become attached by the narrower extremity, while at the opposite one a depression takes place, deepening in the centre till it becomes an aperture, and extending its margin to form the tentacles. All Radiates pass through this Polyp-like condition at some period of their lives, either before or after they are hatched from the eggs, though they do not all attach themselves permanently. In some it forms a marked period of their existence, while in others it passes very rapidly, and is undergone within the egg; but, at whatever time and under whatever conditions it occurs, it forms a necessary part of their development, and shows that all these animals have one and the same pattern of growth.

This difference in the relative importance and duration of certain phases of growth is by no 
means peculiar to the Radiates, but occurs in all divisions of the Animal Kingdom. There are many Insects that pass through their metamorphoses within the egg, appearing as complete Insects at the moment of their birth; but the series of changes is nevertheless analogous to that of the Butterfly, whose existence as Worm, Chrysalis, and Winged Insect is so well known to all. Take the Grasshopper, for instance: with the exception of the wings, it is born in its mature form; but within the egg it has had its Worm-like stage as much as the Butterfly that we knew a few months ago as a Caterpillar. In the same way certain of the higher Radiates undergo all their transformations, from the Polyp phase of growth to that of Acaleph or Echinoderm, after birth; while others pass rapidly through the lower phases of their existence within the egg, and are born in their final condition, when all their intermediate changes have been completed.

We have appropriate names for all the aspects of life in the Insect : we call it Larva in its first or Worm-like period, Chrysalis in its second or Crustacean-like phase of life, and Imago in its third and last condition as Winged Insect. But the metamorphoses of the Radiates are too little known to be characterized by popular names; and when they were first traced, the relation 
between their different phases of existence was not understood, so that the same animal in different stages of growth has frequently been described as two or more distinct animals. This has led to a confusion in our nomenclature much to be regretted; for, however inappropriate it may be, a name once accepted and passed into general use is not easily changed.

That early stage of growth, common to all Radiates, in which they resemble the Polyps, has been called the Hydra state, in consequence of their resemblance to the fresh-water Hydra to be found in quantities on the under side of DuckWeed and Lily-pads. For any one that cares to examine these animals, it may be well to mention that they are easily found and thrive well in confinement. Dip a pitcher into any pool of fresh water where Duck-Weed or Lilies are growing in the summer, and you are sure to bring up hundreds of these fresh-water Hydræ, swarming in myriads in all our ponds. In a glass bowl their motions are easily watched; and a great deal may be learned of their habits and mode of life, with little trouble. Such an animal soon completes its growth : for the stage which I have spoken of as transient for the higher Radiates is permanent for these; and when the little sphere moving about by means of its vibratile cilia has elongated a little, attached itself by the 
lower end to some surface, while the inversion of the upper end has formed the mouth and digestive cavity, and the expansion of its margin has made the tentacles, the very simple story of the fresh-water Hydra is told. But the last page in the development of these lower Radiates is but the opening chapter in that of the higher ones, and I will give some account of their transformations as they have been observed in the Acalephs.

On shells and stones, on sea-weeds or on floating logs, there may often be observed a growth of exquisitely delicate branches, looking at first sight more like a small bunch of moss than anything else. But gather such a

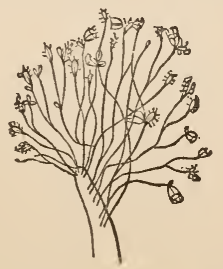

Coryne mirabilis, natural size.

mossy tuft and place it in a glass bowl filled with sea-water, and you will presently find that it is full of life and activity. Every branch of this miniature shrub terminates in a little clubshaped head, upon which are scattered a number of tentacles. They are in constant motion, 
extending and contracting their tentacles, some of the heads stretched upwards, others bent

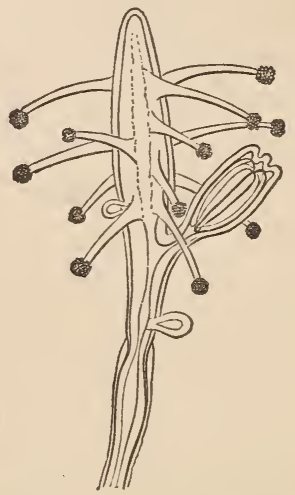

Single head or branch of Coryne mirabilis, magnified, with two Medusa buds.

downwards, all seeming very busy and active. Each tentacle has a globular tip filled with a multitude of cells, the so-called lasso-cells, each one of which conceals a coiled-up thread. These organs serve to seize the prey, shooting out their long threads, thus entangling the rictim in a net more delicate than the finest spider's web, and then carrying it to the mouth by the aid of the lower part of the tentacle. The complication of structure in these animals, a whole community of which, numbering from twenty to thirty individuals, is not more than an inch in height, is truly wonderful. In such 
a community the different animals are hardly larger than a good-sized pin's head; and yet every individual has a digestive cavity and a complete system of circulation.

Its body consists of a cavity enclosed in a double wall, continuing along the whole length of each branch till it joins the common stem forming the base of the stock. In this cavity the food becomes softened and liquefied by the water that enters with it through the mouth, and is thus transformed into a circulating fluid which flows from each head to the very base of the community and back again. The inner surface of the digestive cavity is lined with brownish-red granules, which probably aid in the process of digestion; they frequently become loosened, fall into the circulating fluid, and may be seen borne along the stream as it passes up and down. The rosy tint of the little community is due to these reddish granules.

This crowd of beings united in a common life began as one such little Hydra-like animal as I have described above, - floating free at first, then becoming attached, and growing into a populous stock by putting out buds at different heights along the length of the stem. The formation of such a bud is very simple, produced by the folding outwardly of the double wall of the body, appearing first as a slight projection 
of the stem sideways, which elongates gradually, putting out tentacles as it grows longer, while at the upper end an aperture is formed to make the mouth. This is one of the lower group of Radiates, known as Hydroids, and long believed to be Polyps, from their mode of living in communities and reproducing their kind by budding, after the fashion of Corals.

But if such a little tuft of Hydroids has bee gathered in spring, a close observer may have an opportunity of watching the growth of another kind of individual from it, which would seem to show its alliance with the Acalephs rather than the Polyps. At any time late in February or early in March, bulb-like projections, more globular than the somewhat elongated buds of the true Hydroid heads, may be seen growing either among the tentacles of one of these little animals, or just below the head where it merges in the stem.* Very delicate and transparent in substance, it is hardly perceptible at first; and the gradual formation of its internal structure is the less easily discerned, because a horny sheath, forming the outer covering of the Hydroid stock, extends to enclose and shield the new-comer, whom we shall see to be so different from the animal that gives it birth that one would suppose the Hydroid parent must

* See wood-cut, p. 240. 
be as much surprised at the sight of its offspring as the Hen that has accidentally hatched a Duck's egg. At the right moment this film is torn open by the convulsive contractions of the animal, which, thus freed from its envelope, begins at once to expand. By this time the little bud has assumed the form of a Medusoid or Jelly-Fish disk, with its four tubes radiating from the central cavity. The proboscis, so characteristic of all Jelly-Fishes, hangs from the central opening; and the tentacles, coiled within the internal cavity up to this time, now make their appearance, and we have a complete little Medusa growing upon the Hydroid head. Gradually the point by which it is attached to the parent-stock narrows and becomes more and more contracted, till the animal drops off and swims away, a free Jelly-Fish.

The substance of these animals seems to have hardly more density or solidity than their native element. I remember showing one to a friend who had never seen such an animal before, and, after watching its graceful motions for a moment in the glass bowl where it was swimming, he asked, "Is it anything more than organized water?" The question was very descriptive; for so little did it seem to differ in substance from the water in which it floated that one might well fancy that some drops had taken upon 
themselves organic structure, and had begun to live and move. It swims by means of rapid contractions and expansions of its disk, thus impelling itself through the water, its tentacles floating behind it and measuring many times the length of the body. The disk is very con-

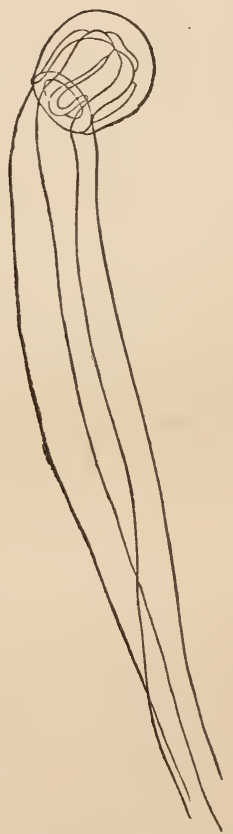

Little Jelly-Fish, called Sarsia, the free Medusa of Coryne mirabilis.

vex, as will be seen by the wood-cut; four tubes radiate from the central cavity to the periphery, 
where they unite in a circular tube around the margin and connect also with the four tentacles; from the centre of the lower surface hangs the proboscis, terminating in a mouth. Notwithstanding the delicate structure of this little being, it is exceedingly voracious. It places itself upon the surface of the animal on which it feeds, and, if it have any hard parts, it simply sucks the juices, dropping the dead carcass immediately aiter; but it swallows whole the little Acalephs of other Species and other soft animals that come in its way. Early in summer these Jelly-Fishes drop their eggs, little trans. parent pear-shaped bodies, covered with vibratile cilia. They swim about for a time, until they have found a resting-place, where they attach themselves, each one founding a Hydroid stock of its own, which will in time produce a new brood of Medusæ.

This series of facts, presented here in their connection, had been observed separately before their true relation was understood. Investigations had been made on the Hydroid stock, described as Coryne, and upon its Medusoid offspring, described as Sarsia, named after the naturalist Sars, whose beautiful papers upon this class of animals have associated his name with it; but the investigations by which all these facts have been associated in one connected series are very recent. 
These transformations do not correspond to our common idea of metamorphoses, as observed in the Insect, for instance. In the Butterfly's life we have always one and the same individual, the Caterpillar passing into the Chrysalis state, and the Chrysalis passing into the condition of the Winged Insect. But in the case I have been describing, while the Hydroid gives birth to the Medusa, it still preserves its own distinct existence; and the different forms developed on one stock seem to be two parallel lives, and not the various phases of one and the same life. This group of Hydroids retains the name of Coryne ; and the Medusa born from it, the Sarsia (represented on p. 244), has received, as I have said, the name of the distinguished investigator to whose labors we owe much of our present knowledge of these animals. Let us look now at another group of Hydroids, whose mode of development is equally curious and interesting.

The little transparent embryos from which they arise, oval in form, with a slight, scarcely perceptible depression at one end, resemble the embryos of Coryne already described. They may be seen in great numbers in the autumn, floating about in the water, or rather swimming, - for the motion of all Radiates in their earliest stage of existence is rapid and constant, in consequence of the vi-

* See wood-cut, p. 239 
bratile cilia that cover the surface. At this stage of its existence such an embryo is perfectly free, but presently its wandering life comes to an end: it shows a disposition to become fixed, and proceeds to choose a suitable resting-place. I use the word "choose" advisedly; for though at this time the little embryo seems to have no developed organs, it yet exercises a certain discrimination in its selection of a home. Slightly pear-shaped in form, it settles down upon its narrower end. It wavers and sways to and fro, as if trying to get a firm foot-hold, and force itself down upon the surface to which it adheres; but presently, as if dissatisfied with the spot it has chosen, it suddenly breaks loose and swims away to another locality, where the same examination is repeated, not more to its own satisfaction apparently, for the creature will renew the experiment half a dozen times, perhaps, before making a final selection, and becoming permanently attached to the soil. In the course of this process the lower end becomes flattened, and moulds itself to the shape of the body on which it rests. Once settled, this animal, thus far hardly more than a transparent oblong body, without any distinct organs, begins to derelop rapidly. It elongates, forming a kind of cup-like base or stem; the upper end spreads somewhat; the depression at its centre deepens; a mouth is formed that gapes widely, and opens 
into the digestive cavity; and the upper margin spreads out to form a number of tentacles, few at first, but growing more and more numerous, till a wreath is completed all around it. In this condition the young Jelly-Fish has been described under the name of Scyphostoma. As soon as the

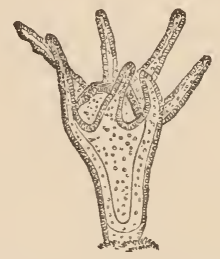

Scyphostoma of Aurelia flavidula, the white Jelly-Fish with a rosy cross, common along the coasts of New England.

wreath of tentacles is complete, a constriction takes place below it, thus separating the upper portion of the animal from the lower by a marked dividing-line. Presently a second constriction. takes place below the first, then a third, till the entire length of the animal is divided across by a number of such transverse constrictions, the whole body growing, meanwhile, in height. But now an extraordinary change takes place in the portions thus divided off. Each one assumes a distinct organic structure, as if it had an individual life of its own. The margin becomes lobed in eight deep scallops, and a tube or canal runs through the centre of each such lobe to the centre of the 
body, where a digestive cavity is already formed. At this time the constrictions have deepened, so that the margins of all the successive divisions of the little Hydroid are very prominent, and the whole animal looks like a pile of saucers, or of disks with scalloped edges, and the convex side turned downward. Its general aspect may be compared to a string of Lilac-blossoms, such as the children make for necklaces in the spring, in

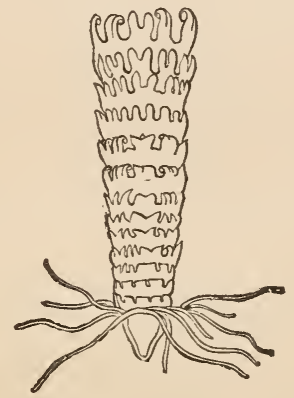

Strobila of Aurelia flavidula.

which the base of one blossom is inserted into the upper side of the one below it. In this condition our Jelly-Fish has been called Strobila.

While these organic changes take place in the lower disks, the topmost one, forming the summit of the pile and bearing the tentacles, undergoes no such modification; but presently the first constriction dividing it from the rest deepens to such 
a degree that it remains united to them by a mere thread only, and it soon breaks off and dies. This is the signal for the breaking up of the whole pile in the same way by the deepening of the constrictions; but, instead of dying, as they part, they begin a new existence as free Medusæ. Only the lowest portion of the body remains, and around its margin new tentacles are developed, corresponding to those which crowned the first little embryo. This repeats the whole history again,

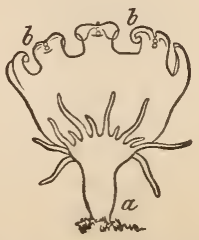

Strobila of Aurelia flavidula : $a$, Scyphostoma reproduced at the base of a Strobila, all the disks of which have dropped off but the last, $b b$.

as it grows up during the following season to divide itself anew into disks, like its predecessor.

As each individual separates from the community of which it has made a part, it reverses its position, and, instead of turning the margin of the disk upward, it turns it downward, thus bringing the mouth below, and the curve of the disk above. These free individuals have been described under the name of Ephyra. This is the third phase of the existence of our Jelly-Fish. It swims freely about, a transparent, umbrella- 
like disk, with a proboscis hanging from the lower side, which, to complete the comparison, we may call the handle of the umbrella. The margin of the disk is even more deeply lobed than in the Hydroid condition, and in the middle of each lobe is a second depression, quite deep and narrow, at

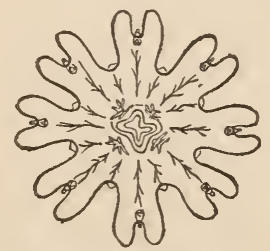

Ephyra or Aurelia flavidula.

the base of which is an eye. How far such organs are gifted with the power of vision we cannot decide; but the cells of which they are composed certainly serve the purpose of facets, of lenses and prisms, and must convey to the animal a more or less distinct perception of light and color. The lobes are eight in number, as before, with a tube diverging from the centre of the body into each lobe. Shorter tubes between the lobes alternate with these, making thus sixteen radiating tubes, all ramifying more or less.

From this stage to its adult condition, the animal undergoes a succession of changes in the gradual course of its growth, uninterrupted, however, by any such abrupt transition as that 
by which it began its life as a free animal. The lobes are gradually obliterated, so that the mar-

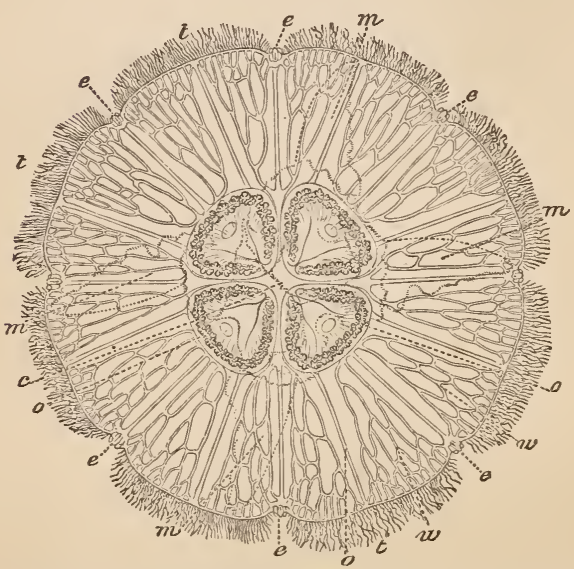

Aurelia flavidula, the common white Jelly-Fish of our sea-shores, seen from ahove : c, mouth ; e e e e e e, eyes ; $m m m m$, lobes or curtain of the mouth in outlines; $o o o$, ovaries; $t t t$, tentacles; $w w$, ramified tubes.

gin becomes almost an unbroken circle. The eight eyes were, as I have said, at the bottom of depressions in the centre of the several lobes; but, by the equalizing of the marginal line, the gradual levelling, as it were, of all the inequalities of the edge, the eyes are pushed out, and occupy eight spots on the margin, where a faint indentation only marks what was before a deep cut in the lobe. The eight tubes of the lobes have extended in like manner to the edge, and 
join it just at the point where the eyes are placed, so that the extremity of each tube unites with the base of each eye. Those parts of the margin filling the spaces between the eyes correspond to the depressions dividing the lobes or scallops in the earlier stage, and to these radiate the eight other tubes alternating with the eye-tubes, now divided into numerous branches. Along each of these spaces is dereloped a fine, delicate fringe of tentacles, hanging down like a veil when the animal is at rest, or swept back when it is in motion. In the previous stage, the tubes ramified toward the margin; but now they branch at or near their point of starting from the central cavity, so extensively that every part of the body is traversed by these collateral tubes, and when one looks down at it from above through the gelatinous transparent disk, the numerous ramifications resemble the fine fibrous structure of a leaf with its net-work of nerrules.

On the lower side, or what I have called in a previous chapter the oral region of the animal, a wonderfully complicated aparatus is developed. The mouth projects in four angles, and at each such angle a curtain arises, stretching outwardly, and sometimes extending as far as the margin. These curtains are fringed and folded on the lower edge, so that they look like four ruffled flounces hanging from the lower side of the 
animal. On the upper side of the body, but alternating in position with these curtains, are the four ovaries, crescent-like in shape, and so placed as to form the figure of a cross, when seen from above through the transparency of the disk. I should add, that, though I speak of some organs as being on the upper and others on the lower side of the body, all are under the convex, arched surface of the disk, which is gelatinous throughout, and simply forms a transparent vaulted roof, as it were, above the rest of the body.

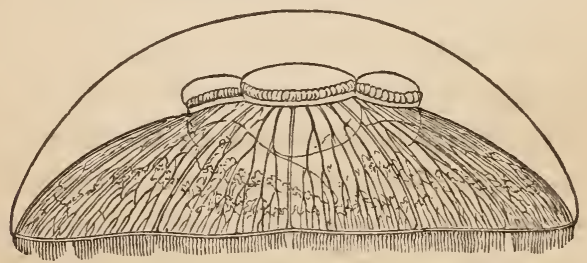

Aurelia flavidula, seen in profile.

When these animals first make their appearance in the spring, they may be seen, when the sky is clear and the sea smooth, floating in immense numbers near the surface of the water, though they do not seek the glare of the sun, but are more often found about sheltered places, in the neighborhood of wharves or overhanging rocks. As they grow larger, they lose something of their gregarious disposition, - they scatter 
more; and at this time they prefer the sunniest exposures, and like to bask in the light and warmth. They assume every variety of attitude, but move always by the regular contraction and expansion of the disk, which rises and falls with rhythmical alternations, the average number of these movements being from twelve to fifteen in a minute. There can be no doubt that they perceive what is going on about them, and are very sensitive to changes in the state of the atmosphere; for, as soon as the surface of the water is ruffled, or the sky becomes overcast, they sink into deeper water, and vanish out of sight. When approached with a dip-net, it is evident, from the acceleration of their movements, that they are attempting to escape.

At the spawning season, toward the end of July or the beginning of August, they gather again in close clusters. At this period I have seen them at Nahant in large shoals, covering a space of fifty feet or more, and packed so closely in one unbroken mass that an oar could not be thrust between them without injuring many. So deep was the phalanx that I could not ascertain how far it extended below the surface of the water, and those in the uppermost layer were partially forced out of the water by the pressure of those below.

It is not strange that the relation between the 
various phases of this extraordinary series of metamorphoses, so different from each other in their external aspects, should not have been recognized at ouce, and that this singular Acaleph should have been called Scyphostoma in its simple Hydroid condition (see p. 248), Strobila after the transverse division of the body had taken place (see p. 249), Ephyra in the first stages of its free existence (see p. 251), and Aurelia in its adult state (see pp. 252 and 254), - being thus described as four distinct animals. These various forms are now rightly considered as the successive stages of a development intimately connected in all its parts, - beginning with the simple Hydroid attached to the ground, and closing in the shape of our common Aurelia, with its white transparent disk, its silky fringe of tentacles around the margin, its ruffled curtains hanging from the mouth, and its four crescentshaped ovaries grouped to form a cross on the summit. From these ovaries a new brood of little embryos is shed in due time.

There are other Hydroids giving rise to Medusæ buds, from which, however, the Medusæ do not separate to begin a new life, but wither on the Hydroid stock, after having come to maturity and dropped their eggs. Such is the Hydractinia polyclina. This curious community begins, like the preceding ones, with a single 
little individual, settling upon somo shell or stone, or on the rocks in a tide-pool, where it will sometimes corer a space of several square feet. Rosy in color, very soft and delicate in texture, such a growth of Hydractinia spreads a velvet-like carpet over the rocks on which it occurs. They may be kept in aquariums with perfect success, and for that purpose it is better to gather them on single shells or stones, so that the whole community may be removed unbroken. These colonies of Hydractinia have one very singular character: they exist in distinct communities, some of which give birth only to male, others to female individuals. The functions, also, are divided, - certain members of the community being appointed to special offices, in which the others do not share. Some bear* the Medusæ buds, which in due time become laden with eggs, but, as I have said, wither and die after the eggs are hatched. Others put forth Hydroid buds only, while others again are wholly sterile. About the outskirts of the community are more simple individuals, whose whole body seems to be hardly more than a double-walled tube, terminating in a knob of lasso-cells. They are like long tentacles placed where they can most easily seize the prey that happens to ap proach the little colony. The entire community is connected at its base by a horny net-work, 
uniting all the Hydroid stems in its meshes, and spreading over the whole surface on which the colony has established itself.

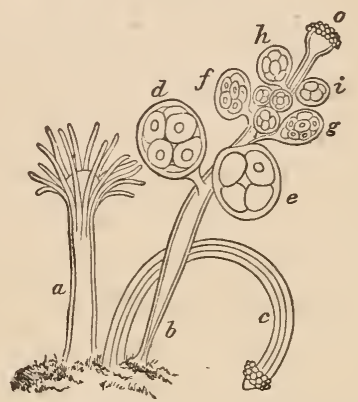

Hydractinia polyclina : $a$, sterile individual ; $b$, fertile individual, producing female Medusæ ; $d, e$, female Medusæ, containing advanced eggs ; $f, g, h, i$, cluster of female Medusæ, with less advanced eggs ; $o$, peduncle of mouth, with short globular tentacles; $c$, individual with globular tentacles, upon which no Medusæ have appeared, or from which they have dropped.

There is a very curious and beautiful animal, or rather community of animals, closely allied to the Hydractinia polyclina, which next deserves to be noticed. The Portuguese Man-ofWar - so called from its bright-colored crest, which makes it so conspicuous as it sails upon the water, and the long and various streamers that hang from its lower side - is such a community of animals as I have just described, reversed in position, however, with the individuals hanging down, and the base swollen and expanded to make the air-bladder which forms its 
brilliant crested float. In this curious Acalephian Hydroid, or Plyysalia, the individuality of function is even more marked than in the $\mathrm{Hy}$ -

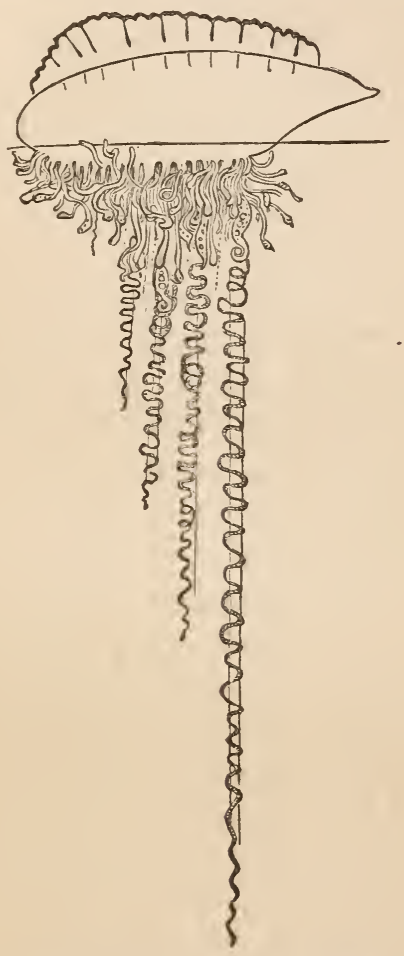

Physalia, or Portuguese Man-of-War.

dractinia. As in the latter, some of the individuals are Medusæ-bearing, and others simple 
Hydræ; but, beside these, there are certain members of the community who act as swimmers, to carry it along through the water, - others that are its purveyors, catching the prey, by which, however, they profit only indirectly, for others are appointed to eat it, and these feeders may be seen sometimes actually gorged with the food they have devoured, and which is then distributed throughout the community by the process of digestion and circulation.

It would be hopeless, even were it desirable, to attempt within the limits of such an article as this to give the faintest idea of the number and variety of these Hydroids; and I will therefore say nothing of the endless host of Tubularians, Campanularians, Sertularians, etc. They are very abundant along our coast, and will well reward any one who cares to study their habits and their singular modes of growth. For their beauty, simply, it is worth while to examine them. Some are deep red, others rosy, others purple, others white with a glitter upon them, as if frosted with silver. Their homes are very various. Some like the fresh, deep sea-water, while they avoid the dash and tumult of the waves; and they establish themselves in the depressions on some low ledge of rocks rumning far out from the shore, and yet left bare for an hour or two, when the tide is out. In such 
a depression, forming a stony cup filled with purest sea-water, and overhung by a roof of rock, which may be fringed by a heavy curtain of brown sea-weed, the rosy-headed, branching Eudendrium, one of the prettiest of the Tubularians, may be found. Others choose the tidepools, higher up on the rocks, that are freshened by the waves only when the tide is full: such are the small, creeping Campanularians. Others, again, like the tiny Dynamena, prefer the rougher action of the sea; and they settle upon the sides of rents and fissures in the cliffs along the shore, where even in calm weather the waves rush in and out with a certain degree of violence, broken into eddies by the abrupt character of the rocks.. Others seek the broad fronds of the larger sea-weeds; and are lashed up and down upon their spreading branches, as they rock to and fro with the motion of the sea. Many live in sheltered harbors, attaching themselves to floating logs, or to the keels of vessels; and some are even so indifferent to the freshness of the water that they may be found in numbers along the city-wharves.*

Beside the Jelly-Fishes arising from Hydroids,

* Those who care to know more of the habits and structure of these animals will find detailed descriptions of all the various species of our coast, illustrated by numerous plates, in the fourth volume of my Contributions to the Natural History of the United States, published some time ago. 
there are many others resembling these in all the essential features of their structure, but differing in their mode of development; for, although more or less Polyp-like when first born from the egg, they never become attached, nor do they ever bud or divide, but reach their mature condition without any such striking metamorphoses as those that characterize the development of the Hydroid Acalephs. All the Medusæ, whether they arise from buds on the Hydroid stock, like the Sarsia, or from transverse division of the Hydroid form, like the Aurelia, or grow directly from the egg to maturity, without pausing in the Hydroid phase, like the Campanella, agree in the general division and relation of parts. All have a central cavity, from which arise radiating tubes extending to the margin of the umbrella-like disk, where they unite either in a net-work of meshes or in a single circular tube. But there is a great difference in the oral apparatus; the elaborate ruffled curtains, that hang from the corners of the mouth, occur only in the Species arising from the transverse division of the Polyp-like young. For this reason they are divided into two Orders, - the $\mathrm{Hy}$ droids and the Discophoræ.

The third order, the Ctenophoræ, are among the most beautiful of the Acalephs. I have spoken of the various hues they assume when in 
motion, and I will add one word of the peculiarity in their structure which causes this effect. The Ctenophoræ differ from the Jelly-Fishes described above in sellding off from the main cavity only two main tubes, instead of four like the others ; but each of these tubes divides and subdivides in four branches as it approaches the periphery. From the eight branches produced in this way there arise vertical tubes extending in

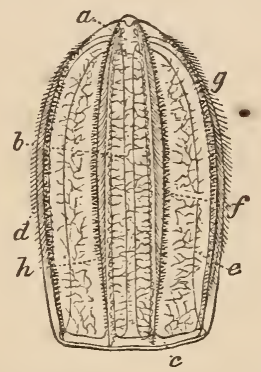

Idyia roseola ; one of our Ctenophoræ: $a$, anal aperture ; $b$, radiating tube ; $c$, circular tube ; $d, e, f, g, h$, rows of locomotive fringes.

opposite directions up and down the sides of the body. Along these vertical tubes run the rows of little locomotive oars, or combs, as they have been called, from which these animals derive their name of Ctenophoræ. The rapid motion of these flappers causes the decomposition of the rays of light along the surface of the body, producing the most striking prismatic effect; and it is no exaggeration to say that no jewel is brighter 
than these Ctenophoræ as they move through the water.*

I trust I have succeeded in showing that the three Orders of the Acalephs are, like the fire Orders of the Echinoderms, different degrees of complication of the same structure. In the Hydroids, the organization does not rise above the simple digestive cavity enclosed by the double body-wall; and we might not suspect their relation to the Acalephs, did we not see the JellyFish born from the Hydroid stock. In the Hydroid-Medusæ and Discophoræ, instead of a simple digestive sac, as in the Hydroids, we have a cavity sending off tubes toward the periphery, which ramify more or less in their course. Now whether there are four tubes or eight, whether they ramify extensively or not, whether there are more or less complicated appendages around the margin or the mouth, makes no difference in the essential structure of these bodies. They are all disk-like in outliné, they all have tentacles hanging from the margin, and a central cavity from which tubes diverge that divide the body.into a certain number of segments, bearing in all the same relation to each other and to the central cavity. In the Ctenophoræ, another complication of structure is introduced in the combination of

* For more details concerning the Ctenophoræ, see the third volume of my Contributions. 
vertical with horizontal tubes and the external appendages accompanying them.

But, whatever their differences may be, a very slight effort of the imagination only is needed to transform any one of these forms into any other. Reverse the position of any simple Hydra, so that the tentacles hang down from the margin, and let four tubes radiate from the central cavity to the periphery, and we have the lowest form of Jelly-Fish. Expand the cup of the Hydra to form a gelatinous disk, increase the number of tubes, complicate their ramifications, let eyes be developed along the margin, add some external appendages, and we have the Discophore. Elongate the disk in order to give the body an oval form, diminish the number of main tubes, and let them give off vertical as well as horizontal branches, and we have the Ctenophore.

In the Class of Polyps there are but two Orders, - the Actinoids and the Halcyonoids; and I have already said so much of the structure of Polyps that I think I need not repeat my remarks here in order to show the relation between these groups. The body of all Polyps consists of a sac divided into chambers by vertical partitions, and having a wreath of hollow tentacles around the summit, each one of which opens into one of the chambers. The greater complication of these parts and their limitation in definite numbers 
constitute the characters upon which their superiority or inferiority of structure is based. Here the comparison is easily made; it is simply the complication and number of identical parts that make the difference between the Orders. The Actinoids stand lowest from the simple character and indefinite increase of these parts; while the Halcyonoids, with their eight lobed tentacles, corresponding to the same number of internal divisions, are placed above them.

In the name of the division to which they all belong we have the key-note to the common structure of the three Classes whose Orders we have been comparing: they are Radiates. The idea of radiation lies at the foundation of all these animals, whatever be their form or substance. Whether stony, like the Corals, or soft, like the Sea-Anemone, or gelatinous and transparent, like the Jelly-Fish, or hard and brittle, like the SeaUrchins, - whether round or oblong or cylindrical or stellate, their internal structure always obeys this law of radiation.

Not only is this true in a general way, but the comparison may be traced in all the details. One may ask how the narrow radiating tubes of the Acalephs, traversing the gelatinous mass of the body, can be compared to the wide radiating chambers of the Polyp; and yet nothing is more simple than to thicken the partitions in the 
Polyps so much as to contract the chambers between them, till they form narrow alleys instead of wide spaces, and then we have the tubes of the Jelly-Fish. In the Jelly-Fish there is a circular tube around the margin, into which all the radiating tubes open. What have we to compare with this in the Polyps? The outer edge of each partition in the Polyp is pierced by a hole near the margin. Of course when the partition is thickened, this hole, remaining open, becomes a tube; for what is a tube but an elongated hole? The comparison of the Acalephs with the Echinoderms is still easier, for they both have tubes; but in the latter the tubes are enclosed in walls of their own, instead of traversing the mass of the body, as in Acalephs, etc.

In preparing these chapters on the homologies of Radiates, I have felt the difficulty of divesting my subject of the technicalities which cling to all scientific results, until they are woven into the tissue of our every-day knowledge and assume the familiar garb of our common intellectual property. When the forms of animals are as familiar to children as their A B C, and the intelligent study of Natural History, from the objects themselves, and not from text-books alone, is introduced into all our schools, te 
shall have popular names for things that can now only be approached with a certain professional stateliness on account of their technical nomenclature. The best result of such familiarity with Nature will be the recognition of an intellectual unity holding together all the various forms of life as parts of one Creative Conception. 


\section{CHAPTER XV .}

THE OVARIAN EGG.

AlL important changes in the social and political condition of man, whether brought about by violent convulsions or effected gradually, are at once recognized as eras in the history of humanity. But on the broad high-road of civilization along which men are ever marching, they pass by unnoticed the landmarks of intellectual progress, unless they chance to have some direct bearing on what is called the practical side of life. Such an era marked the early part of our own century ; and though at the time a thousand events seemed more full-freighted for the world than the discovery of some old bones in the quarries of Montmartre, and though many a man seemed greater in the estimation of the hour than the professor at the Jardin des Plantes who strove to reconstruct these fragments, yet the story that they told lighted up all the past, and showed its true connection with the present.

Before the year 1800, men had never suspected that their home had been tenanted in past times 
by a set of beings totally different from those that inhabit it now ; still farther was it from their thought to imagine that creation after creation had followed each other in successive ages, every one stamped with a character peculiarly its own. It was Cuvier who, aroused to new labors by the hint he received from the bones unearthed at Montmartre, to which all his vast knowledge of living animals gave him no clew, established by means of most laborious investigations the astounding conclusion, that, prior to the existence of the animals and plants now living, this globe liad been the theatre of another set of beings, every trace of which had vanished from the face of the earth. To his alert and active intellect, and powerful imagination, a word spoken out of the past was pregnant with meaning; and when he had once convinced himself that he had found a single animal that had no counterpart among living beings, it gave him the key to many mysteries. The existence of a past creation once suggested, confirmation was found in a thousand facts overlooked before. The solid crust of the earth gave up its dead, and from the snows of Siberia, from the soil of Italy, from caves of Central Europe, from mines, from the rent sides of mountains and from their highest peaks, from the coral beds of ancient oceans, the varied animals that had possessed the earth, ages before man was created, spoke to us of the past. 
No sooner were these facts established, than the relation between the extinct world and the world of to-day became the subject of extensive researches and comparisons; innumerable theories were started to account for the differences, and to determine the periods and manner of the change; and the science of Paleontology became one of the most important departments of investigation in modern times. It is not my intention to enter now at any length upon the subject of geological succession, though I hope to return to it hereafter in a series of papers upon that and kindred topics; but I allude to it here, before presenting some views upon the maintenance of organic types as they exist in our own period, for the following reason. Since it has been shown that from the beginning of Creation till the present time the physical history of the world has been divided into a succession of distinct periods, each one accompanied by its characteristic animals and plants, so that our own epoch is only the closing one in a long procession of ages, naturalists have been constantly striving to find the connecting link between them all, and to prove that each such creation has been a normal and natural growth out of the preceding one. With this aim they have tried to adapt the phenomena of reproduction among animals to the problem of creation, and to make the beginning 
of life in the individual solve that great mystery of the beginning of life in the world. In other words, they have endeavored to show that the fact of successive generations is analogous to that of successive creations, and that the processes by which animals, once created, are maintained unchanged during the period to which they belong, will account also for their primitive existence.

I wish, at the outset, to forestall any such mis. application of the facts I am about to state, and to impress upon my readers the difference between these two subjects of inquiry, since it by no means follows, that, because individuals are endowed with the power of reproducing and perpetuating their kind, they are in any sense self-originating. Still less probable does this appear, when we consider, that, since man has existed upon the earth, no appreciable change has taken place in the animal or vegetable world; and so far as our knowl. edge goes, this would seem to be equally true of all the periods preceding ours, each one maintaining unbroken to its close the organic character impressed upon it at the beginning.

The question I propose to consider here is simply the mode by which organic types are preserved as they exist at present. Every one has a summary answer to this question in the statement that all these short-lived individuals reproduce themselves, and thus maintain their kinds. 
But the modes of reproduction are so varied, the changes some animals undergo during their growth so extraordinary, the phenomena accompanying these changes so startling, that, in the pursuit of the subject, a new and independent science - that of Embryology - has grown up, of the utmost importance in the present state of our knowledge.

The prevalent ideas respecting the reproduction of animals are made up from the daily observation of those immediately about us, in the barn-yard and on the farm. But the phenomena here are comparatively simple and easily traced. The moment, however, we extend our observations beyond our cattle and fowls, and enter upon a wider field of investigation, we are met by the most startling facts. Not the least baffling of these are the disproportionate numbers of males and females in certain kinds of animals, their unequal development, as well as the extraordinary difference between the sexes among certain species, so that they seem as distinct from each other as if they belonged to separate groups of the Animal Kingdom. We have close at hand one of the most striking instances of disproportionate numbers in the houszhold of the Bee, with its one fertile female charged with the perpetuation of the whole community, while her innumerable sterile sisterhood, amid a few hundred drones, contribute to 
its support in other ways. Another most interesting chapter connected with the maintenance of animals is found in the various methods and different degrees of care with which they provide for their progeny : some having fulfilled their whole duty toward their offspring when they have given them birth, while others seek liding-places for the eggs they have laid, and watch with a ce:"tain care over their development, and still others feed their young till they can provide for themselves, or build nests, or burrow holes in the ground, or construct earth mounds for their shelter, and by a variety of means secure them from possible dangers.

But, whatever be the difference in the outward appearance or the habits of animals, one thing is common to them all without exception : at some period of their lives they produce eggs, which, being fertilized, give rise to beings of the same kind as the parent. This mode of generation is universal, and is based upon that harmonious antagonism between the sexes, that contrast between the male and the female element, that at once divides and unites the whole Animal Kingdom. And although this exchange of influence is not kept up by an equality of numeric relations, - since not only are the sexes very unequally divided in some kinds of animals, but the male and female elements are even combined in cer- 
tain types, so that the individuals are uniformly hermaphrodites, - yet I firmly believe that this numerical distribution, however unequal it may seem to us, is not without its ordained accuracy and balance. He who has assigned its place to every leaf in the thickest forest, according to an arithmetical law which prescribes to each its allotted share of room on the branch where it grows, will not have distributed animal life with less care and regularity.

Although reproduction by eggs is common to all animals, it is only one among several modes of multiplication. We have seen that certain animals, besides the ordinary process of generation, also increase their numbers naturally and constantly by self-division, so that out of one individual many individuals may arise by a natural breaking up of the whole body into distinct surviving parts. This process of normal self-division may take place at all periods of life: it may form an early phase of metamorphosis, as in the $\mathrm{Hy}$ droid of our common Aurelia, described in the last article; or it may even take place before the young is formed in the egg. In such a case, the egg itself divides into a number of portions, two, four, eight, or even twelve and sixteen individuals being normally developed from every egg, in consequence of this singular process of segmentation of the yolk, which takes place, 
indeed, in all eggs, but in those which produce but one individual is only a stage in the natural growth of the yolk during its transformation into a young embryo. As the facts here alluded to are not very familiar, even to professional naturalists, I may be permitted to describe them more in detail.

No one who has often walked across a sandbeach in summer can have failed to remark what the children call "sand saucers." The name is not a bad one, with the exception that the saucer lacks a bottom; but the form of these circular bands of sand is certainly very like a saucer with the bottom knocked out. Hold one of them against the light and you will see that it is composed of countless transparent spheres, each of the size of a small pin's head. These are the eggs of our common Natica or Sea-Snail. Any one who remembers the outline of this shell will easily understand the process by which its eggs are left lying on the beach in the form I have described. They are laid in the shape of a broad, short ribbon, pressed between the mantle of the animal and its shell, and, passing out, they cover the exterior of the shell, over which they are rolled up, with a kind of glutinous envelope, for the eggs are held together by a soft glutinous substance. Thus surrounded, the Natica, whose habit is to burrow under the surface of 
the beach, soon covers itself with sand, the particles of which, in contact with the glutinous substance of the eggs, quickly form a cement that binds the whole together in a kind of paste. When consolidated, it drops off from the shell, having taken the mould of its form, as it were, and retaining the curve which distinguishes the outline of the Natica. Although these saucers look perfectly round, it will be found that the edges are not soldered together, but are simply lapped one over the other. Every one of the thousand little spheres crowded into such a circle of sand contains an egg. If we follow the development of these eggs, we shall presently find that each one divides into two halves, these again dividing to make four portions, then the four breaking up into eight, and so on, till we may lave the yolks divided into no less than sixteen distinct parts. Thus far this process of segmentation is similar to that of the egg in other animals; but, as we shall see hereafter, the regular segmentation of an egg seems usually to result only in a change in the quality of its substance, for the portions coalesce again to form one mass, from which a new individual is finally sketched out, as a simple embryo at first, but gradually undergoing all the changes peculiar to its kind, till a new-born animal escapes from the egg. In the case of the Natica, however, this 
regular segmentation changes its character, and at a certain period, in a more or less advanced stage of the segmentation, according to the species, each portion of the yolk assumes an individuality of its own, and, instead of uniting again with the rest, begins to subdivide for itself. In our Natica heros, for instance, the common large gray SeaSnail of our coast, this change takes place when the yolk has subdivided into eight or sixteen parts. At that time each portion begins a life of its own, not reuniting with its twin portions; so that in the end, instead of a single embryo growing out of this yolk, we have from eight to sixteen embryos arising from a single yolk, each one of which undergoes a series of developments similar in all respects to that by which a single embryo is formed from each egg in other animals. We have other Naticas in which the normal number is twelve; others, again, in which no less than thirty-two individuals arise from one yolk. . But this process of segmentation, though in these animals it leads to such a multiplication of individuals, is exactly the same as that discovered by K. E. von Baer in the egg of the Frog, and described and figured by Professor Bischoff in the egg of the Rablit, the Dog, the Guinea-Pig, and the Deer; while other embryologists have traced the same process in Birds, Reptiles, and Fishes, as well as in a variety of Articulates, Mollusks, and Radiates. 
Multiplication by division occurs also normally in adult animals that have completed their growth. This is especially frequent among Worms; and strange to say, there are species in this Class which never lay eggs before they have already multiplied themselves by self-division.

Another mode of increase is that by budding, as in the Corals and many other Radiates. The most common instance of budding we do not, however, generally associate with this mode of multiplication in the Animal Kingdom, because we are so little accustomed to compare and generalize upon phenomena which we do not see to be directly connected with one another. I allude here to the budding of trees, which year after year enlarge by the addition of new individuals arising from buds. It must be remembered here that I use the word individual simply in its scientific sense, as designating singleness of existence, and I trust that its usual acceptation will not prevent a correct appreciation of the true relation of buds to their parents and to the beings arising from them. All buds have the same organic significance, whether they drop from the parent stock to become distinct individuals in the common acceptation of the term, or remain connected with the parent stock, as in Corals and in trees, thus forming growing communities of combined individuals. Nor will it maiter much in 
connection with the subject under discussion, whether these buds start from the surface of an animal or sprout in its interior, to be cast off in due time. Neither is the inequality of buds, rarying more or less among themselves, any sound reason for overlooking their essential identity of structure. We have seen instances of this among Acalephs, and it is still more apparent among trees which produce simultaneously leaf and flower buds, and even separate male and female flower-buds, as is the case with our Hazels, Oaks, etc.

It is not, however, my purpose here to describe the various modes of reproduction and multiplication among animals and plants, nor to discuss the merits of the different opinions respecting their numeric increase, according to which some persons hold that all types originated from a few primitive individuals, while others believe that the very numbers now in existence are part of the primitive plan, and essential to the harmonious relations existing between the animal and regetable world. I would only attempt to show that in the plan of Creation the maintenance of types has been secured through a variety of means, but under such limitations, that, within a narrow range of individuai differences, all representatives of one kind of animals agree with one another, whether derived from 
eggs, or produced by natural division, or by budding; and that the constancy of these normal processes of reproduction, as well as the uniformity of their results, precludes the idea that the specific differences among animals have been produced by the very means that secure their permanence of type. The statement itself implies a contradiction, for it assumes that the same influences prevent and produce changes in the condition of the Animal Kingdom. Facts are all against such an assumption; there is not a fact known to science tending to show that any being, in the natural process of reproduction and multiplication, has ever diverged from the course natural to its kind, or that a single kind has ever been transformed into any other. But this once established, and setting aside the idea that Embryology is to explain to us the origin as well as the maintenance of life, it yet has most important lessons for us, and the field it covers is constantly enlarging as the study is pursued.

The first and most important result of the science of Embryology was one for which the scientific world was wholly unprepared. Down to our own century, nothing could have been farther from the conception of anatomists and physiologists than the fact, now generally admitted, that all animals, without exception, arise from eggs. Though Linnæus had already ex- 
pressed this great truth in the sentence so often quoted, _ "Omne vivum ex ovo," - yet he was not himself aware of the significance of his own statement, for the existence of the Mammalian egg was not then dreamed of. Since then the discoveries of Von Baer and others have shown not only that the production of eggs is common to all living beings without exception, from the lowest Radiate to the highest Vertebrate, but that their structure is at first identical in all, composed of the same primitive elements, and undergoing exactly the same process of growth up to the time when they assume the special character peculiar to their kind. This is unquestionably one of the most comprehensive generalizations of modern times.

In common parlance, we understand by an egg something of the nature of a hen's egg, a mass of yolk surrounded with white and enclosed in a shell. But to the naturalist, the envelopes of the egg, which vary greatly in different animals, are mere accessories, while the true egg, or, as it is called, the ovarian egg, with which the life of every kind of living beings may begin, is a minute sphere, uniform in appearance throughout the Animal Kingdom, though its intimate structure is hardly to be reached even with the highest powers of the microscope. Some account of these earlier stages of growth in the egg may 
not be uninteresting to my readers. I will take the egg of the Turtle as an illustration, since that has been the subject of my own especial study; but, as I do not intend to carry my remarks beyond the period during which the history of all vertebrate eggs is the same, they may be considered of more general application.

It is well known that all organic structures, whether animal or vegetable, are composed of cells. These cells consist of an outside bag enclosing an inner sac, within which there is a dot. The outer bag is filled with a more or less transparent fluid, and the inner one generally with a more perfectly transparent fluid, while the dot has a dark appearance. In the language of our science, the outer envelope is called the Ectoblast, the inner sac the Mesoblast, and the dot the Entoblast. Although they are peculiarly modified to suit the different organs, these cells never lose this peculiar structure; it may be traced even in the long drawn-out cells of the flesh, which are like mere threads, but yet have, at least while forming, their outer and inner sac and their dot.

- In the Turtle the ovary is made up of such cells, spherical at first, but becoming hexagonal under pressure, when they are more closely packed together. Between these ovarian cells the egg originates, and is at first a mere granule, 
so minute, that, when placed under a very high magnifying power, it is but just visible. This is the incipient egg, and at this stage it differs from the surrounding cells only in being somewhat darker, like a drop of oil, and opaque, instead of transparent and clear like the surrounding cells. Under the microscope it is found to be composed of two substances only: namely, oil and albumen. It increases gradually, and when it has reached a size at which it requires to have its diameter magnified one thousand times in order to be distinctly visible, the outside assumes the aspect of a membrane thicker than the interior and forming a coating around it. This is owing, not to an addition from outside, but to a change in the consistency of the substance at the surface, which becomes more closely united, more compact, than the loose mass in the centre. Presently we perceive a bright, luminous, transparent spot on the upper side of the egg, near the wall or outer membrane. This is produced by a concentration of the albumen, which now separates from the oil and collects at the upper side of the egg, forming this light spot, called by naturalists the Purkinjean vesicle, afte its discoverer, Purkinje. When this albuminous spot becomes somewhat larger, there arises a little dot in the centre, - the germinal dot, as it is called. And now we have a perfect cell-struc- 
ture, differing from an ordinary cell only in having the inner sac, enclosing the dot, on the side, instead of in the centre. The outer membrane corresponds to the Ectoblast, or outer cell sac, the Purkinjean vesicle to the Mesoblast, or inner cell sac, while the dot in the centre answers to the Entoblast. When the Purkinjean vesicle has completed its growth, it bursts and disappears; but the mass contained in it remains in the same region, and retains the same character, though no longer enclosed as before.

At a later stage of the investigation, we see why the Purkinjean vesicle, or inner sac of the egg, is placed on the side, instead of being at the centre, as in the cell. It arises on that side along which the axis of the little Turtle is to lie, - the opposite side being that corresponding to the lower part of the body. Thus, the lighter, more delicate part of the substance of the egg is collected where the upper cavity of the animal, enclosing the nervous system and brain, is to be, while the heary oily part remains beneath, where the lower cavity, enclosing all the organs of mere material animal existence, is afterwards devveloped. In other words, when the egg is a mere mass of oil and albumen, not indicating as yet in any way the character of the future animal, and discernible only by the microscope, the distinction is indicated between the brains and 
the senses, between the organs of instinct and sensation and those of mere animal functions. At that stage of its existence, however, when the egg consists of an outer sac, an inner sac, and a dot, its resemblance to a cell is unmistakable; and, in fact, an egg, when forming, is nothing but a single cell. This comparison is important, because there are both animals and plants which, during their whole existence, consist of a single organic cell, while others are made up of countless millions of such cells. Between these two extremes we have all degrees, from the innumerable cells that build up the body of the highest Vertebrate to the singlecelled Worm, and from the myriad cells of the Oak to the single-celled Alga.

But while we recognize the identity of cellstructure and egg-structure at this point in the history of the egg, we must not forget the great distinction between them, - namely, that while the cells remain component parts of the whole body, the egg separates itself, and assumes a distinct individual existence. Even now, while still microscopically small, its individuality begins. Other substances collect around it, are absorbed into it, nourish it, serve it. Every being is a centre about which many other things cluster and converge, and which has the power to assimilate to itself the necessary elements of its life. 
Every egg is already such a centre, differing from the cells that surround it by no material elements, but by the principle of life in which its individuality consists, which is to make it a new being, instead of a fellow-cell with those that build up the body of the parent animal, and remain component parts of it. This intangible something is the subtile element that eludes our closest analysis; it is the first indication of the immaterial principle according to which the new being is to develop. The physical germ we see; the spiritual germ we cannot see, though we may trace its action on the material elements through which it is expressed.

The first change in the yolk after the formation of the Purkinjean vesicle is the appearance of minute dots near the wall at the side opposite the vesicle. These increase in number and size, but remain always on that half of the yolk, leaving the other half of the globe clear. One can hardly conceive the beauty of the egg as seen through the microscope at this period of its growth, when the whole yolk is divided, with the dark granules on one side; while the other side, where the transparent halo of the vesicle is seen, is brilliant with light. With the growth of the egg these granules enlarge, become more distinct, and under the microscope some of them appear to be hollow. They are not round in form, but rather 
irregular, and under the effect of light they are exceedingly brilliant. Presently, instead of being scattered equally over the space they occupy, they form clusters, - constellations, as it were, - and between these clusters are clear spaces, produced by the separation of the albumen from the oil.

At this period of its growth there is a wonderful resemblance between the appearance of the egg, as seen under the microscope, and the firmament with the celestial bodies. The little clusters or constellations are unequally divided. Here and there they are two and two like double stars, or sometimes in threes or fires, or in sevens, recalling the Pleiades; and the clear albuminous tracks between are like the empty spaces separating the stars. This is no fanciful simile. It is simply true that such is the actual appearance of the yolk at this time; and the idea cannot but suggest itself to the mind, that the thoughts which have been embodied in the universe are recalled here within the little egg, presenting a miniature diagram of the firmament. This is one of the first changes of the yolk, ending by forming regular clusters, with a sort of network of albumen between, and then this phase of the growth is complete.

Now the clusters of the yolk separate, and next the albumen in its turn concentrates into clusters, 
and tlie dark bodies, which have been till now the striking points, give way to the lighter spheres of albumen between which the clusters are scattered. Presently the whole becomes re-dissolved: these stages of the growth being completed, this little system of worlds is melted, as it were; but while it undergoes this process, the albuminous spheres, after being dissolved, arrange themselves in concentric rings, alternating with rings of granules, around the Purkinjean vesicle. At this time we are again reminded of Saturn and its rings, which seems to have its counterpart here. These rings disappear, and now once more out of the yolk mass loom up little dots as minute as before ; but they are round instead of angular, and those nearest the Purkinjean vesicle are smaller and clearer, containing less of oil than the larger and darker ones on the opposite side. From this time the yolk begins to take its color, the oily cells assuming a yellow tint, while the albuminous cells near the vesicle become whiter.

Up to this period the processes in the different cells seem to have been controlled by the different character of the substance of each; but now it would seem that the changes become more independent of physical or material influences, for each kind of cell undergoes the same process. They all assume the ordinary cell character, with outer and inner sac, - the inner sac forming on 
the side, like the Purkinjean vesicle itself; but it does not retain this position, for, as soon as its wall is formed and it becomes a distinct body, it floats away from the side and takes its place in the centre. Next there arise within it a number of little bodies crystalline in form, and which actually are wax or oil crystals. They increase with great rapidity, the inner sac or mesoblast becoming sometimes so crowded with them that its shape is affected by the protrusion of their angles. This process goes on till all the cells are so filled by the mesoblast, with its myriad brood of cells, that the outer sac or ectoblast becomes a mere halo around it. Then every mesoblast contracts; the contraction deepens till it is divided across in both directions, separating thus into four parts, then into eight, then into sixteen, and so on, till every cell is crowded with hundreds of minute mesoblasts, each containing the indication of a central dot or entoblast. At this period every yolk cell is itself like a whole yolk; for each cell is as full of lesser cells as the yolk-bag itself.

When the mesoblast has become thus infinitely subdivided into hundreds of minute spheres, the ectoblast bursts, and the new generations of cells thus set free collect in that part of the egg where the embryonic disk is to arise. This process of segmentation continues to go on downward till the whole yolk is taken in. These myriad cells 
are, in fact, the component parts of the little Turtle that is to be. They will undergo certain modifications, to become flesh-cells, blood-cells, braincells, and so on, adapting themselves to the different organs they are to build up; but they have as much their definite and appointed share in the formation of the body now as at any later stage of its existence.

We are so accustomed to see life maintained through a variety of complicated organs, that we are apt to think this the only way in which it can be manifested; and, considering how entirely the life of an adult animal is dependent upon the organs through which it is sustained, it is natural that we should be deeply impressed by their comnection. But embryological investigations have taught us that during the incipient growth of the higher animals none of these organs exist, and yet the principle of life is actire, and even after the organs are formed, they cannot act at once, most of them being enclosed in the whole structure, in a way which interferes with their later functions. In the little Chicken, for instance, before it is hatched, the lung's cannot breathe, for they are surrounded by a fluid; the senses are inactive, for they receive no impressions from without, and all those functions establishing its relations with the exterual world lie dormant, for as yet they are not needed. But 
the organs are there, though, as we have seen in the Turtle's egg, they were not there at the beginning. How, then, are they formed? We may answer, that the first function of every organ is to make itself. The building material is, as it were, provided by the process which divides the yolk into innumerable cells, and by the gradual assimilation and modification of this material the organs arise. Before the lungs breathe, they make themselves; before the stomach digests, it makes itself; before the organs of the senses act, they make themselves; before the brain thinks, it makes itself. In a word, before the whole system works, it makes itself out of the elements given by the formation of independent eggs : its first office is self-structure.

At the period described above, however, when the new generations of cells are just set free and have taken their place in the region where the new being is to develop, nothing is to be seen of the animal whose life is beginning there, except the filmy disk lying on the surface of the yolk. Next come the layers of white or albumen around the egg, and last the shell which is formed from the lime in the albumen. There is always more or less of lime in albumen, and the hardening of the last layer of white into shell is owing only to the greater proportion of lime in its substance. In the layer next to the shell there is enough of 
lime to consolidate it slightly, and it forms a membrane; yet the white, the membrane, and the shell have all the same quality, except that the proportion of lime is more or less in the different layers.

But, as I have said, the various enrelopes of eggs, the presence or absence of a shell, and the absolute size of the egg, are accessory features, belonging not to the egg as egg, but to the special kind of being from which the egg has arisen, and into which.it is to develop. What is common to all eggs and essential to them all is that which corresponds to the yolk in the bird's egg. But their later mode of development, the degree of perfection acquired by the egg and germ before being laid, the term required for the germ to come to maturity, as well as the frequency and regularity of the broods, are all features varying with the different kinds of animals. There are those that lay egg's once a year, at a particular season, and then die; so that their existence may be compared to that of annual plants, undergoing their natural growth in a season, to exist during the remainder of the year only in the form of an egg or seed. The majority of Insects belong to this category, as do also our large Jelly-Fishes; many others have a slow growth, extending over several years, during which they reach their maturity, and for a longer or shorter 
time produce broods at fixed intervals; while others, again, reach their mature state very rapidly, and produce a number of successive generations in a comparatively short time, it may be in a single season.

I do not intend to enter upon the chapter of special differences of development among animals, for in this article I have aimed only at showing that the egg lives, that it is itself the young animal, and that the vital principle is active in it from the earliest period of its existence. But I would say to all young students of Embryology that their next aim should be to study those intermediate phases in the life of a young animal, when, having already acquired independent existence, it has not yet reached the condition of the adult. Here lies an inexhaustible mine of valuable information unappropriated, from which, as my limited experience has already taught me, may be gathered the evidence for the solution of the most perplexing problems of our science. Here we shall find the true tests by which to determine the various kinds and different degrees of affinity which animals now living bear not only to one another, but also to those that have preceded them in past geological times. Here we shall find not a material connection by which blind laws of matter have evolred the whole creation out of a single germ, but the clew to that 
intellectual conception which spans the whole series of geological ages, and is perfectly consistent in all its parts. In this sense the present will indeed explain the past, and the young naturalist is happy who enters upon his life of investigation now, when the problems that were dark to all his predecessors have received new light from the sciences of Paleontology and Embryology. 


\section{CHAPTER XVI.}

\section{EMBRYOLOGY AND CLASSIFICATION.}

THe investigation of the structure and gradual growth of the ovarian egg is so laborious that it will be many years before we can hope to have a complete picture of all its phases. The apparatus required for the task is very complicated, and a long training is necessary merely to prepare the student for the use of his instruments. A superficial familiarity with the microscope gives no idea of the exhausting kind of labor which the naturalist must undergo who would make an intimate microscopic study of these minute living spheres. The glance at the moon, or at Jupiter's satellites, which the chance visitor at an observatory is alloweu to take through the gigantic telescope, reveals to him nothing of the intense concentrated watching by which the observer wius his higher reward. The nightly vision of the astronomer, revealing myriad worlds in the vague nebulous spaces of heaven, is not for him; he must take the great results of astronomy for granted, cince 
no man capable of original research has the time to prepare for the uninitiated the attendant circumstances essential to his more difficult investigations, or to train their eyes to see what he sees. So is it also with the microscopic observer; the deeper insight he has gained by long training in steadiness of hand and eye, as well as in the concentration of intellect that makes the brain work harmoniously with them, he cannot communicate. He may interest and amuse his friends and visitors with some easy exhibition of specimens under the microscope; he may open the door into the laboratory of Nature, but he cannot invite them to cross the threshold or to enter in with him. I think people are not generally aware of the difficulty of microscopic observation, or the amount of painful preparation required merely to fit the organs of sight and touch for the work. In old times men prepared themselves with fast and vigil for entrance into the temple; and Nature does not open her sanctuary without exacting due penance from her votaries. It seems an easy matter for a man to sit down and look at objects through a glass which enlarges everything to his vision; but there are subjects of microscopic research so obscure that the student must observe a special diet before undertaking his investigation, in order that even the beating 
of his arteries may not disturb the steadiness of his gaze, and the condition of his nervous system be so calm that his whole figure will re main for hours in rigid obedience to his fixed and concentrated gaze.

After these remarks I trust I shall not be misunderstood by those who have been working in the field of microscopic investigation, and for whose persevering devotion no one can feel a deeper reverence than $I \mathrm{do}$, if $I$ add that there is as yet hardly a beginning in the study of the egg during its growth, and anterior to the formation of the germ. Since Embryology became a science, the great aim of students in that department has been to demonstrate the uniform structure of the egg in all animals, and investigators have limited their observations to that stage of the ovarian egg during which it appears in all animals as a perfect cell. But a new field now opens before us, requiring a careful survey of every stage of growth of the egg, from its first formation to the period when a well-defined germ is developed. The growth of the egg during this period requires to be studied as minutely through all its changes, and in the various combinations of its constitutive elements, as the germ itself has been in its later transformations. Here again, in this later pliase, another field presents itself equally new and 
full of promise. Embryologists have generally considered their work as complete when they have traced the new being to a point at which it resembles somewhat any of the members of the natural group to which it belongs. The process by which the gradual completion of the whole frame is attained has been assumed to be one of little interest, hardly deserving the careful scrutiny of the embryologist; while the zoölogist has also overlooked, or regarded as of little importance, the differences which still distinguish the young from the adult, even after its typical characters are perfectly distinct. Yet naturalists might have taken a hint from one class of Vertebrates long known for their peculiar metamorphoses, and which show how important are the facts to be learned from these early stages in the life of any animal.

More than a century ago Roesel, in his masterly work on the Frogs and Toads of Germany, represented the mode of reproduction and growth of these animals with a remarkable degree of accuracy, and this subject has since been traced with additional precision and minuteness by Rusconi, Von Siebold, and Funke. Notwithstanding this, no special application has yet been made of the results of these investigations to the classification of these animals, beyond the general recognition that the caudate Batrachians, with 
permanent external gills, rank lower than the Salamanders, which lose their gills in the adult condition, while these again are inferior to the Frogs and Toads, in which the tail also is resorbed before the animal completes its growth. But the comparison of the higher and lower Batrachians should not stop here. A more extensive examination shows that the Tadpole begins as an elongated body, not only without legs, but also without external gills, and that it passes to a branchiate condition, with more or less developed legs, before it loses the gills, while there are various modes of development of the limbs themselves, - various phases in the formation of the tail, in its growth and resorption; various phases also in the formation of the fingers, up to their final separation, in those which are destitute, in their adult condition, of any web between them. This gradation is so complete, that if we follow all the phases of development of the several representatives of this class, so common everywhere in our temperate zone, we cannot fail to perceive that the changes these animals undergo during their growth furnish a complete scale; and if we now compare this scale with one founded upon the various degrees of structural complication in the adult representatives of the class, we find that these two series agree perfectly; so that Nature herself 
furnishes us with a classification, to establish which needs no arbitrary interference on the part of the naturalist, since it is founded upon natural evidence, both embryological and zoölogical. While this is so obvious and easy among Batrachians, I have no doubt, from the scanty investigations I have already made, that Embryology will in the end furnish us with the means of recognizing the true affinities among all animals, and of ascertaining their relative standing and normal position in their respective classes with the utmost degree of accuracy and precision; but, before this can be done, we must be as familiar with the different stages of growth of the young animals of all classes as we already are with those of Batrachians, and shall probably have to push our researches in directions not yet dreamed of.

Without entering into any details upon this subject, I may as well state here, that among Fishes I have lately discovered metamorphoses as extensive as those known to take place among Reptiles. Pisciculture being carried on upon so large a scale in some parts of Europe, it is surprising that the fact should not have been ascertained long ago. This is perhaps owing to the circumstance, that these metamorphoses begin after the hatching of the young, at a time when they are apt to die if reared in close con- 
finement. In this stage, they are, moreover, generally too small to be readily seen in their natural element. Nevertheless, this is the most important period of their growth, with reference to their natural affinities, and I shall take an early opportunity to show how our young fishes, aping the Gadoid or Blennioid type in their transition period, pass gradually into that of Labroids and Lophioids; how fish embryos, resembling the tadpoles of frogs and toads, gradually assume the form of Cyprinodonts; how Apods are transformed into Jugulars and Abdominals, and Malacopterygians into Acanthopterygians; and, finally, how a natural classification of the fishes may be founded upon the correspondence which exists between their embryonic development and their structural gradation.

In order to show further how much we may expect from such investigations, I will allude briefly to some of the facts with which my own studies have thus far made me acquainted. One important truth already assumes great significance in the history of the growth of animals; namely, that whatever the changes may be through which an animal passes, and however different the aspect of these phases at successive periods may appear, they are always limited by the character of the type to which the animal belongs, and never pass that boundary. Thus, the Radiate begins 
life with characters peculiar to Radiates, and ends it without assuming any feature of a higher type. The Mollusk starts with a character essentially its own, in no way related to the Radiates, and never shows the least tendency to deviate from it, either in the direction of the Articulate or the Vertebrate types. This is equally true, of the Articulates. At no stage of growth are their young homologous to those of Mollusks or Radiates any more than to those of Vertebrates, and in their final development they stand equally isolated from all others. That this is emphatically true of the Vertebrates has already been fully recognized; and the facts known with reference to this highest type of the Animal Kingdom might have served as a warning against the loose statements still current concerning the socalled infusorial condition of the young Invertebrates. These results are of the highest importance at this moment, when men of authority in science are attempting to renew the theory of a general transmutation of all animals of the higher types out of the lower ones. If such views are ever to deserve serious consideration, and be acknowledged as involving a scientific principle, it will only be when their supporters shall have shown that the fundamental plans of structure cliaracteristic of the primary groups of the Animal Kingdom are transmutable, or pass into one 
another, and that their different modes of de- velopment may lead from one to the other. Thus far Embryology has not recorded one fact on which to base such doctrines.

In Radiates, as soon as the young is formed, it is a spheroidal, radiated animal, exhibiting from the beginning, in all the three classes of this primary division,-Polyps, Acalephs, and Echinoderms, - the general plan of structure so characteristic of the Radiate type, and so distinct from all others. Let us first see what inference may be drawn from the development of the lower representatives of this type; even though I can only allude here very generally to facts which could not be stated more at length without a great deal of illustration and detail. The young Polyp reaches its mature condition through a succession of changes, which, when compared with the structural complication of the adult representatives of the different orders in this same class, promise to furnish better data for the classification of these animals than have ever been obtained heretofore. The various modes of increase observed among Astræans, and especially among Fungidæ, already show that the families in which independent animals complete their growth, without forming compound communities, are inferior to the compound ones; while those in which one diameter prevails over 
the other are superior to those with circular outlines. The Manicina, with its convoluted trenches, is, in its earlier condition, a perfectly circular hydra-like simple Polyp; and the young Herpolitha is also a simple circular animal, so closely resembling a young Fungia that it might be referred to the same gemrs. I have no doubt that, when the embryonic history of the young Madrepore is fully understood, it will be found that this group also resembles the young Astræa at first, though it stands so much abore it in its adult condition. In trutl, all these higher representatives of the class of Polyps resemble the lower ones in their earliest state, starting from a point common to all, and passing through phases which are permanent and final for the lower forms, but are only transient stages in the development of the higher ones.

I have dwelt so much upon the Embryology of the Acalephs in another chapter, that I need only remind my readers here that this class also has a common starting-point, exhibiting a remarkable uniformity among the young, which extends even to the Ctenophoræ, the affinities of which have been, and still are, the subject of controversy among naturalists. In this class also, the different phases of development furnish the best basis for a classification of its representatires.

Until very recently it had been believed that 
the highest class in this division - the Echinoderms - made an exception to this rule, and did not agree with the other Radiates in its mode of development. Johannes Müller, one of the most eminent investigators of modern times, in a long series of memorable papers upon the Embryology of Radiates, has maintained that the larval condition of the young Echinoderm, so far from being homologous with the early stages of development in the other classes, is essentially bilateral. It is true that there is in many of the Radiates something akin to a bilateral symmetry, though it is always subordinate to the prevailing idea of radiation in the plan. This tendency is already quite perceptible in the highest order of the Acalephs, the Ctenophoræ, and becomes still more so in some representatives of the class of Echinoderms, the highest in this type. The resemblance of the larvæ of the Echinoderms to the Ctenophoræ had not escaped my notice; but during the past year my son has shown conclusively, in a series of microscopic investigations not yet published, that they are as truly radiated as the most circular or spheroidal of the type. The further growth of the young Echinoderms, from the young Comatula (as far as its history is known in its pentacrinal condition) to the gradual transformation of the common Star-Fish, with its undivided circular ouiline, with its two rows of simple ambulacral 
suckers without a disk at their end, and to the various Echinoids and Holothurians, the early phases of whose growth are described by J. Müller, shows plainly that the metamorphosis of the Comatula furnishes a scale for the classification of all the Crinoids of past ages, just as that of the common Five-Finger (Asterias) gives the key to the relative standing of all the families of StarFishes, the more circular or pentagonal forms of which are respectively inferior to their star-shaped allies, those with two rows of suckers inferior to those with four, and those with simple ambulacra inferior to those in which the ambulacra have a disk-shaped extremity.

The beautiful investigations of Müller hare made us acquainted with the young of sereral families of the order of Echini or Sea-Urchin, including the Spatangoids, so different with their oblong form and eccentric mouth from the circular Sea-Urchin, with its central mouth. Yet the Spatangoid in its earlier stages is spheroidal, like the young Echinus; and the ambulacral apparatus, so highly differentiated in its vertical extension in the adult Spatangoid, is as simple in the young as in the Echinus. The adult Spatangoid is covered with innumerable hair-like spines, while the young bears only a few large rods, resembling eren more those of a Cidaris than those of an Echinus. We may, indeed, fairly say, that 
the successive changes of the higher Echinoids make us acquainted with a series of transformations which have their counterparts, not only in the different families of the order as ranked one above the other, but also in the order of succession of these Radiates in past geological times. Even among the Holothurians, imperfectly as their development is known, it already appears, upon embryonic data, that those without exterual ambulacra are inferior to those which have them, since the latter are destitute of these organs in their earlier stages of growth. Notwithstanding the direct bearing of these embryological facts upon the classification of the Echinoderms, it is surprising that no attention has thus far been paid to the subject; the eminent physiologist himself, to whom we owe so large a share of our knowledge of the facts above referred to, has failed to perceive their significance in this connection.

It would require a discussion of facts not yet sufficiently familiar even to naturalists, were I to attempt a similar comparison of the successive stages of growth of the Mollusks with the relative standing of the different members of their respective classes; and yet, as I have by my own inrestigations reached a synthesis which enables me to discuss the question in its most general bearing, I beg leave to submit here a few statements, the full demonstration of which may be 
furnished hereafter. In many marine slugs ana univalre shells the development of the young has been traced again and again ; and their great resemblance among themselves, during the earlier phases of their growth, has already attracted the attention of all zoölogists. This is the more remarkable when taken in connection with the extraordinary external difference in the appearance of the adult. The young resemble a somewhat compressed oblong bag, supporting a broad crescent-shaped veil, stretching evenly in every direction on one side of the bag, and provided around its edge with powerful vibratile cilia, by the agency of which these small animals rotate in the water with great activity. In this condition the bag is protected by a very thin transparent shell, existing even in those which are destitute of shell both in the earlier and later stages of their existence, being unprovided with any such covering at first, and dropping it before they complete their growth. The young of the Sea-Slugs, which, with a large number of our marine Gasteropods and Pteropods, have been very carefully observed, may give an idea of the younger stages of all Mollusks; for, different as may be the appearance of the young Cephalopod at some periods of its life, it is not difficult, nerertheless, to trace their homology, and even their close resemblance, at certain periods, to the young of 
the Gasteropods, described above. I have satisfied myself of this fact while studying the transformation of the young of our common Squid (Loligo illecebrosa). Nor are the young of our common Bivalves, and even those of our Ascidians (the so-called soft-shelled Clams) or of the Bryozoa, essentially different; while a closer comparison of the condition of the young of the two latter groups, during the stage when they swarm in the water as free floating animals, will readily show that they bear a similar relation to the young Gasteropods and the young Cephalopods as the Echinoderm larvæ bear to the young swarming Acalephs or the young Polyps. In the later phases of their advance toward a mature condition they constantly recall the appearance and form of other representatives of their respective classes, so that even an imperfect acquaintance with this subject leads to the inference that there probably exists between the successive stages of growth of the Mollusk the same correspondence with the different members of their respective classes, in their natural gradation, as has already been observed in the other types. A comparison of the young of many Gasteropods, which, like Natica, Pyrula, Buccinum, and Purpura, undergo their early development in solid egg-cases, has already furnished very interesting results; and collectors cannot be too careful in gather- 
ing these specimens, and making constant efforts to ascertain by what Mollusks they are laid. The fact that among Acephala the bivalve shells, which have two transverse bundles of muscles in their adult condition, have only one in earlier life, furnishes a satisfactory evidence of the lower standing of the Monomyaria when compared to the Dimyaria; and a closer investigation leaves no doubt that the one large transverse muscle of the Oyster corresponds to the posterior muscle of the Clam (Mactra or Mya). Again, the prevalence of the vertical diameter over the longitudinal and the transverse in the young, while later the longitudinal diameter takes the lead, affords valuable information respecting the relative standing of short-bodied or rounded Bivalves in comparison with their more elongated allies. And this is in accordance with the inferior position of the Brachiopods and Bryozoa. But the classification of Mollusks is too little advanced as regards the relative standing of their numerous families to allow a more direct comparison at present.

In the type of Articulates the difficulties are of another kind. The extraordinary number of representatives in the classes of this type renders a comprehensive view of their respective standing particularly difficult; and yet, if we leave out of sight the minor divisions, and keep in mind 


\section{2}

only the most prominent ones, the correspondence between the phases of growth of the young and the relative position of the different groups of adults in their respective classes is very obvious. The worm-like character of the larval condition of Insects has been noticed by all entomologists, and the crustacean features of their pupa are equally apparent. Neither can the analogy be overlooked between the Centipedes and the Worms, or that between the Spiders and Crustacea. We have here the fullest evidence that while the highest Insects recall in their earlier condition the permanent character of the adult representatives of the lower classes in their type, those Insects which in their class occupy a middle and lower position, such as the Spiders and Centipedes, also correspond to the lower classes of the same type. Any one familiar with the transformations of Butterflies, and the successive phases of their final development, must have perceived that, even while unfolding its wings, in one single act preliminary to taking its flight, the Butterfly truly recalls the form and mode of folding the wings peculiar to the Moths and Sphinxes. It is therefore particularly desirable that all these changes should not only be separately described, as they have been successively observed in different Insects, but minutely compared with one another, so as to establish with more pre- 
cision the correspondence of all their different conditions. In this direction there is a boundless field open to the researches of young naturalists.

In the class of Crustacea enough is already known to establish a correspondence between the young of the higher members of the class and the adults of its lower members; and the comparison may here be extended with remarkable precision to the fossils of past ages, since representatives of this class are known from the earliest geological epochs in which animals existed at all to the present time. The class of worms has of late attracted so much attention, and so many of them have been studied during their transformation, that, were these animals more generally known, I could adduce striking instances of this correspondence between the younger stages of growth in the higher members of the class and the adult forms of its lower representatives. But I will not enter into these details, as I have no vernacular names by which I could designate them intelligibly, and for professional naturalists this allusion is sufficient. They will remember that the highest worms so remarkable for the various locomotive and respiratory appendages on their sides, are, in their earlier phases, as destitute of these appendages as are the lowest members of the class in their adult condition. 
If we now pass to the highest type of the Animal Kingdom, the Vertebrates, there is no lack of evidence to show the identity in their mode of development, as well as the striking resemblance of the young in their earliest stages of growth. The young Fish, the young Reptile, the young Bird, the young Mammal, resemble one another to an astonishing degree, while they have not one feature in their mode of growth which recalls either the Articulate, the Mollusk, or the Radiate. It is, therefore, not true, though so often stated, that in their development the higher animals pass successively through the condition of all the lower ones; while it is emphatically true that in each of the four great branches of the Animal Kingdom there is a common mode of develop ment. It is equally true that in certain features the higher classes of each branch in their younger condition recall the characteristic features of the lower ones, though each class has its own structural character, and early diverges from the common starting-point. One single case may suffice to demonstrate this general statement. When the young Skate begins to form upon the large yolk of its egg, it has an oblong form, somewhat club-shaped, the broader end representing the head, while the tapering end is the tail. It is early surrounded by a network of bloodvessels circumscribed upon the yolk by a circular vein. 
In this condition it closely resembles the young Snake as represented by Rathke, or the young Bird as represented by Pander, or the young Rabbit as represented by Bischoff, and the inexperienced student of Embryology would find it difficult to detect any character by which these different embryos could be referred to their respective classes among Vertebrates; for nothing indicates in them as yet the Fish or the Reprile, the Bird or the Mammal. But as they increase in size and complication of structure, the young Skate becoming prominent above the yolk from which it is nourished, it may be perceived that, while it retains its primitive connection with the yolk, through the enlarged vessels first observed, its body remains exposed above it, while in the other three the body becomes enclosed in a bag which gradually grows out of its own lower margin, and, bending over the back, closes upon it to form a protecting envelope, the amnios, while another bag, the allantois, now extends from the lower side, covered with vessels, which increase in number and extent as the bag grows larger, while at the same time the vessels of the yolk and the yolk itself are gradually drawn into the body. This new bag, with its innumerable vessels, folds also in every direction over the young alrealy enclosed in its first bloodless envelope, and so forms a second protecting sac. From this time forward 
the Fish can no longer be confounded with the young Bird or Reptile or Mammal, and the bloodvessels of the latter will soon enter into such connection with the parent as to distinguish it also from the young Bird or Reptile which forms no such connection. I will not pursue this transformation farther in all its details, which would require numerous figures to be well understood, but briefly allude to a few facts proving still more clearly the unity of plan prevailing throughout the whole Vertebrate type.

The young Skate up to the period already described does not differ from the young Shark; but when the fins make their appearance, though exactly the same at first in both these animals, one pair in the Skate presently grows larger than the others, expanding upon the sides of the body and extending towards the tail and towards the front of the head. Thus the young Skate, as it advances in life, leaves behind the Shark character, common to both in their younger state, but permanent only in the Shark, in which the fins undergo no such change. This shows beyond a doubt that the family of Skates is superior to that of Sharks, - an inference which is confirmed by the order of their succession upon earth, the Shark family having preceded that of the Skates, in geological times. But it is not only among the lower groups that such cor- 
respondences may be traced. The resemblance of an adult Skate, especially in the configuration of the face, the form of the mouth, the position of the nostrils, the arrangement of the gills, to some of the earlier conditions in the growth of the young Mammal, not excepting the human family, is equally striking. No one can fail to be impressed with this resemblance who compares the head of an embryo quadruped, looking at it in front face, with the adult Skate.*

Indeed, modern Embryology leads at once to the consideration of the most occult problem, as to the origin of animals, suggested by these comparisons. What do these resemblances mean, from some of which we shrink as unnatural and even revolting? If we put a material interpretation upon them, and believe that even Man himself has been gradually developed out of a Fish, they are repugnant to our better nature. But looked at in their intellectual significance, they truly reveal the unity of the organic conception of which Man himself is a part, and mark not only the incipient steps in its manifestation, but also, with equal distinctness, every phase in its gradual realization. They mean that when the first Fish was called into existence, the Ver-

* Let any one who doubts the truth of this statement as regards the human embryo compare the figures of the latter, published by Ecker, in the Icones Physiologica, with any adult Skate. 
tebrate type existed as a whole in the creative thought, and the first expression of it embraced potentially all the organic elements of that type, up to Man himself. To me the fact that the embryonic form of the highest Vertebrate recalls in its earlier stage the first representatives of its type in geological times and its lowest representatives at the present day, speaks only of an ideal relation, existing, not in the things themselves, but in the mind that made them. It is true that the naturalist is sometimes startled at these transient resemblances of the young among the higher animals in one type to the adult condition of the lower animals in the same type; but it is also true that he finds each one of the primary divisions of the Animal Kingdom bound to its own norm of development, which is absolutely distinct from that of all the others; it is also true, that, while he perceives correspondences between the early phases of the higher animals and the mature state of the lower ones, he never sees any one of them diverge in the slightest degree from its own structural character, - never sees the lower rise by a shade beyond the level which is permanent for the group to which it belongs, - never sees the higher ones stop short of their final aim, either in the mode or the extent of their transformation. I cannot repeat too emphatically, that there is not a single fact 
in Embryology to justify the assumption that the laws of development, now known to be so precise and definite for every animal, have ever been less so, or have ever been allowed to run into each other. The philosopher's stone is no more to be found in the organic than the inorganic world; and we shall seek as vainly to transform the lower animal types into the higher ones by any of our theories, as did the alchemists of old to change the baser metals into gold.

THE END. 




why do

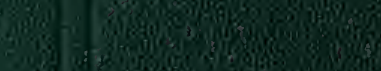

*)

150\%

1)

$=$.

7.6.

3.8.

$\log _{0} 0.3$

wowas

xis 3 